\title{
CONTINUUM MODELING OF THE DENSIFICATIONOF W-NI-FE \\ DURING SELECTIVE LASER SINTERING
}

\author{
A Thesis \\ presented to \\ the Faculty of California Polytechnic State University, \\ San Luis Obispo
}

\author{
In Partial Fulfillment \\ of the Requirements for the Degree \\ Master of Science in Industrial Engineering
}

by

Connor M. West

June 2016 
(C) 2016

Connor M. West

ALL RIGHTS RESERVED 
TITLE:

AUTHOR:

DATE SUBMITTED:

COMMITTEE CHAIR:

COMMITTEE MEMBER:

COMMITTEE MEMBER:
Continuum Modeling of the Densification of W-Ni-Fe during Selective Laser Sintering

Connor M. West

June 2016

Xuan Wang, Ph.D.

Assistant Professor of Industrial and Manufacturing

Engineering

Scott Hazelwood, Ph.D.

Professor of Biomedical Engineering

Jianbiao Pan, Ph.D.

Professor of Industrial and Manufacturing Engineering 


\begin{abstract}
Continuum Modeling of the Densification of W-Ni-Fe during Selective Laser Sintering Connor M. West
\end{abstract}

The purpose of this thesis is to effectively model the time history of the temperature distribution during the selective laser sintering process and use this information to investigate the resulting relative density. The temperature is a critical parameter of the process because it directly effects the overall quality of the part. First, an efficient, affordable, and reliable simulation was developed within the finite element software, Abaqus. Next, the results from the simulations were compared to the experimental results performed by Wang et al. (2016). The FEA model consisted of a 3 layer simulation. Multiple simulations at various laser recipes were conducted using $\mathrm{W}-\mathrm{Ni}-\mathrm{Fe}$ as the powder material. The $\mathrm{P} / \mathrm{v}$ (laser power/scanning speed) was plotted against the resulting total time above the melting temperature for various simulation. It was concluded that a linear relationship exists between the $\mathrm{P} / \mathrm{v}$ parameters used in the laser recipe and the resulting time above the melting temperature. The average $\mathrm{R}^{2}$ values for the $\mathrm{W}$ Ni-Fe simulations for layer $1,2,3$ were $0.962,0.950$, and 0.939 , respectively. Additionally, the experimental results from the Wang et al. (2016) study confirmed that a linear relationship is present. Thus, it can be concluded that the $\mathrm{P} / \mathrm{v}$ parameters used within the laser recipe has a direct relation to the resulting relative density of the SLS part.

Keywords: Selective Laser Sintering, Selective Laser Melting W-Ni-Fe, Finite Element Analysis, Abaqus 


\section{ACKNOWLEDGMENTS}

I would like to thank my thesis committee for their help and support throughout this study. Dr. Wang was essential in helping me understand the SLS process and help resolve issues that arose. Dr. Hazelwood was always willing to help me figure out how to implement modeling aspects within Abaqus. Dr. Pan was able to provide advice with regard to a thorough literature review and guidance during the entire graduate program. Additionally, I would like to thank the entire faculty in the Industrial and Mechanical Engineering Departments. 
LIST OF TABLES ix

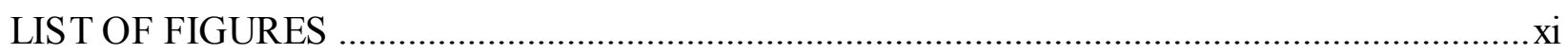

\section{CHAPTER}

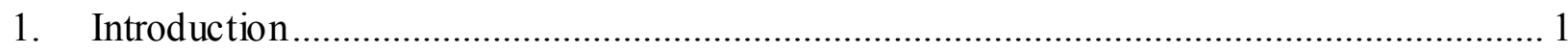

1.1. Introduction to Solid Freeform Fabrication ............................................................ 1

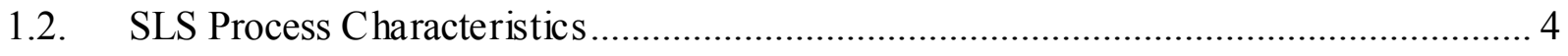

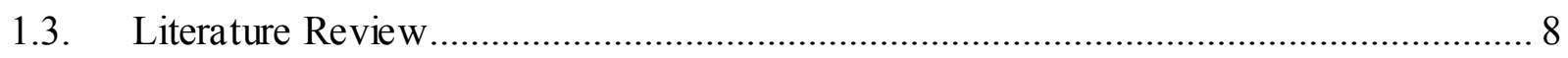

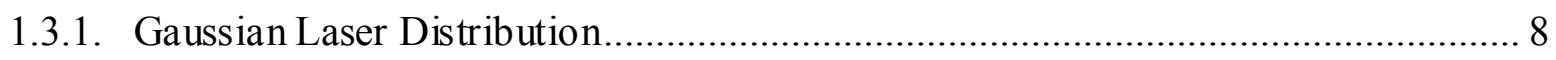

1.3.2. Temperature Dependent Material Properties …………………………………..... 11

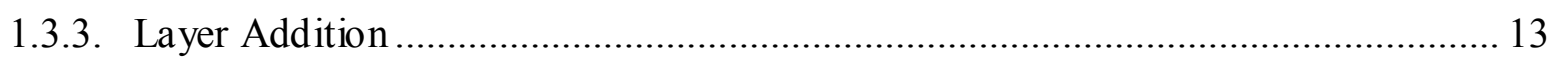

1.3.4. Summary of Past Research Studies .......................................................................... 14

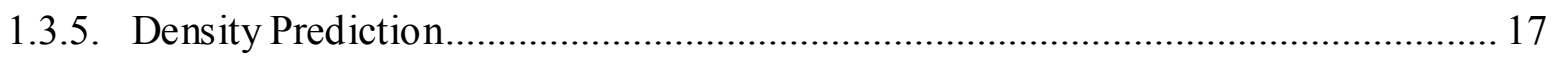

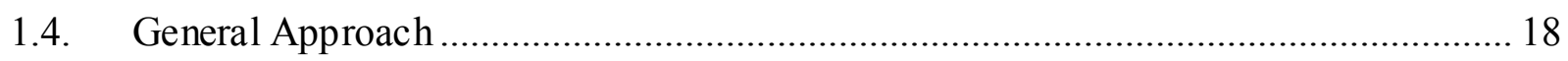

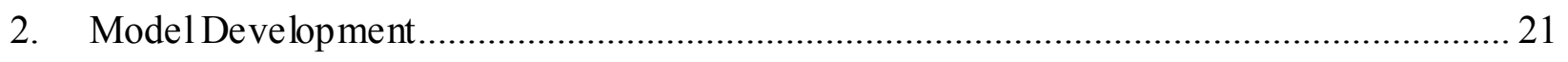

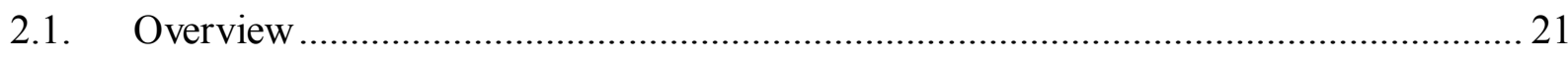

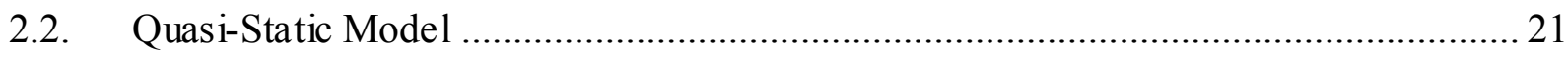

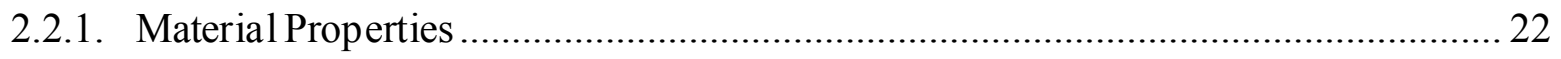

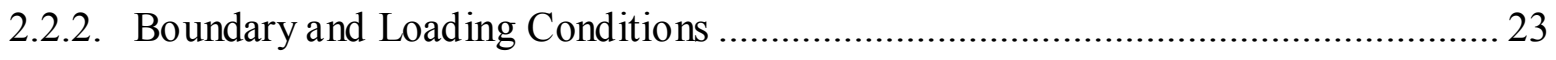

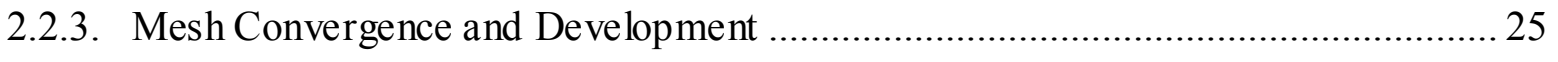

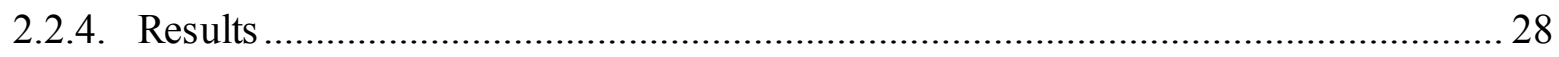




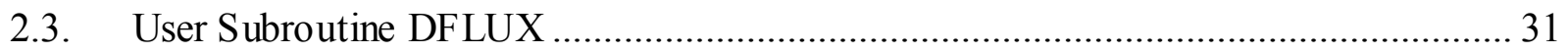

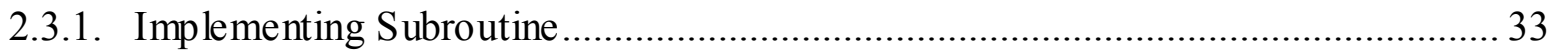

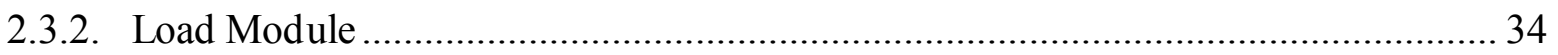

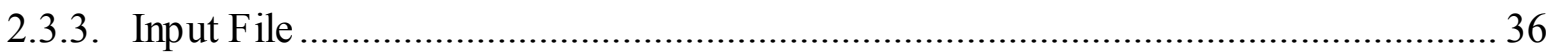

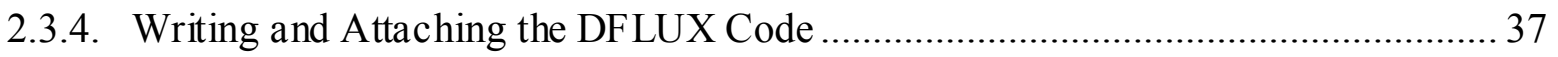

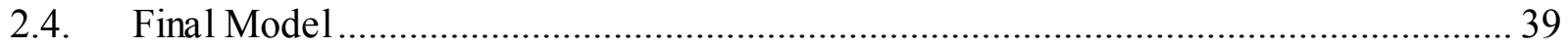

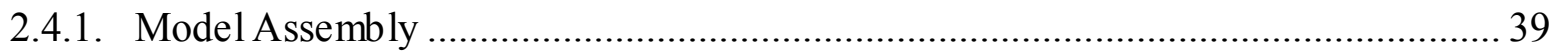

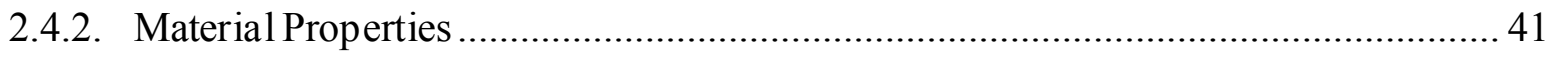

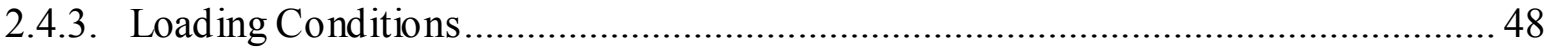

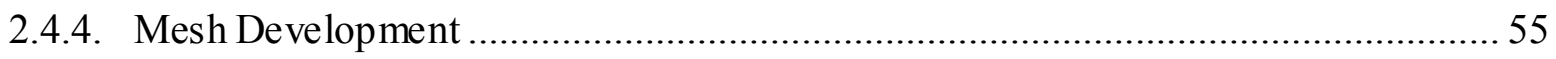

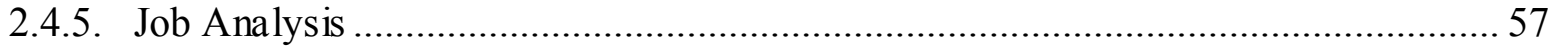

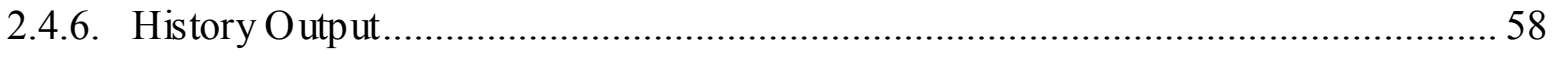

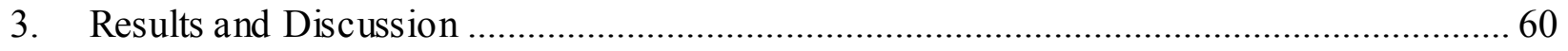

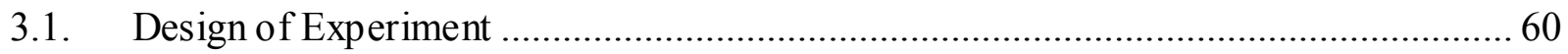

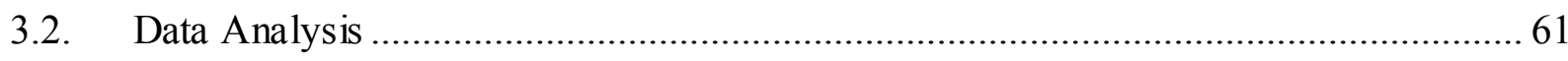

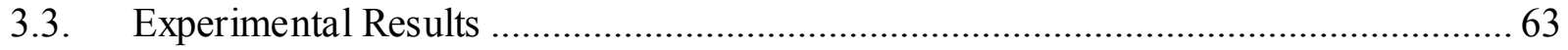

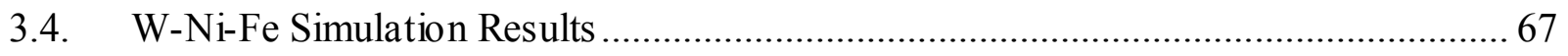

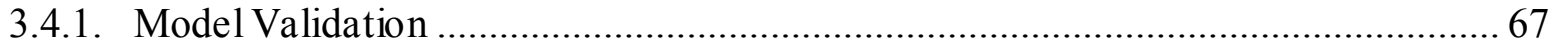

3.4.2. Linear Regression Results................................................................................ 71

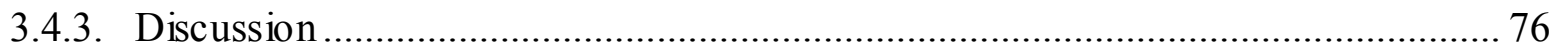

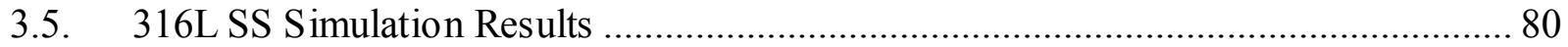

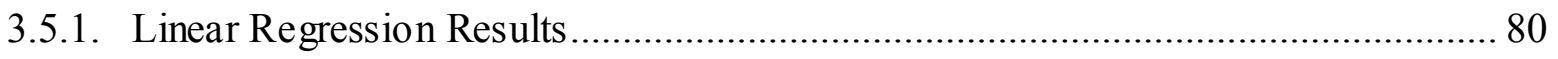

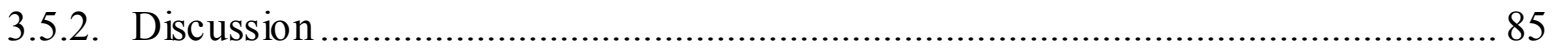




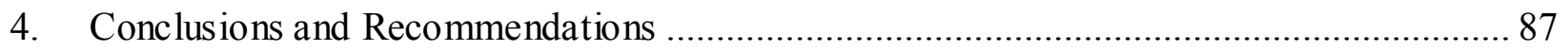

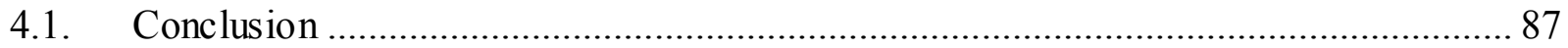

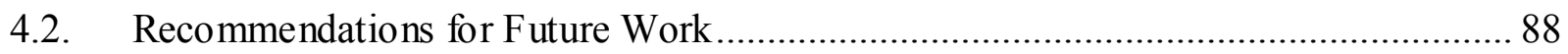

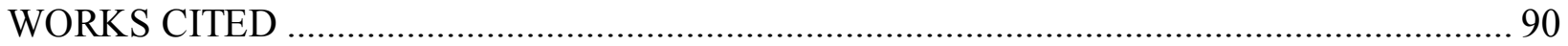

\section{APPENDICES}

Appendix A: W-Ni-Fe Full Simulation Result ......................................................... 93

Appendix B: 316L SS Full Simulation Results .................................................................. 94

Appendix C: MATLAB Melt Time Filter ................................................................ 95 


\section{LIST OF TABLES}

Table

Table 1. Summary of previous research studies involving modeling of SLS 14

Table 2. Properties of 316L Stainless Steel

Table 3. Additional properties used in "Quasi-Static" Model ................................................ 23

Table 4. Loading Parameters for Quasi-Static Model ...................................................... 25

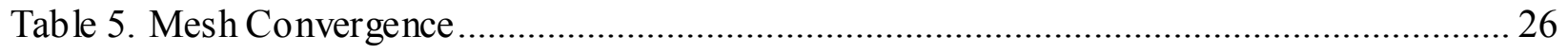

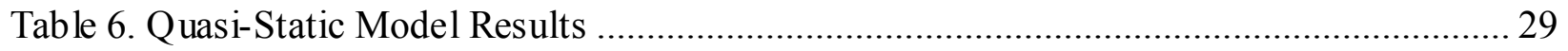

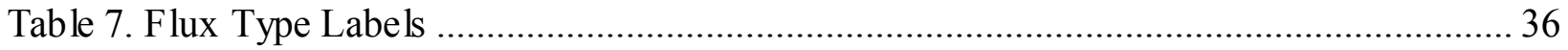

Table 8. Properties of Stainless Steel Substrate ................................................................ 42

Table 9. Parameters used for calculation of the thermal conductivity due to radiation............... 44

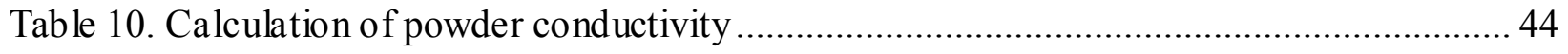

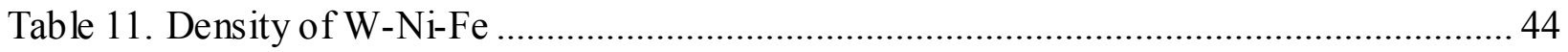

Table 12. Thermal conductivity values used in $\mathrm{W}-\mathrm{Ni}$-Fe simulations ................................... 45

Table 13. Specific heat values used in W-Ni-Fe simulations ............................................. 45

Table 14. Temperature Dependent Conductivity for 316L Stainless Steel ............................... 46

Table 15. Temperature Dependent Specific Heat for 316L Stainless Steel............................. 47

Table 16. Additional Material Properties for 316L Stainless Steel ........................................ 47

Table 17. Summary of important input file modifications .............................................. 55

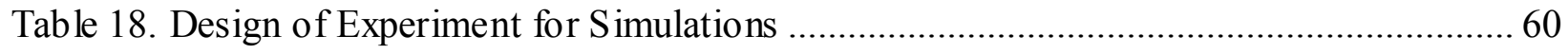

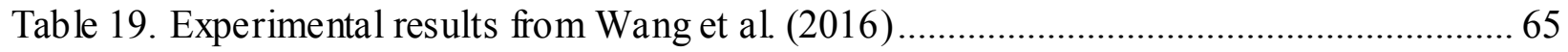

Table 20. Summary of results for comparison between Experiment 1 and Experiment 2 .......... 70

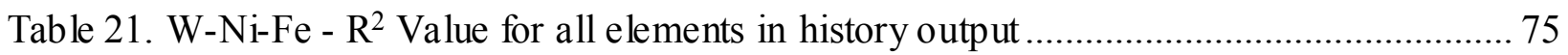


Table 22. 316L SS - $\mathrm{R}^{2}$ Value for all elements in history output 


\section{LIST OF FIGURES}

Figure

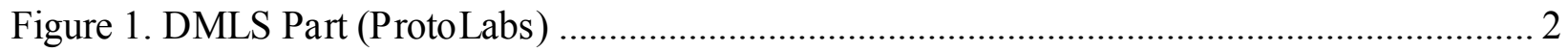

Figure 2. Biomedical implant (Blackman, 2008) ................................................................. 3

Figure 3. SLS process (Encyclopedia Britannica, 2012) ................................................... 5

Figure 4. Selective Laser Sintering Process (Palermo, 2013) ............................................... 5

Figure 5. Gaussian distribution of for a laser power of $50 \mathrm{~W}$ (Teng et al., 2015) ..................... 9

Figure 6. Schematic of the layer modeling approach (Fu and Guo, 2014)............................ 13

Figure 7. Comparison of laser scan on solid substrate vs powder bed (Hussein et al., 2013)...... 16

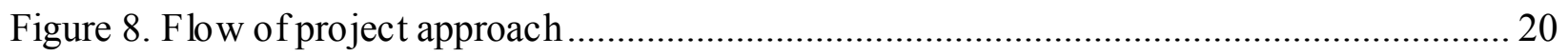

Figure 9. Gaussian and Top Hat Distribution of heat flux ................................................... 24

Figure 10. Demonstration of quasi-static loading condition............................................. 25

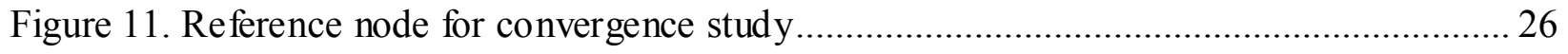

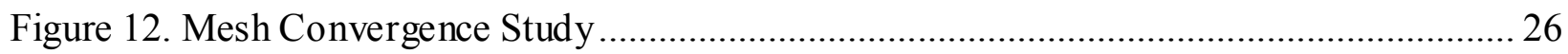

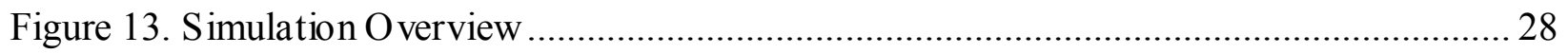

Figure 14. Comparison between Hussien et al. Model and Quasi-Static Model........................ 29

Figure 15. Flowchart for implementation of DFLUX subroutine ........................................ 33

Figure 16. Edit Load Settings for applying a heat flux ................................................... 34

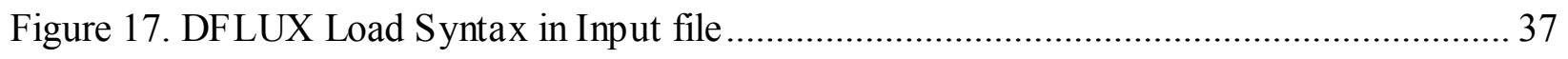

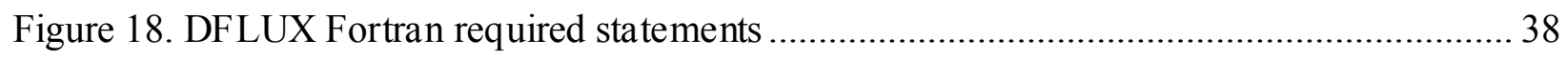

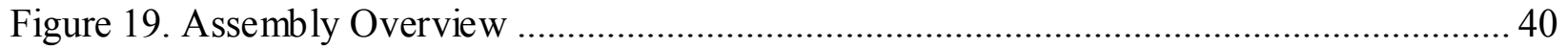

Figure 20. Implementation of defining initial Field Variable ............................................... 41

Figure 21. Implementation of changing field variable during simulation ................................ 42 


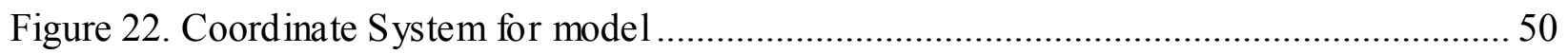

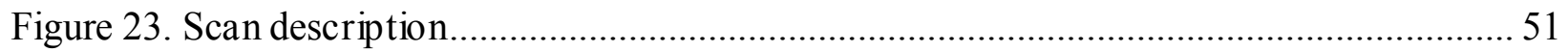

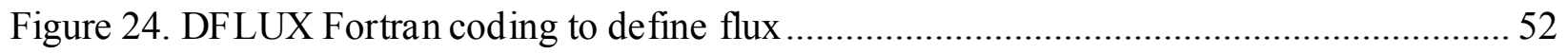

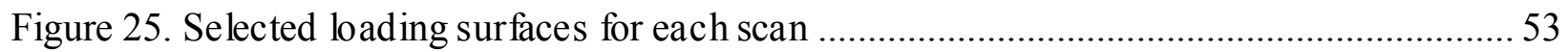

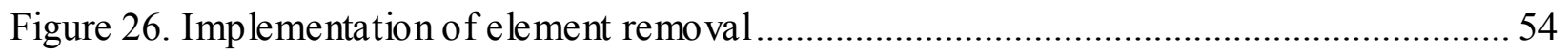

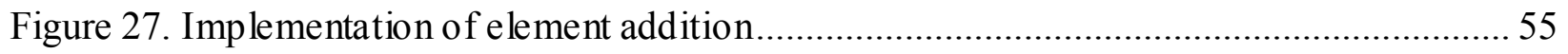

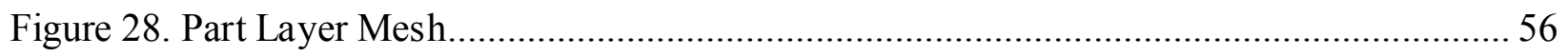

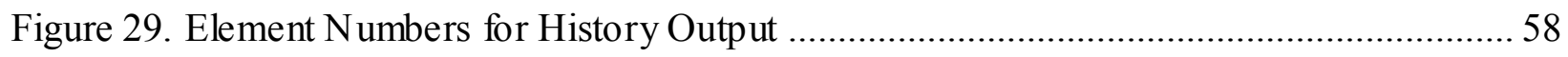

Figure 30. Nodes and Integration Points for a 20-Node Heat Transfer Brick (Dhondt 2014). .... 59

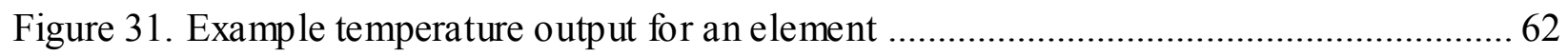

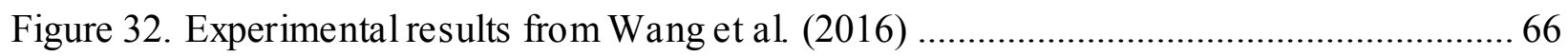

Figure 33. Layer 1 melt time for simulation 1 vs. simulation 2 comparison .................................6 67

Figure 34. Layer 2 melt time for simulation 1 vs. simulation 2 comparison................................ 68

Figure 35. Layer 3 melt time for simulation 1 vs. simulation 2 comparison................................. 68

Figure 36. Elements numbers for elements shown in W-Ni-Fe results ..................................... 71

Figure 37. W-Ni-Fe - Total melt time vs P/v for Element 648 ..................................................... 72

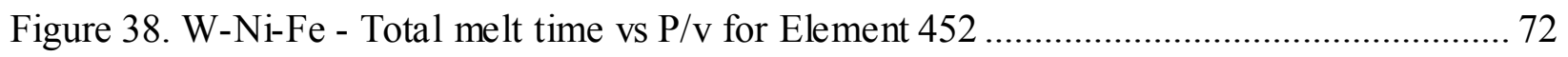

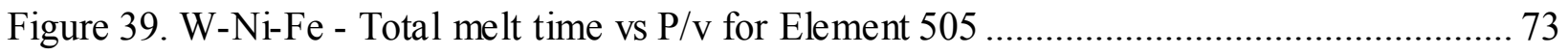

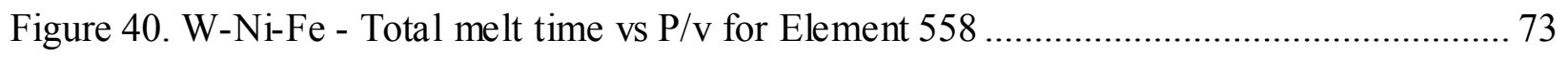

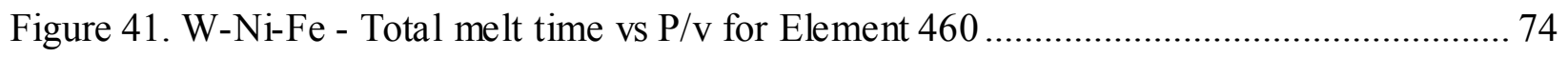

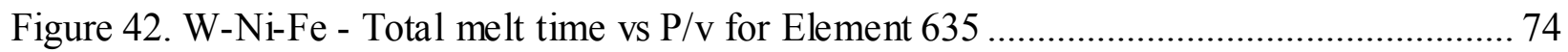

Figure 43. Microstructure evolution during SLS (German et al., 2009) ...................................... 76

Figure 44. Elements numbers for elements shown in 316L SS results ..................................... 80 
Figure 45. 316L SS - Total melt time vs P/v for Element 648

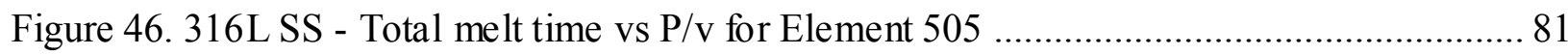

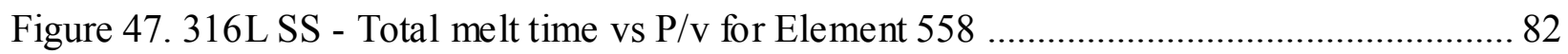

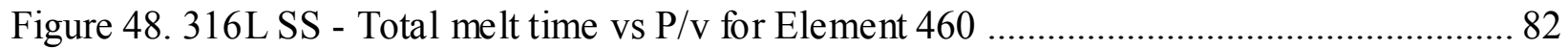

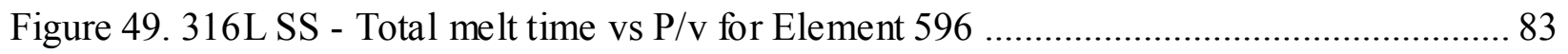

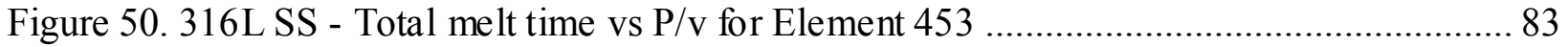




\section{INTRODUCTION}

\subsection{INTRODUCTION TO SOLID FREEFORM FABRICATION}

Selective Laser Sintering (SLS) is an additive manufacturing (AM) process that utilizes a high powered laser to "selectively" fuse material powder, layer by layer, into a three dimensional part. SLS technology has been emerging as a manufacturing process due to its ability to quickly produce complex geometry features for prototyping as well as high end production parts. SLS parts are built upon a powder bed which supports the subsequent layers allowing for internal channels and overhanging structures to be built without support material.

Selective Laser Melting (SLM) is a very similar process to SLS, but in SLM the material is fully melted into one homogeneous part. The complete melting of the powder allows for near full density parts to be achieved. SLM can be more difficult to control than SLS due to issues of incomplete powder melting and material phase changes occurring at the higher temperatures (Teng, Pal, Gong, \& Stucker, 2015). A special type of SLS that is specific to metal alloys is called Direct Metal Laser Sintering (DMLS). In general, SLS can be used with metals, plastics, nylon, glass, and ceramics. DMLS is just a branch of SLS that refers to the sintering of metals.

Two of the most common lasers used in selective laser processes are fiber and $\mathrm{CO}_{2}$ lasers. The main difference between the two is the wavelength of the laser, with the wavelength of the fiber lasers being approximately ten times smaller. Since smaller wavelengths are more easily absorbed by metals, fiber lasers (1064 nm) are typically used in the SLM process. In comparison, a $\mathrm{CO} 2$ laser beam is used for organic materials including wood, rubber, and acrylic. Accordingly, SLS processes that use organic 
materials typically use a CO2 laser while DMLS utilizes a fiber laser. Additionally, DMLS is usually associated with the sintering of alloys while SLM is the melting of a single powdered material. None the less, there is still great uncertainly of the exact phenomena occurring during these processes. The terms are helpful for classification but melting may occur during sintering processes and sintering may occur during melting processes.

A few other similar solid freeform fabrication (SFF) processes include electron beam melting (EBM), laser metal deposition (LMD), and laser engineered net shaping (LENS). EBM uses an electron laser beam to melt the metal powder inside of a high vacuum chamber. LMD also uses a laser beam to melt the material powder, however, instead of a powder bed, a separate nozzle is used to deliver the powder. In the LENS process, powder is injected into a molten pool created by a high power laser beam enclosed within an argon atmosphere (Contuzzi, Campanelli, \& Ludovico, 2011). In comparison to SLS, parts made from LENS can be much larger in size, such as turbine blades. The main advantages of SLM and SLS over other SFF processes are that a variety of materials can be used and the equipment is relatively less complicated and less expensive.

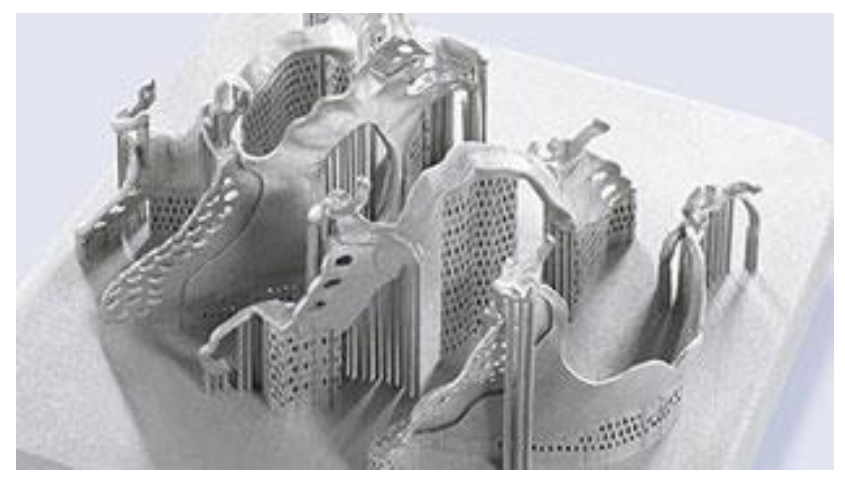

Figure 1. DMLS Part (ProtoLabs) 
Selective laser processes are becoming more prevalent in industry. In the automotive and aerospace industries, being able to manufacture lightweight parts can save money and improve performance. SLM can allow custom control over part density by varying process parameters such laser power and scanning speed. Additionally, designers now have the freedom to construct parts without restriction on internal features. The ability to build without support material allows for hollow parts to be built, requiring less material and money. SLM technology is also being utilized in the biomedical industry due to the ability to create very complicated shapes such as exact models for bone transplants. The wide array of materials that can be used in these processes allow for customization over the porosity and mechanical properties of the implants.

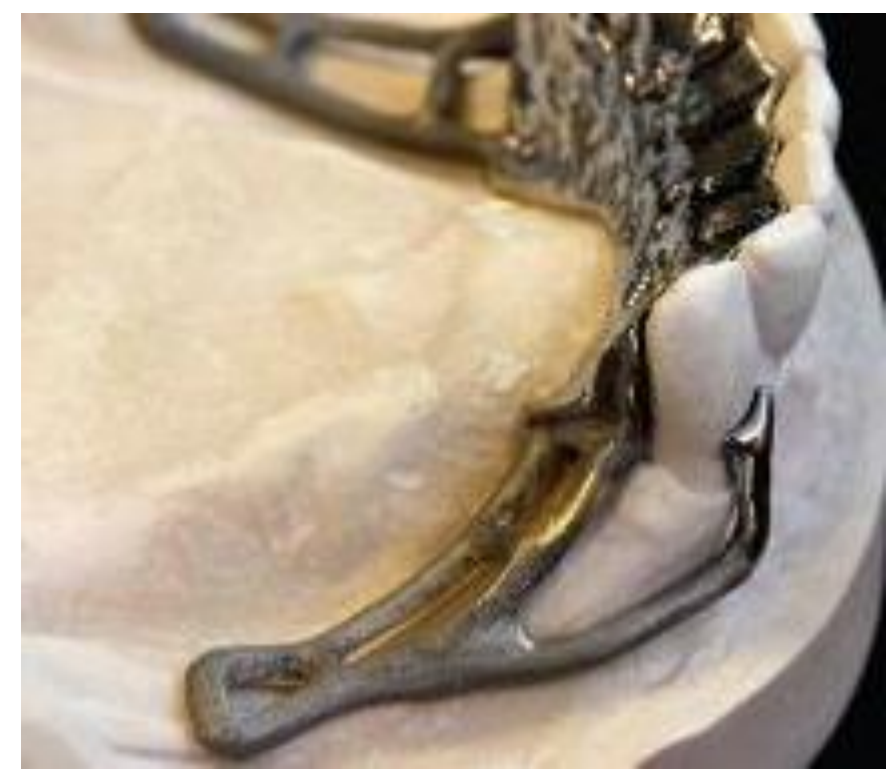

Figure 2. Biomedical implant (Blackman, 2008) 
All in all, SLM technology is emerging as a very powerful manufacturing technique, but is also a very complicated process due to the various thermo-mechanical phenomena occurring. The large amount of heat output from the laser and the repeated temperature cycles from the layer by layer approach results in a nonlinear thermal field within the part. As a result, several issues arise such as the balling effect, residual stresses, incomplete melting, and part distortion ( $\mathrm{Fu} \& \mathrm{Guo}$ ).

\subsection{SLS PROCESS CHARACTERISTICS}

The process begins with a CAD model of the part, which will be sliced into several layers ranging from .02-.15 $\mathrm{mm}$ in thickness. Inside of the laser sintering machine, a leveling roller distributes a layer of fine powder across a substrate plate (Figure 3). This plate is heated to a few degrees below the melting temperature of the material. A laser beam will then scan the path of the first layer and selectively fuse the material powder. The substrate plate will then be lowered by one layer in thickness and a new layer of powder will be distributed by the roller across the build platform. The process will be repeated until all the slices or layers of the 3D CAD model have been completed. The process is performed under an inert gas atmosphere in order to protect the part from oxidation (Contuzzi et al., 2011). Upon completion, the part can be removed from the powder bed and does not require any post processing operations. 

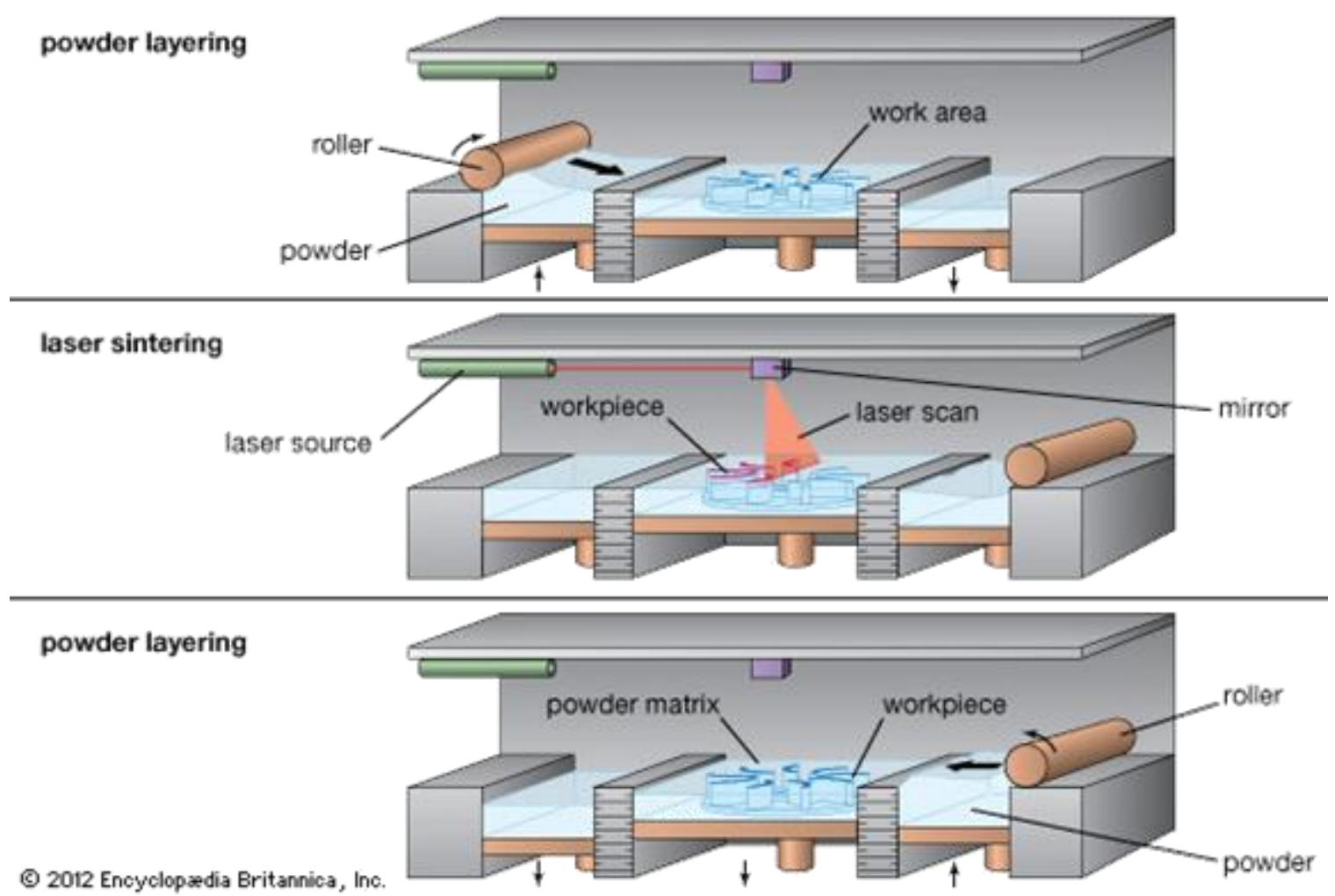

Figure 3. SLS process (Encyclopedia Britannica, 2012)

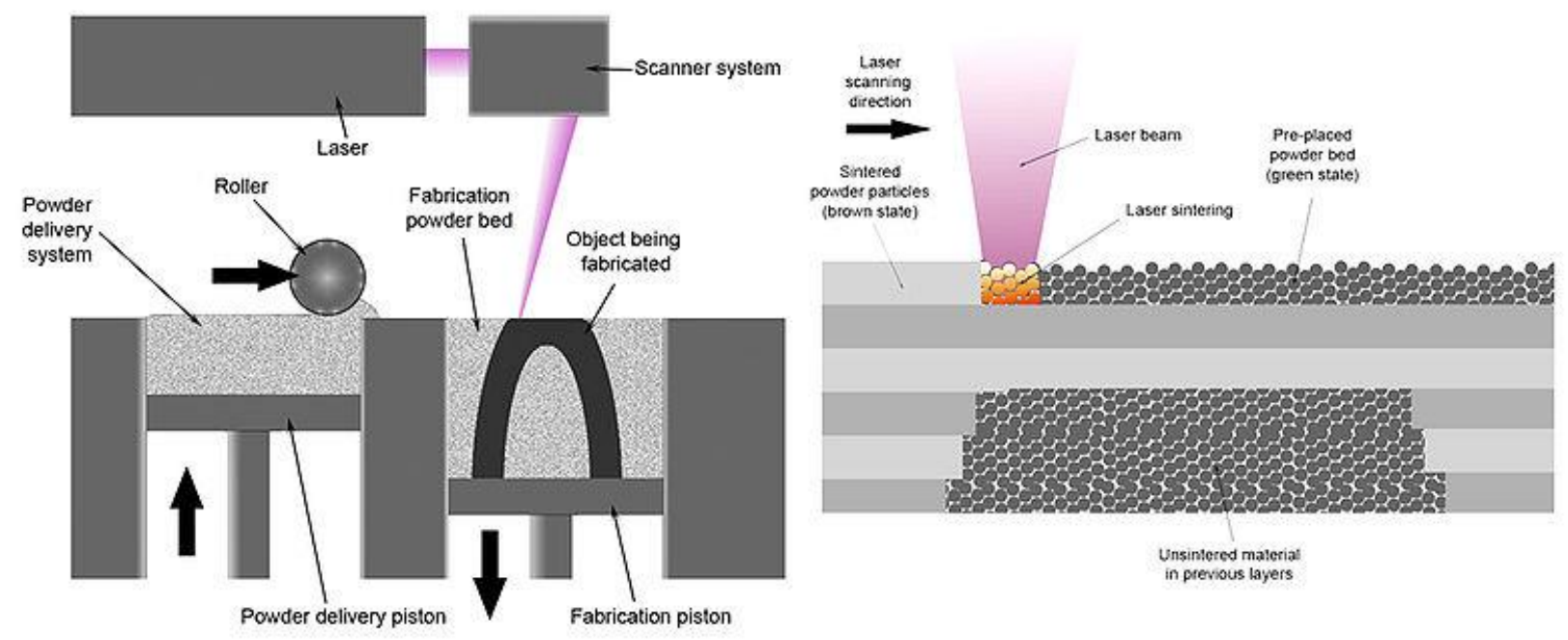

Figure 4. Selective Laser Sintering Process (Palermo, 2013) 
As stated earlier, SLS and SLM are very similar processes, differing only by a technical detail of whether the powder is partially or completely melted. In order to completely melt the powder, SLM requires more laser energy and as a result, creates a steeper temperature gradient. Thus, some of the manufacturing issues and challenges that are present with laser additive manufacturing technology are more evident in SLM. A few of the key problems that arise though the SLM process are the balling effect, steep temperature gradient, internal tensile stresses, and part distortion.

As the laser beam traces the powder layer, a molten melting pool is formed in which the fusing of the powder occurs. Two of the most important process parameters that control the dimensions of the molten pool as well as the quality of the particle fusing are the laser power and laser scanning speed (Papadakis, Loizou, Risse, Bremen, \& Schrage, 2014). One critical problem that arises from inadequate process parameters is a phenomenon called the balling effect. The exact cause of the balling effect is unknown but the molten pool has a tendency to shrink releasing surface energy, allowing the molten pool to break into separate balls. The balling effect is problematic because it increases the surface roughness and degrades mechanical properties of the part due to low quality fusing (Li, Liu, Shi, Wang, \& Jiang, 2011). The size and dimensions of the molten pool are known to be a determining factor as to whether the balling effect will occur as it has been observed to occur when the length to diameter ratio of the molten pool becomes greater than " $\pi$ "( $\mathrm{Fu} \& \mathrm{Guo})$. As a result, the laser intensity and scanning speed are two of the most important process parameters to control part integrity. Other contributing factors to balling initiation is the oxygen content in the atmosphere, powder layer thickness, and the type of powdered material. 
A large amount of laser energy is dispersed over a small time interval in order to melt the metallic powder. The layer-by-layer process approach requires that the part undergo several instances of intense heating and then rapidly cooling cycles, creating a steep temperature gradient. As a result, a buildup of thermal stresses can cause the part to deform or crack. This temperature gradient created during the SLM process plays a critical role in determining the overall part quality.

A better understanding of how different process parameters affect the temperature gradient will allow for improved control over the resulting molten pool, internal tensile stresses, and thermal distortion of the part. If the temperature distribution can be accurately modeled, then the subsequent mechanical properties can be also predicted. The goal of this project is to be able to accurately model the temperature distribution and output the relatively density of a SLS printed part. Due to the complexity of the selective laser melting process, a finite element software will be implemented in order to more accurately predict results. 


\subsection{LITERATURE REVIEW}

This sections begins by outlining the main factors, models, and considerations used to model the SLM process. Additionally, a comparison between past studies and their main focus of research is included. Due to the complexity of the SLM process, the finite element analysis method (FEA) using either Abaqus or ANSYS software is the most common method of analysis. The three key modeling aspects include a Gaussian distribution of the laser heat flux, incorporating the nonlinear temperature dependent material properties, and modeling the layer build up process. Finally, the literature review is concluded with a section on densification modeling of laser sintered parts.

\subsubsection{GAUSSIAN LASER DISTRIBUTION}

The most widely accepted laser model is the Gaussian beam model. This model assumes that the beam has a Gaussian irradiance profile where the maximum intensity is located at the center of the beam and is symmetrically distributed from the beam axis. The fundamental equation for the beam irradiance is as follows (Hussein, Hao, Yan, and Everson (2013):

$$
I(r)=I_{o} e^{\left(-2 \frac{r^{2}}{w_{o}^{2}}\right)}
$$

In this equation $\mathrm{I}_{\mathrm{o}}$ represents the maximum irradiance at the beam center, $\mathrm{r}$ is the radial distance from the center of the beam, and $\mathrm{w}_{\mathrm{o}}$ is the beam waist. The beam waist is the radius in which drives the irradiance of the beam to the following value.

$$
I=I_{o} e^{-2}
$$

The heat flux from a Gaussian beam can then be defined in a similar manner as

$$
q(r)=\frac{2 A P}{\pi r_{o}^{2}} e^{\left(-B \frac{r^{2}}{r_{o}^{2}}\right)}
$$


where:

- P - Laser Power (W)

- A - Absorptivity of the powder material

- B - Gaussian shape factor

- $\mathrm{r}_{\mathrm{o}}$ - laser spot radius (m)

- $r$ - radial distance from center of laser (m)

Fu and Guo (2014) state that a shape factor of 2 is typically used for the Gaussian heat flux distribution $(\mathrm{B}=2)$. The absorptivity of the powder material is typically taken as the absorptivity for the bulk material (Roberts, Wang, Esterlein, Stanford, \& Mynors, 2009). A schematic of the Gaussian distribution for a laser power of $50 \mathrm{~W}$ by Teng, et al. (2015) is shown in Figure 5. Notice how the intensity of the beam is radially symmetric from the beam center.

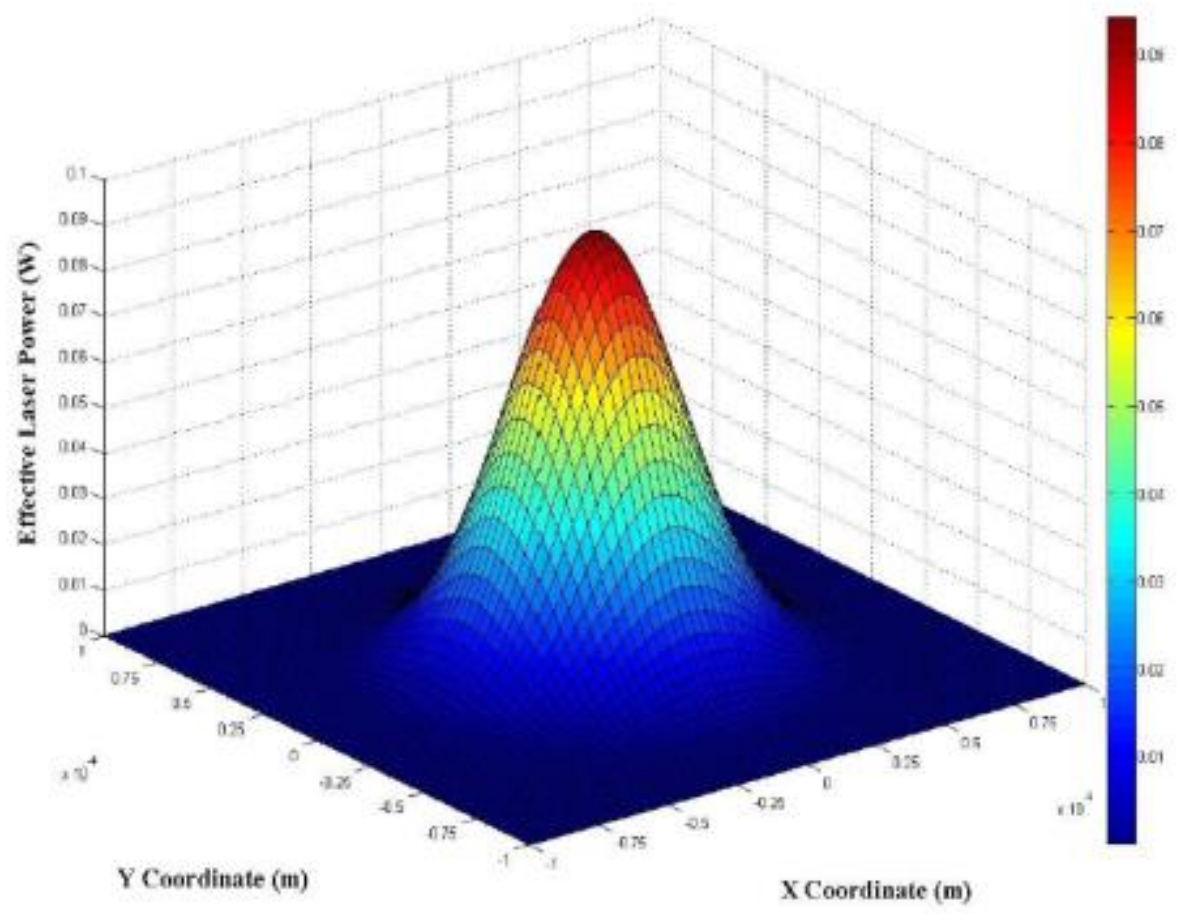

Figure 5. Gaussian distribution of for a laser power of $50 \mathrm{~W}$ (Teng et al., 2015) 
Equation [3] above corresponds to a surface based heat flux. The majority of past simulations have used a surface heat flux due since the powder layer is typically very thin. Alternatively, a few studies have used a 3D volumetric heat flux instead of the 2D surface heat flux. The most notable use of a volumetric heat flux is the study by Hodge, Ferencz, and Solberg (2014). They rationalize that it is possible that the heating of a powder that is not closely packed may occur within the bulk of the material. As a result, the heating is not only at the surface and thus a volumetric heat flux was used. 


\subsubsection{TemPerature DePENDENT MATERIAL PROPERTIES}

The thermo-mechanical properties between a solid bulk body and a powder layer of the same material differ. Additionally, since the SLS processes involves a material state change some properties will vary with temperature. Some of the key material properties needed to complete 3D heat conduction analysis include the density, thermal conductivity, and the specific heat of the powder. Two of the most common materials used in SLS applications are Ti-6Al-4V and 316L stainless steel.

The density of the powder layer is much smaller than the bulk material and as a result has a much higher absorptivity. Hussein et al. (2013) state that the absorptivity of the powder material is a function of the reflectivity of the material.

$$
A=1-\lambda
$$

In equation [4], " $\mathrm{A}$ " represents the absorptivity and " $\lambda$ " represents the reflectivity. This value is an important factor in determining the surface heat flux as it is represented in the Gaussian heat flux model, equation [3] above. Hussein et al. (2013) used the reflectivity of iron $(\lambda=0.7, \mathrm{~A}=0.3)$ to calculate the absorptivity for $316 \mathrm{~L}$ stainless steel. As a comparison $\mathrm{Fu}$ and Guo (2014) used the absorption coefficient for pure titanium powder $(\mathrm{A}=0.77)$.

Also, the thermal conductivity of the powder layer is much smaller than that of the bulk material. This is due to the larger porosity within the powder layer which results in a smaller contact area. In addition, gas fills the voids in the porous powder which has a much lower thermal conductivity. Thus the compactness of the powder layer plays a critical role in analyzing the heat conduction during SLS. 
The relationship between the powder bed and effective thermal conductivity can be related through the porosity of the powder layer. The porosity, $\phi$, is represented through the densities of the bulk, $\rho$ bulk, and powder layer, $\rho_{\text {powder, }}$ as

$$
\phi=\frac{\rho_{\text {bulk }}-\rho_{\text {powder }}}{\rho_{\text {bulk }}}
$$

Typically values for porosity range from 0.4 to 0.6 . The effective thermal conductivity, $\mathrm{k}_{\mathrm{powder}}$, can then be represented as a function of the porosity of the powder and thermal conductivity of the bulk material, kbulk (Hussein et al., 2013).

$$
k_{\text {powder }}=k_{\text {bulk }}(1-\phi)
$$




\subsubsection{LAYER ADDITION}

One important aspect of modeling is to be able to account for the addition of multiple layers. Roberts et al. (2009) focused on analysis of the temperature field during laser melting through simulation of the "element birth and death" method. This method is able to model layer addition by activating new elements or layers at specific time intervals. This enables the ability to model the time delay and cooling effect of rolling a new layer of powder before the next laser scan. Only once the elements are activated are they included in the overall stiffness matrix. Through this method, it was concluded that successive laser scanning over additional layers will affect the temperature distribution of previous layers. The reheating of layers creates secondary peaks in temperature as well as a small build-up of temperature in the part and substrate. A helpful schematic of the layer build up process from Fu and Guo (2014) is provided in Figure 6 .

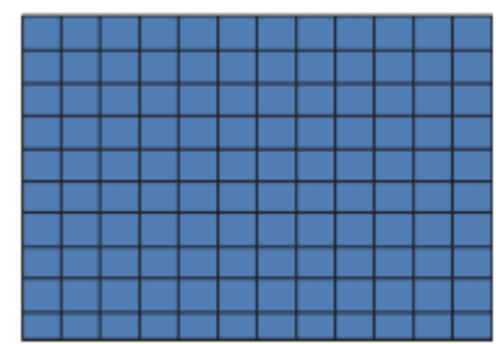

Powder mesh

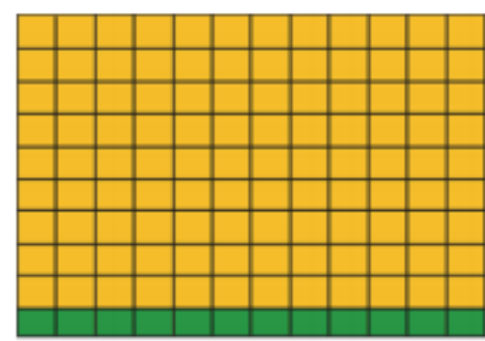

Scan of $1^{\text {st }}$ layer

Deactivated elements

Activated elements

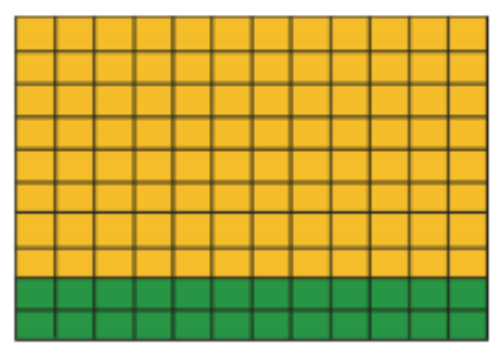

Scan of $2^{\text {nd }}$ layer

Figure 6. Schematic of the layer modeling approach (Fu and Guo, 2014) 


\subsubsection{SUMMARY OF PAST RESEARCH StUdies}

Several research studies on different SLS and SLM process characteristics have been conducted in the past. The most common modeling technique involves use of the finite element analysis method (FEA) using either Abaqus or ANSYS software. The most relevant studies conducted include a focus on modeling layer build up and a moving heat source.

Table 1. Summary of previous research studies involving modeling of SLS

\begin{tabular}{|c|c|c|}
\hline Research Focus & Material & Source \\
\hline $\begin{array}{l}\text { Melting pool shape and dimensions, } \\
\text { Temperature gradient and thermal } \\
\text { history, Effect of process parameters }\end{array}$ & Ti-6Al-4V & Fu and Guo (2014) \\
\hline $\begin{array}{l}\text { Temperature history from the } \\
\text { addition of layers }\end{array}$ & Ti-6Al-4V & Roberts et al. (2009) \\
\hline $\begin{array}{l}\text { Temperature and stress fields in } \\
\text { single layers built without-support }\end{array}$ & $\begin{array}{l}\text { 316L Stainless } \\
\text { Steel }\end{array}$ & Hussein et al. (2013) \\
\hline Residual stresses and deformations & $\begin{array}{l}316 \text { Stainless } \\
\text { Steel }\end{array}$ & Jiang et al. (2002) \\
\hline $\begin{array}{l}\text { Computational reduction model to } \\
\text { decrease modeling time }\end{array}$ & IN718 & Papadakis et al. (2014) \\
\hline $\begin{array}{l}\text { Effect of process parameters on } \\
\text { temperature evolution }\end{array}$ & $\begin{array}{l}\text { 316L Stainless } \\
\text { Steel }\end{array}$ & Contuzzi et al. (2011) \\
\hline $\begin{array}{c}\text { Effect of process parameters on } \\
\text { tensile properties }\end{array}$ & $\begin{array}{l}304 \text { Stainless } \\
\text { Steel }\end{array}$ & Guan et al. (2013) \\
\hline Effect of volume shrinkage & $\begin{array}{l}\text { Dental } \\
\text { Porcelain }\end{array}$ & Dai and Shaw (2005) \\
\hline Balling "Effect" Behavior & $\begin{array}{l}\text { Stainless } \\
\text { Steel, Nickel } \\
\text { Powder }\end{array}$ & Li et al. (2011) \\
\hline $2 \mathrm{D}$ analysis of thermal fields & Ti-6Al-4V & Teng, et al. (2015) \\
\hline
\end{tabular}


Another main component of accurately modeling the laser output is being able to model a moving heat flux source. Fu and Guo (2014) modeled the laser as a moving heat flux by using the subroutine "DFLUX" in Abaqus/Standard. This subroutine is able to implement a non-uniform flux as a function of time, position, and temperature. In this study, the "element birth and death" method was also utilized to activate a new layer of elements after each scan.

They were able to conclude that using compact powders can reduce the temperature gradient and molten pool size. Also, the temperature gradient is much steeper in the depth direction (towards previous layers) due to the increased density and thermal conductivity after the laser melting of previous layers. Similarly to Roberts et al. (2009), they also concluded that reheating previous layers has a significant effect on the temperature distribution. One recommendation to improve modeling accuracy is to experimentally measure the absorptivity, specific heat, and thermal conductivity of the powder material.

Other studies on SLS and SLM have focused on a variety of different process parameters. Hussein et al. (2013) investigated the temperature and stress field in single layers of 316L stainless steel built without support material. They found that the steepest temperature gradient occurred at the start of the first layer scan and that there is a higher cooling rate during a scan over the substrate in comparison to a scan over a powder layer. These two aspects coincide as a faster cooling rate will in return result in a steeper temperature gradient. A FEA model simulation from Hussein et al. (2013) of the cooling rates between a layer built on the substrate and on a powder bed is shown in Figure 7 . 


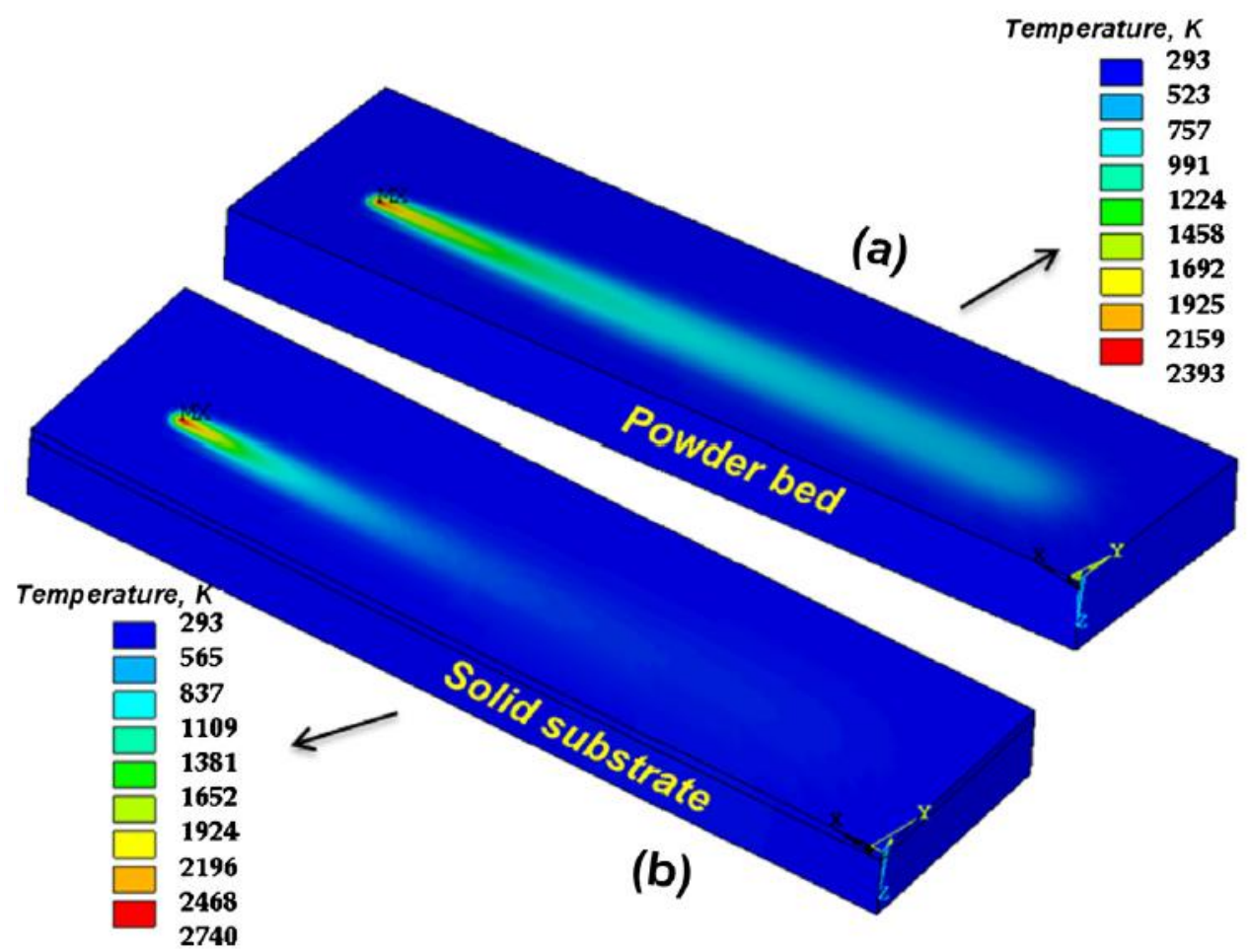

Figure 7. Comparison of laser scan on solid substrate vs powder bed (Hussein et al., 2013)

Jiang, Dalgarno, and Childs (2002) evaluated the internal residual stresses and deformations occurring during the SLS process. They discovered that vertical distortion is mainly due to thermal shrinkage of porous powders and horizontal deformation is mainly due to the thermal loading. Li et al. (2012) studied the balling behavior of stainless steel and nickel powder during the melting process. Teng et al. (2015) performed a 2-D evaluation of the thermal distribution occurring during SLM. Dai and Shaw (2005) used a 3-D finite element simulation to analyze the effect of volume shrinkage during the transformation from a compact powder to a dense liquid. 


\subsubsection{DENSITY PREDICTION}

One gap in current research is predicting the resulting mechanical properties of SLS parts. The density is a very important quality of the finished part because it has a direct relationship to strength, weight, and integrity. Wang et al. (2016) have proposed a model to predict the relative density based on the processing parameters used within the scan. They were able to conclude that the most important parameters were the scanning speed and laser powder. Additionally, the trace width or hatch spacing and the number of passes did not result in a significant effect on the resulting density.

The equation for porosity is as follows:

$$
\theta=\theta_{0} \exp \left(-\frac{9 \alpha}{4 \eta_{0} r_{0}} t\right)
$$

And the equation for relative density is:

$$
\rho=1-\theta=1-\theta_{0} \exp \left(-\frac{9 \alpha}{4 \eta_{0} r_{0}} t\right)
$$

Where:

- $\rho$-Relative Density

- $\theta$ - Porosity

- $\theta_{0}$ - Initial Porosity

- $\alpha$-Surface Tension

- $\eta_{0}$ - Viscosity

- $r_{0}$-Average radius of particle

- $t$-Sintering time 


\subsection{GENERAL APPROACH}

There are two main problems in which this project attempts to resolve. First, is to be able to model the time history of the temperature distribution from different laser recipes. The temperature is an important parameter because it directly affects several other resulting properties such as density, distortion, delamination, residual stress, surface roughness, etc. Second, using the temperature history results, be able to predict the relative density. Density is one of the most important properties of the overall integrity and quality of the part. Thus, insight into the predication of the density is critical.

The current solutions to the above-mentioned problems utilizes a multiscale modeling approach. Multiscale modeling consists of a mesoscale model to represent the powder and a continuum model to represent the part as a whole. The mesoscale model predicts the behavior of the powder layer within the range of a few hundred particles. The mesoscale model will take the input parameters of the laser recipe and output the resulting temperature field and melt pool characteristics to the continuum model. The continuum model will then use this information to predict behavior, including density, distortion, stress, etc, on the part scale (Campbell et al., 1998).

The main drawback of the current solutions using the multiscale modeling approach is that they are very expensive. The software platform and computing power required make the current solutions unfeasible to most users, however, the modeling process is critical to reveal the fundamental physical phenomenon occurring within the SLS process. This situation reveals the need for an affordable modeling tool that can be implemented using a low cost, commercially available package. 
This project will be approached through a two phase approach. First, an efficient, affordable, and reliable simulation will be developed within the software Abaqus. The model must be efficient as to minimize computation time required to run the analysis. The model must be affordable in that a commercially available finite element software will be used. The model must be reliable such that all important modeling considerations are taken into account and completed model is validated to experimental data. The second phase of the project includes using data from this FEA model and incorporating it into the relative density model proposed by Wang et al (2015). Upon completion, the results will be compared to experimental data and evaluated. Figure 8 is a visual representation of the flow of the project approach. 


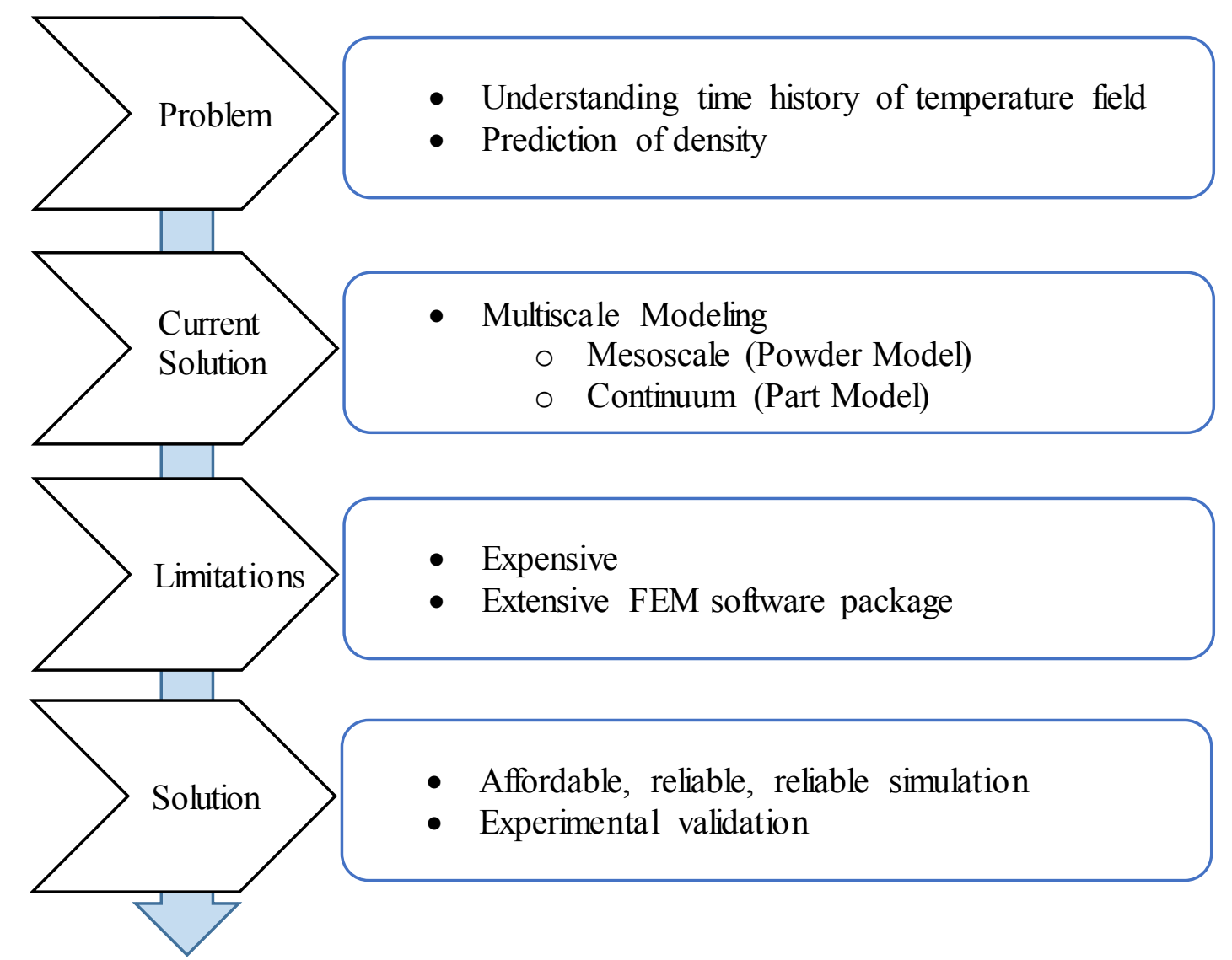

Figure 8 . Flow of project approach

The following sections of the report include a full description of the modeling development process and the results from various simulations. The modeling process began with a simplified basic model to obtain a working starting point. Advanced functionality and complex model considerations are then described and incorporated into the final model. Next, numerous simulations were conducted using W-Ni-Fe as the powder material and the results were compared to an experiment performed by Wang et al. (2016). Additionally, a second study was performed in which 316L stainless steel was as the material. Finally, discussion, conclusions, and recommendations of the results are presented. 


\section{MODEL DEVELOPMENT}

\subsection{OVERVIEW}

This section will explain the complete development of the model used during the simulations. First, a basic underlying structure was developed to obtain a starting point. This model is named the "Quasi-Static" model as multiple static loads were implemented in attempt to model a moving heat flux. Once a simplified model was created, further complexities were implemented. One of the main modeling development steps was the implementation of the user subroutine DFLUX. Additional aspects include using field variables to adjust the temperature dependent material properties and an element birth and death type approach to model the layer build up process. The final model is described in great detail with the rationale behind specific changes to the FORTRAN subroutine file and the job input file.

\subsection{QUASI-STATICMODEL}

The purpose of the Quasi-Static model was to reduce complexity and have a starting point for a working model. In order to simplify the model, only one layer of material powder is used in the simulation. The dimensions of the powder layer are .665 $\mathrm{mm} \mathrm{Lx} .133 \mathrm{~mm} \mathrm{~W} \times 30 \mu \mathrm{m} \mathrm{T}$. The $30 \mu \mathrm{m}$ thickness is the typical thickness of a powder layer. The dimensions are based on the chosen the seed size of the mesh which will be discussed later. The $.665 \mathrm{~mm}$ length is the direction in which the laser will scan and corresponds to exactly 30 elements. The $.133 \mathrm{~mm}$ width was selected because it is 3 times the effective laser spot area. The powder is going to be built upon a substrate with dimensions $2 \mathrm{~mm} \mathrm{Lx} 1 \mathrm{~mm} \mathrm{Wx} .5 \mathrm{~mm}$ T. The substrate acts as a built plate and will be modeled as a steel layer. 


\subsubsection{MATERIAL PROPERTIES}

The thermo-mechanical properties between a solid bulk body and a powder layer of the same material differ. Additionally, since the SLS processes involves a material state change, some properties will vary with temperature. Some of the key material properties needed to complete $3 \mathrm{D}$ heat conduction analysis include the density, thermal conductivity, and the specific heat of the powder. The material used in this simulation is 316L stainless steel because it is one of the most common materials used in SLS applications. Table 2 shows the conductivity and specific heat of the bulk and powder material. The conductivity used in this model was adapted from Hussein et al (2013) and the specific heat values were adapted from Jiang et al. (2002). Some additional mechanical and physical properties are listed in Table 3.

Table 2. Properties of 316L Stainless Steel

\begin{tabular}{|c|c|c||c|c|}
\hline \multicolumn{5}{|c|}{ Properties of 316L Stainless Steel } \\
\cline { 1 - 2 } $\begin{array}{c}\text { Temperature, } \\
{[\mathbf{K}]}\end{array}$ & $\begin{array}{c}\text { Conductivity } \\
{\left[\mathbf{W} / \mathbf{m}^{*} \mathbf{K}\right]}\end{array}$ & $\begin{array}{c}\text { Powder, } \\
{\left[\mathbf{W} / \mathbf{m}^{*} \mathbf{K}\right]}\end{array}$ & $\begin{array}{c}\text { Temperature, } \\
{[\mathbf{K}]}\end{array}$ & $\begin{array}{c}\text { Specific } \\
\text { Heat, } \\
{\left[\mathbf{J} / \mathbf{K g} \mathbf{K}^{*}\right]}\end{array}$ \\
\hline 293 & 13 & 1 & 200 & 400 \\
\hline 400 & 15 & 1.6 & 400 & 500 \\
\hline 600 & 17 & 2 & 600 & 550 \\
\hline 800 & 21 & 2.4 & 800 & 600 \\
\hline 1000 & 24 & 2.8 & 1000 & 650 \\
\hline 1200 & 26 & 3.2 & 1200 & 700 \\
\hline 1500 & 22 & 3.6 & & \\
\hline 1644 & 28 & 30 & & \\
\hline 1700 & 27.5 & 27.5 & & \\
\hline
\end{tabular}


Table 3. Additional properties used in "Quasi-Static" Model

\begin{tabular}{|c|c|}
\hline \multicolumn{2}{|c|}{$\begin{array}{c}\text { Mechanical and Physical } \\
\text { Properties of 316L Stainless Steel }\end{array}$} \\
\hline Density (bulk) $\left[\mathrm{kg} / \mathrm{m}^{\wedge} 3\right]$ & 8000 \\
\hline Density (powder) $\left[\mathrm{kg} / \mathrm{m}^{\wedge} 3\right]$ & 3200 \\
\hline Solidus Temperature $[\mathrm{K}]$ & 1650 \\
\hline Liquidus Temperature $[\mathrm{K}]$ & 1675 \\
\hline Latent Heat $[\mathrm{kJ} / \mathrm{Kg}]$ & 280 \\
\hline
\end{tabular}

\subsubsection{BOUNDARY AND LOADING CONDITIONS}

The boundary conditions implemented in the model include a predefined temperature field and a surface film condition to account for convection. The predefined temperature field was set to room temperature, $293 \mathrm{~K}$, and was applied to all surfaces of both the powder layer and the substrate. The surface film condition with a heat transfer coefficient of $10 \mathrm{~W} / \mathrm{m}^{\wedge} 2 * \mathrm{~K}$ was applied over the top and slides of the powder layer and the top of the substrate with a sink temperature of $293 \mathrm{~K}$ (Hussein, Hao, Yan, and Everson, 2013). Both of these conditions were necessary in order for the model to reach equilibrium. Additionally, a tie constraint was used to fuse the mesh between the bottom of the powder layer and the top of the substrate since the meshes of these two parts are dissimilar.

A code was developed to turn the Gaussian beam distribution into a "top-hat" distribution in order to simplify the loading case. This was accomplished by integrating the Gaussian distribution and then dividing by the limits of the integration (Figure 9). This methodology approximates the heat flux which would be applied within the laser spot radius. The calculated load was then applied over an equivalent area of elements. 


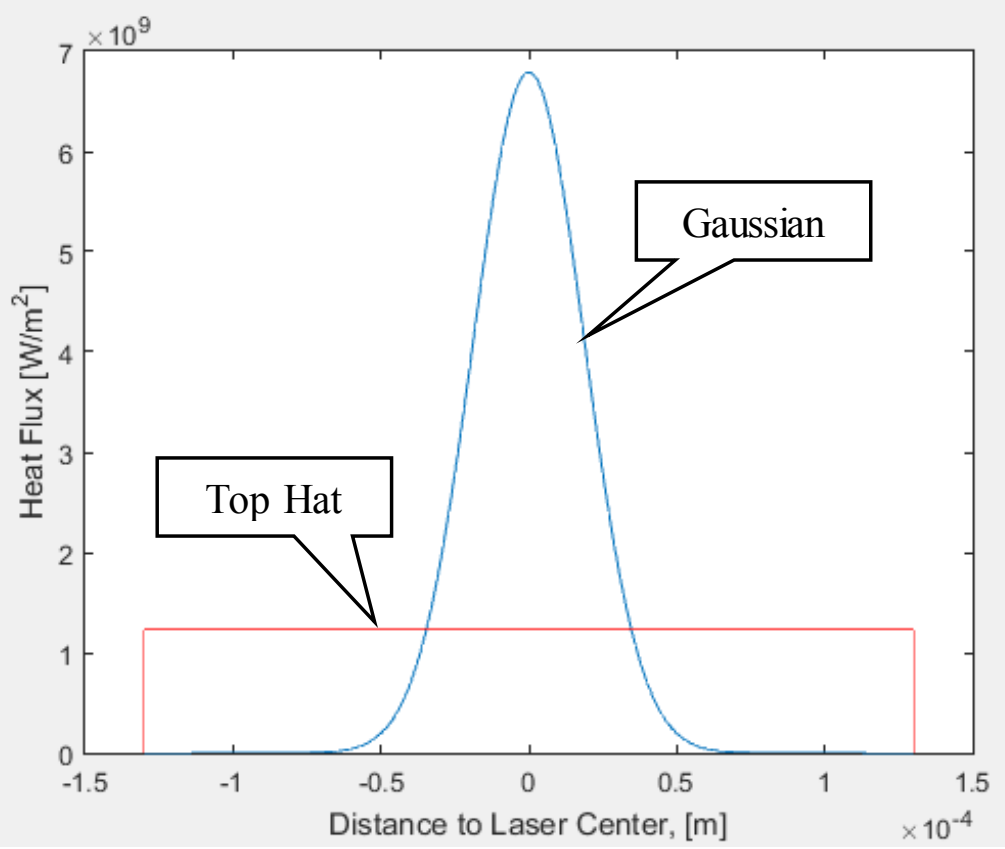

Figure 9. Gaussian and Top Hat Distribution of heat flux

Additionally, a quasi-static loading case was implemented by applying several loads at different steps. A laser scanning speed of $200 \mathrm{~mm} / \mathrm{s}$ was used to determine the time period of each step. A time period of .00031 seconds was used for the first step and was calculated by dividing the scanning speed by length of loading surface. Additional steps used a time period of $1.0339 \mathrm{E}-4$ seconds which is equivalent to $1 / 3$ of the initial time step because each step moved the load by $1 / 3$ of the equivalent area. The loading condition is demonstrated in Figure 10 below. A total of 25 loads and 25 steps were used to propagate the laser heat flux across the layer. Each step only included the load for that surface by making the previous loads inactive. The loading parameters are shown in Table 4. 

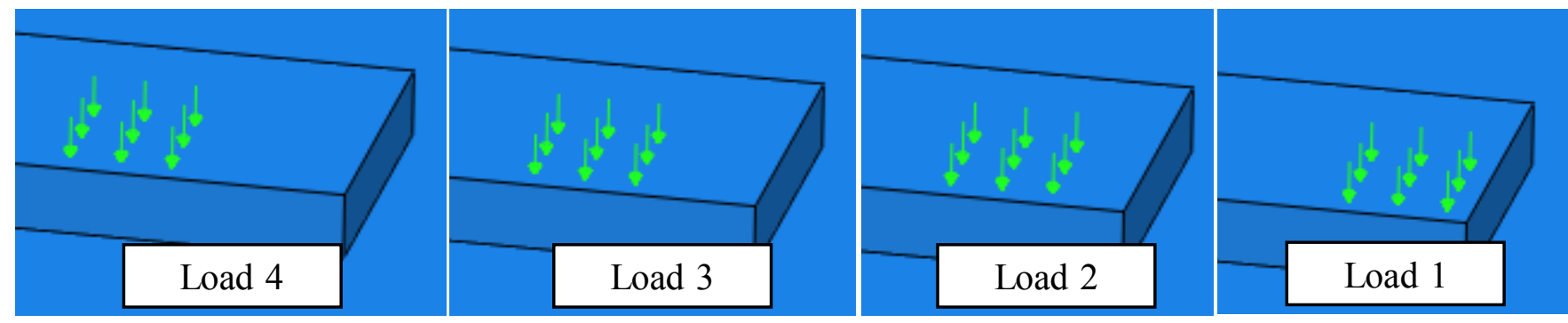

Figure 10. Demonstration of quasi-static loading condition

Table 4. Loading Parameters for Quasi-Static Model

\begin{tabular}{|c|c|}
\hline \multicolumn{2}{|c|}{ Loading Parameters } \\
\hline Absorptivity, A & 0.3 \\
\hline Laser Power, $\mathrm{P}[\mathrm{W}]$ & 100 \\
\hline Spot Radius $[\mu \mathrm{m}]$ & 35 \\
\hline Scanning Speed $[\mathrm{mm} / \mathrm{s}]$ & 200 \\
\hline Top Hat Flux $\left[\mathrm{W} / \mathrm{m}^{\wedge}\right.$ ] $]$ & $1.23 \mathrm{E}+09$ \\
\hline
\end{tabular}

\subsubsection{MESH CONVERGENCE AND DEVELOPMENT}

The method in which the surface heat flux was calculated was based on the area of the laser spot radius. In order to keep the loading condition consistent, the element surfaces were selected such that the area in which the load was applied remained the same. Thus, as the seed size and element size was decreased, the load was applied over more elements; however, the total surface area remained the same for each case in Table 5. The seed size was decreased in incremental amounts and for some cases the element type was changed to quadrilateral in order to increase the degrees of freedom in the model. The temperature was then recorded at the same reference node indicated in Figure 11. From the results, it was concluded that the model would be converged using quadrilateral elements with a seed size of $2.22 \mathrm{E}-.05 \mathrm{~m}$. 


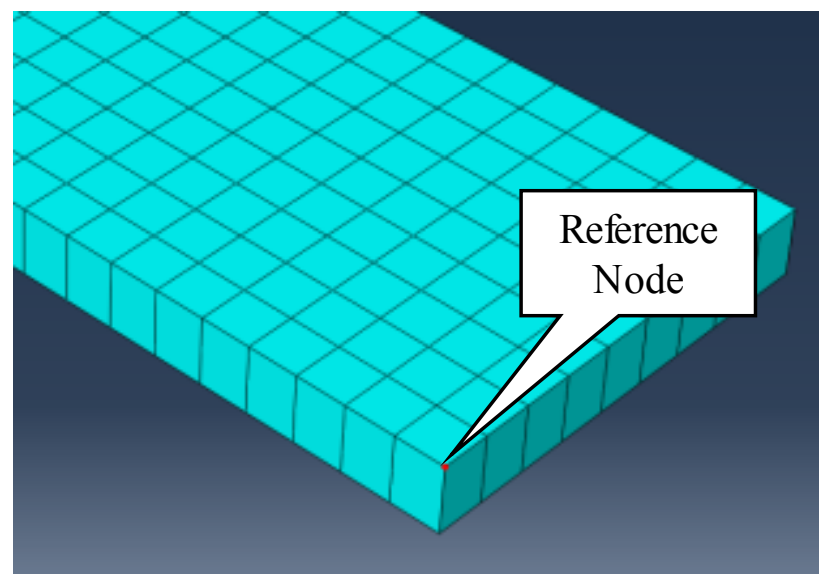

Figure 11. Reference node for convergence study

Table 5. Mesh Convergence

\begin{tabular}{|c|c|c|c|}
\hline $\begin{array}{c}\text { Geometric } \\
\text { Order }\end{array}$ & Seed Size & $\begin{array}{c}\text { Degrees of } \\
\text { Freedom }\end{array}$ & NT11 \\
\hline Linear & $6.65 \mathrm{E}-05$ & 1474 & 3242 \\
\hline Linear & $3.32 \mathrm{E}-05$ & 1680 & 2829 \\
\hline Linear & $2.22 \mathrm{E}-05$ & 2006 & 2799 \\
\hline Quad & $3.32 \mathrm{E}-05$ & 2359 & 2665 \\
\hline Linear & $1.66 \mathrm{E}-05$ & 2985 & 2295 \\
\hline Quad & $\mathbf{2 . 2 2 E - 0 5}$ & $\mathbf{3 4 7 4}$ & $\mathbf{2 6 0 7}$ \\
\hline Quad & $1.66 \mathrm{E}-05$ & 7087 & 2603 \\
\hline
\end{tabular}

Mesh Convergence Study

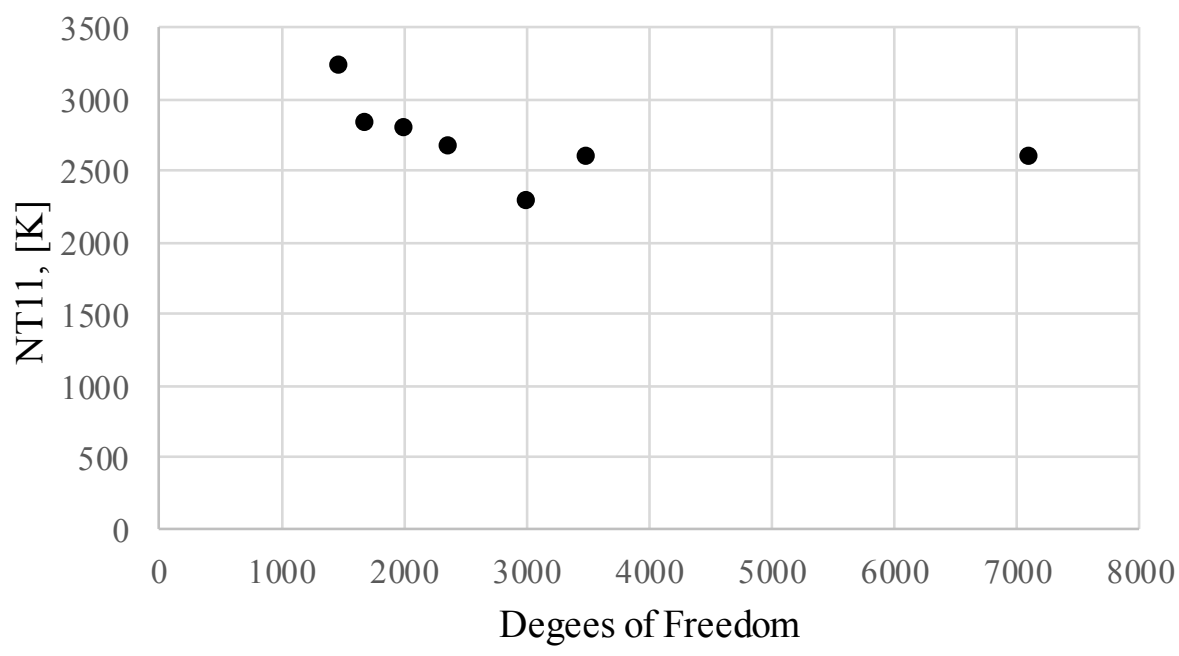

Figure 12. Mesh Convergence Study 
The powder layer was meshed using a quadratic hexahedral, DC3D20: A 20node linear heat transfer brick, as the element type. Through a literature review in modeling of selective laser sintering, the hexahedral element shape was the most popular in heat conduction problems and resulted in the most accurate temperature in the simulation. A quadrilateral geometric order and a seed size of 2.22E-5 m was used due to the results of the convergence study as described above. The substrate was modeled as a linear hexahedral element with a seed size of 1.0E-4 m. A coarser mesh was used for the substrate to save computational time since the temperature distribution in this part was not of interest in this project. The total number of elements and degrees of freedom in the model are 1270 and 3474, respectively. The elements were of high quality, meeting the Abaqus criteria for both aspect ratio and skew angle. 


\subsubsection{RESULTS}

The Quasi-Static model was used as a stepping stone in the model development. A lot of assumptions were made and parameters were chosen based off similar simulations. The purpose of this model was simply to get a better understanding of how this problem should be approached. As a result, the results from this simulation are not of any significance with respect to actual modeling of the selective laser sintering process. Instead conclusions were made from these results in an attempt to improve upon the accuracy of the model.

The results from this simulation were compared to a similar simulation performed by Hussein et al. (2013). Since this is also a simulation model, it is not the ideal method for validation. However, the results from this study were presented in a clear manner such that it was an ideal model to try and replicate as an initial approach. An overview of the results performed in this simulation is shown in Figure 14.

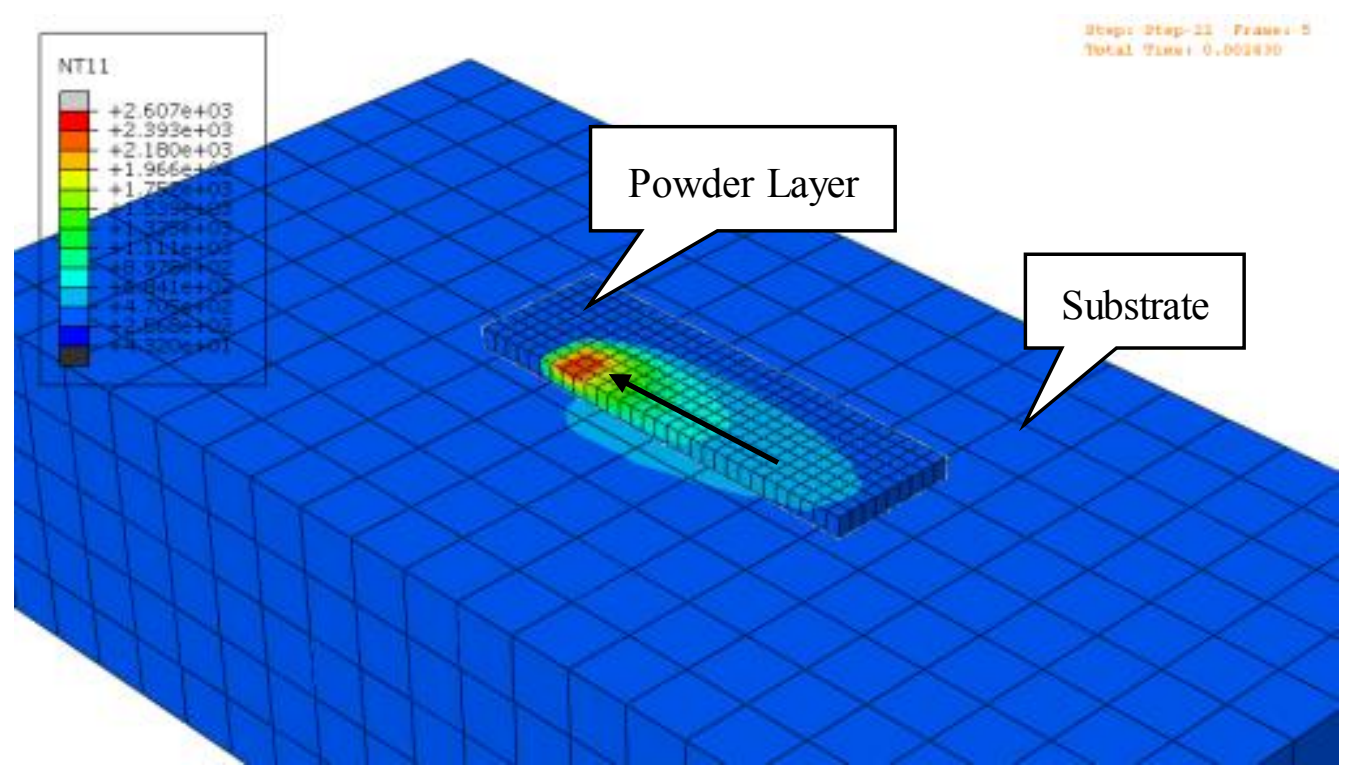

Figure 13. Simulation Overview 
A comparison was made between the models of the temperature with respect to the distance from the spot center. The temperature was recorded starting at the max temperature node and progressing in the direction of laser movement. Since the Hussein Model used a different seed size, $75 \mu \mathrm{m}$, the results were not compared directly. Instead a visual inspection of the melt pool was examined. The values were probed for the Quasi-Static Model (nodes circles in Figure 14).
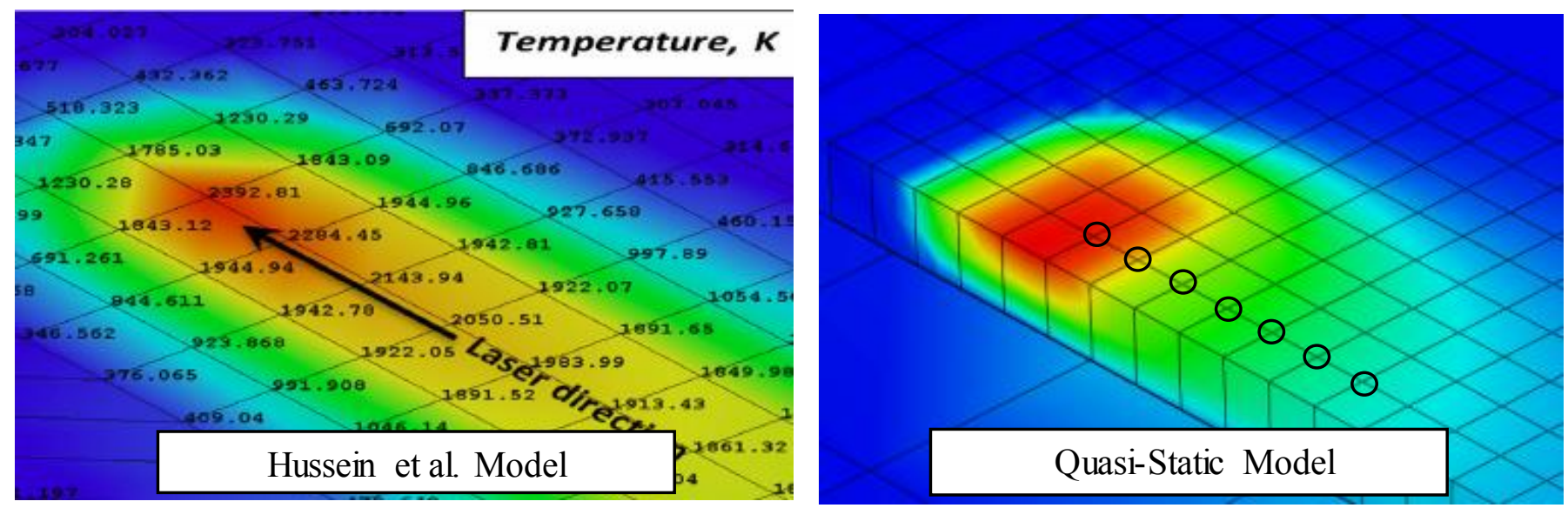

Figure 14. Comparison between Hussien et al. Model and Quasi-Static Model

Table 6. Quasi-Static Model Results

\begin{tabular}{|c|c|}
\hline $\begin{array}{c}\text { Distance From Spot } \\
\text { Center }[\mathbf{m m}]\end{array}$ & $\begin{array}{c}\text { Quasi-Static } \\
\text { Model }\end{array}$ \\
\hline 0 & 2370 \\
\hline 0.022 & 2394 \\
\hline 0.044 & 1979 \\
\hline 0.066 & 1624 \\
\hline 0.088 & 1454 \\
\hline 0.11 & 1222 \\
\hline 0.132 & 1076 \\
\hline
\end{tabular}


Overall the model acts as a good starting approach; however, several additions can be made to improve accuracy. Key model improvements include implementing the Gaussian heat flux through the user subroutine DFLUX, layer addition, and further control over material properties.

First, the magnitude of the temperature was similar to past models suggesting that the material properties were implemented correctly. The biggest discrepancy within the Quasi-Static model is shape and time history of the temperature distribution. This is most likely due to the way in which the load was applied. I used a quasi-static approach in which I applied the loads in several steps. In future simulations, I will implement the user subroutine "DFLUX." This subroutine is able to implement a non-uniform flux as a function of time, position, and temperature. I believe this is a more accurate approach to a moving heat source.

Another future consideration includes analysis of multiple layers. This has been done in past studies by the use of the element "birth and death" method in which elements are activated at certain time intervals. This enables the ability to model the time delay and cooling effect of rolling a new layer of powder before the next laser scan. Additionally, the material properties have a large impact over the results. A better way to control the properties as specific moments within in the simulation can increase the model's accuracy. 


\subsection{USER SUBROUTINE DFLUX}

Abaqus is equipped with a set of user subroutines that enables the user to modify and adapt particular variables within Abaqus to meet specific needs. The user subroutine "DFLUX" allows for a non-uniform distributed flux to be defined during heat transfer analysis. This feature is applicable for laser modeling as it allows for the laser heat flux to be defined with respect to coordinates within the model. Thus, a Gaussian laser distribution can be modeled through the implementation of the DFLUX subroutine.

The variables that can be defined within the subroutine include FLUX, SOL, KSTEP, KINC, TIME, NOEL, NPT, COORDS, JLTYP, TEMP, PRESS, SNAME. It is important to understand the meaning of these variables as they are an essential part of how the model operates. A brief introduction of each variable as it pertains to a heat transfer problem is described below. More in depth information can be found within Abaqus's User Subroutines Reference Guide.

- FLUX: FLUX(1) represents the magnitude of the flux and FLUX(2) represents the rate of change of the flux. FLUX(1) must be defined otherwise it will be given a value of " 0 ." FLUX(2) was not used in this simulation and was assumed to be " $0 . "$

- SOL: Estimated temperature value at corresponding time in simulation

- KSTEP: Step number. This variable was used extensively in defining laser movement.

- KINC: Increment number. 
- TIME: TIME(1) represents the value of the time during that step where $\operatorname{TIME}(2)$ represents the total time within the simulation. TIME(1) was used as a way to implement a scanning speed for the laser.

- NOEL: Element number.

- NPT: Integration point number.

- COORDS: COORDS(1) represents " $\mathrm{X}$ " coordinate, COORDS(2) represents " $\mathrm{Y}$ " coordinate, and COORDS(3) represents " $Z$ " coordinate in model. This variable was used to define the Gaussian distribution and define starting coordinates for each scan.

- JLTYP: This variable defines whether the applied flux is a body flux, surfacebased flux, or an element-based surface flux.

- TEMP: Current temperature (Used only in mass diffusion analysis)

- PRESS: Equivalent pressure stress ( Used only in mass diffusion analysis)

- SNAME: Surface name if surface based flux is used for the JLTYP 


\subsubsection{IMPLEMENTING SUBROUTINE}

The section introduces how DFLUX is implemented within an Abaqus simulation. Additionally, the following sections will provide a broad overview of what must be changed within the input file and how to write the DFLUX Fortran code. The specifics of the changes used for this project will be defined in Section 2.4. Different subroutines within Abaqus are implemented at different stages within a job. Figure 15 below outlines the general steps that are required to run a simulation using the DFLUX subroutine.

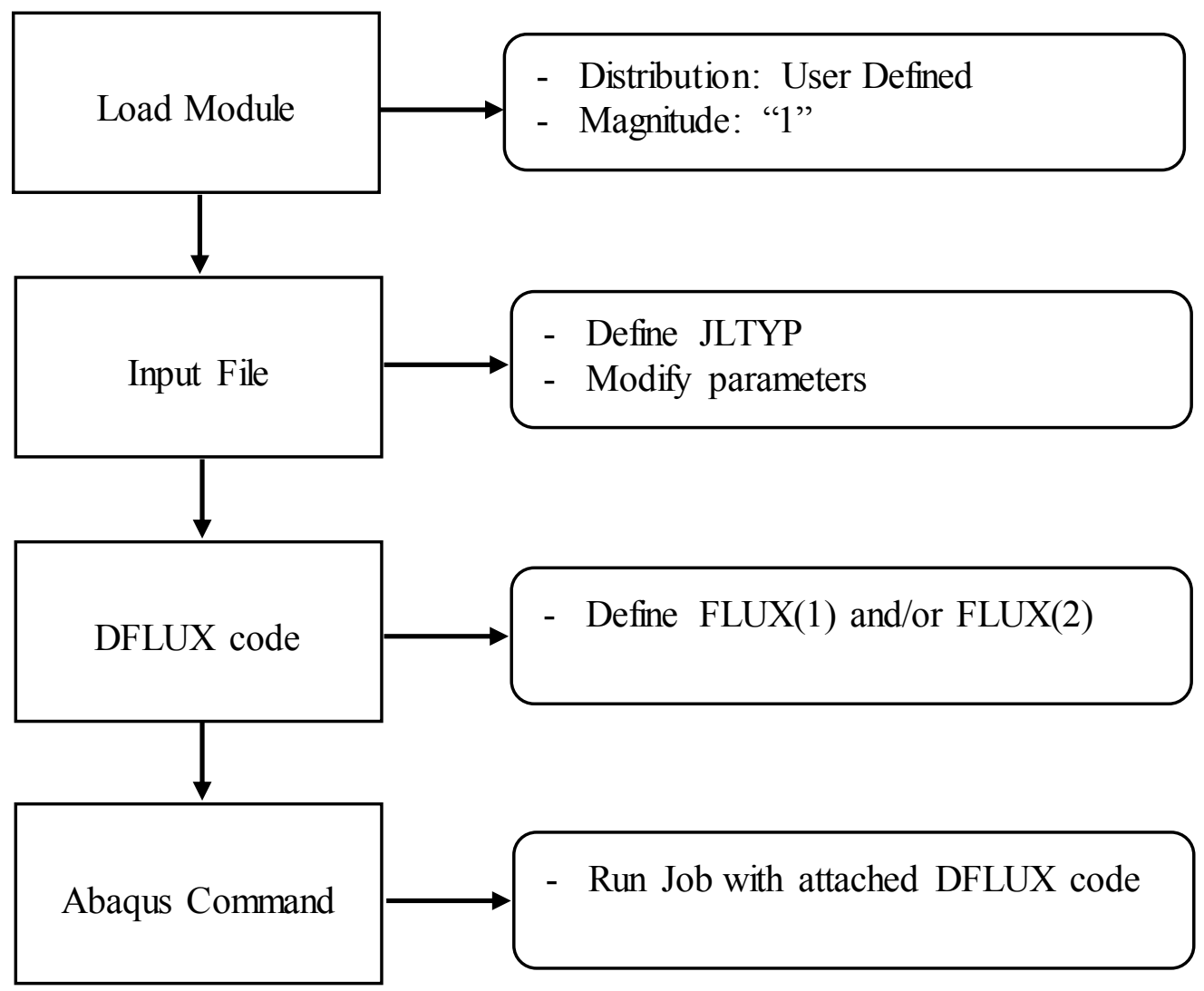

Figure 15. Flowchart for implementation of DFLUX subroutine 


\subsubsection{LOAD MODULE}

There are a few different approaches to implementing the subroutine upon reaching the load model within Abaqus. As stated earlier, the applied flux can be a body flux, surface-based flux, or an element-based surface flux. For a body flux or elementbased surface flux, an element or element set must be selected when selecting the load region. For a surface-based flux, the surfaces must be selected. However, the selected region may be changed within the input file. More importantly, upon reaching the "Edit Load" settings (Figure 16), the following must be selected:

- Distribution: "User-Defined"

- Magnitude: "1"

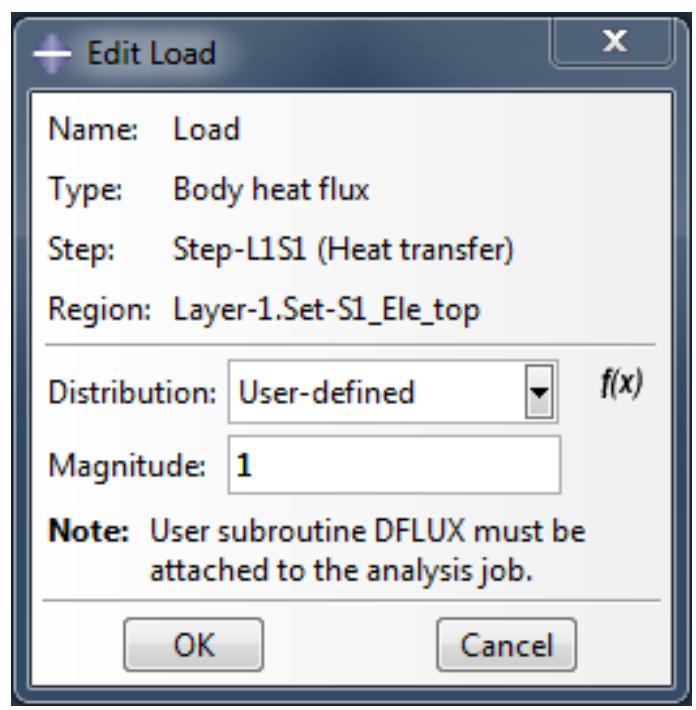

Figure 16. Edit Load Settings for applying a heat flux 
By selecting the distribution as "User-defined," it signals that a user subroutine DFLUX will be attached to the analysis job to define the flux. The entered magnitude will be passed into the DFLUX subroutine and thus should be set to "1" so it will not affect the value of the defined flux. 


\subsubsection{INPUT FILE}

Next, modifying the input file allows for greater control over the subroutine capabilities. To modify the input before running the analysis job, right click on the job and select "Write Input." The input file will then be created and located in the working directory. The DFLUX call out should be located within the desired step in which it is to be implemented. The data lines should be formatted in the following format:

*Dflux

"Element Set", "Flux Type", "Magnitude"

The flux type parameter depends on the desired JLTYP for the flux being applied. Table 7 below outlines the different flux type labels.

Table 7. Flux Type Labels

\begin{tabular}{|c|c|c|}
\hline Flux Type & JLTYP & Description \\
\hline Surface-based flux & 0 & Surface-based flux \\
\hline BFNU & 1 & Body flux \\
\hline S1NU & 11 & Element-based surface flux: Surface 1 \\
\hline S2NU & 12 & Element-based surface flux: Surface 2 \\
\hline S3NU & 13 & Element-based surface flux: Surface 3 \\
\hline S4NU & 14 & Element-based surface flux: Surface 4 \\
\hline S5NU & 15 & Element-based surface flux: Surface 5 \\
\hline S6NU & 16 & Element-based surface flux: Surface 6 \\
\hline
\end{tabular}


Additionally, there are a couple optional parameters including "OP" and "AMPLITUDE" that can be used to further modify the DFLUX load. "AMPLITUDE" allows the user to insert an amplitude curve to define the magnitude of the flux. "OP" allows the user to either keep or remove all previous DFLUX loads. "OP=MOD" is the default setting and will keep existing DFLUX loads where as "OP=NEW" will remove them. Figure 17 below provides an example of how the "OP" parameter can be implemented.

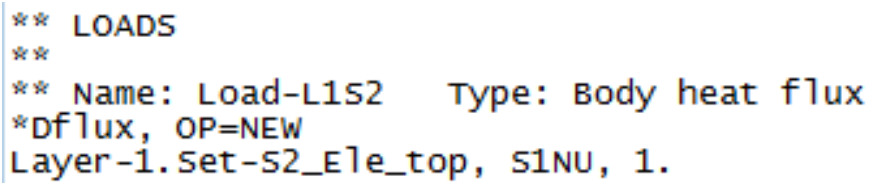

Figure 17. DFLUX Load Syntax in Input file

\subsubsection{WRITING AND ATtACHING THE DFLUX CODE}

The subroutine file will contain the coding that will define the flux within the simulation. The code is written in FORTRAN and may call upon the various variables that were described above. The general format required for the file to interface with Abaqus is shown in Figure 18. The only variable that is required to be defined is FLUX(1). The DFLUX code used in this simulation will be described in further detail in section 2.4 . 


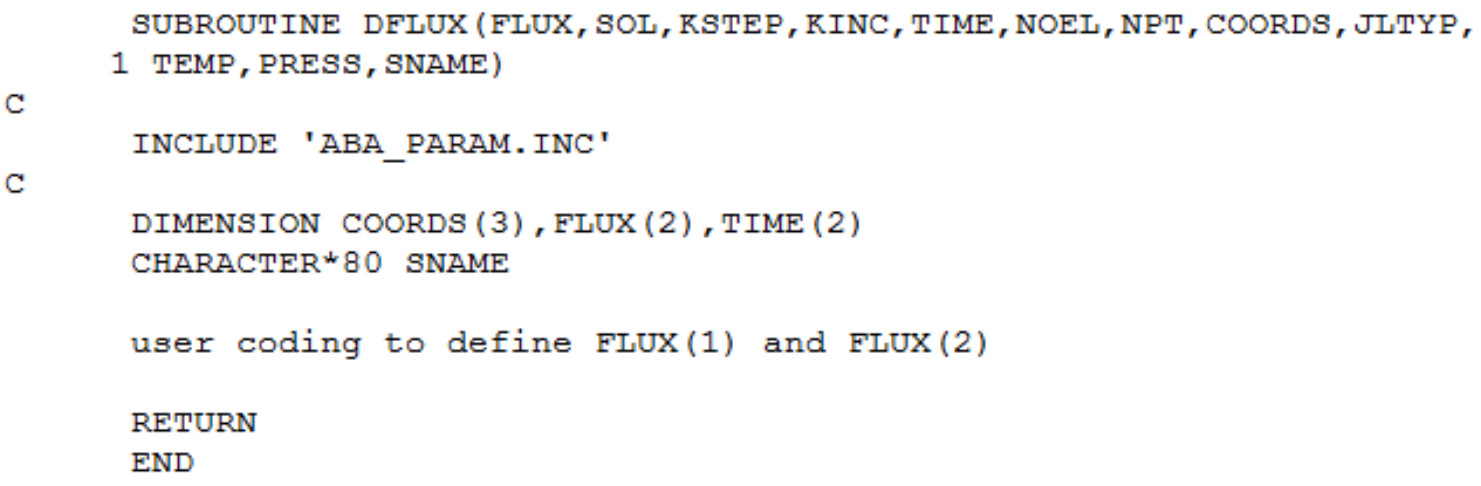

Figure 18. DFLUX Fortran required statements

The subroutine file must be attached to the job in order for the analysis to be completed. I recommend running the analysis within the Abaqus Command window. The input file and the subroutine file must be located in the current directory. The subroutine may be attached to the job and submitted for analysis using the following command:

abaqus job=Name_of_Input_file user=Name_of_subroutine_file 


\subsection{FINAL MODEL}

The previous section introduced the general methodology used to implement a Gaussian heat flux distribution. This section will discuss the specific details of the model used within this simulation. The important modeling considerations include using predefined field variables to change material properties, element addition/removal to perform multi-layer analysis, and implementation of a Gaussian heat flux distribution through the user subroutine DFLUX.

\subsubsection{MODEL ASSEMBLY}

The model assembly consists of three instances of a powder layer and one instance of a substrate build surface (Figure 19). The dimensions of the powder layer are $.5 \mathrm{~mm} \mathrm{~L} \times .5 \mathrm{~mm} \mathrm{~W} \times 30 \mu \mathrm{m}$ T. The inner $.25 \times .25 \mathrm{~mm}$ of the powder layer was meshed with a finer seed size as this was the portion of the layer that would be heated during the simulation. A coarser mesh was used on the outer part of the powder to save computation time. Further details of the mesh development will be discussed later. The $30 \mu \mathrm{m}$ thickness was chosen as it is the typical thickness of a powder layer. A square $(.25 \times .25 \mathrm{~mm})$ powder layer was selected in order to compare to experimental data. The powder layers were centered in the middle of the substrate layer. The dimensions of the

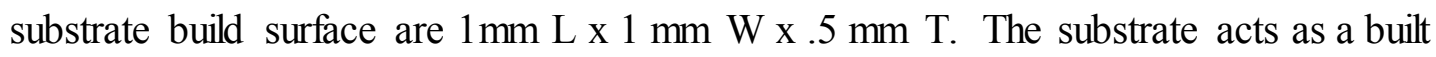
plate and was modeled using steel properties. 


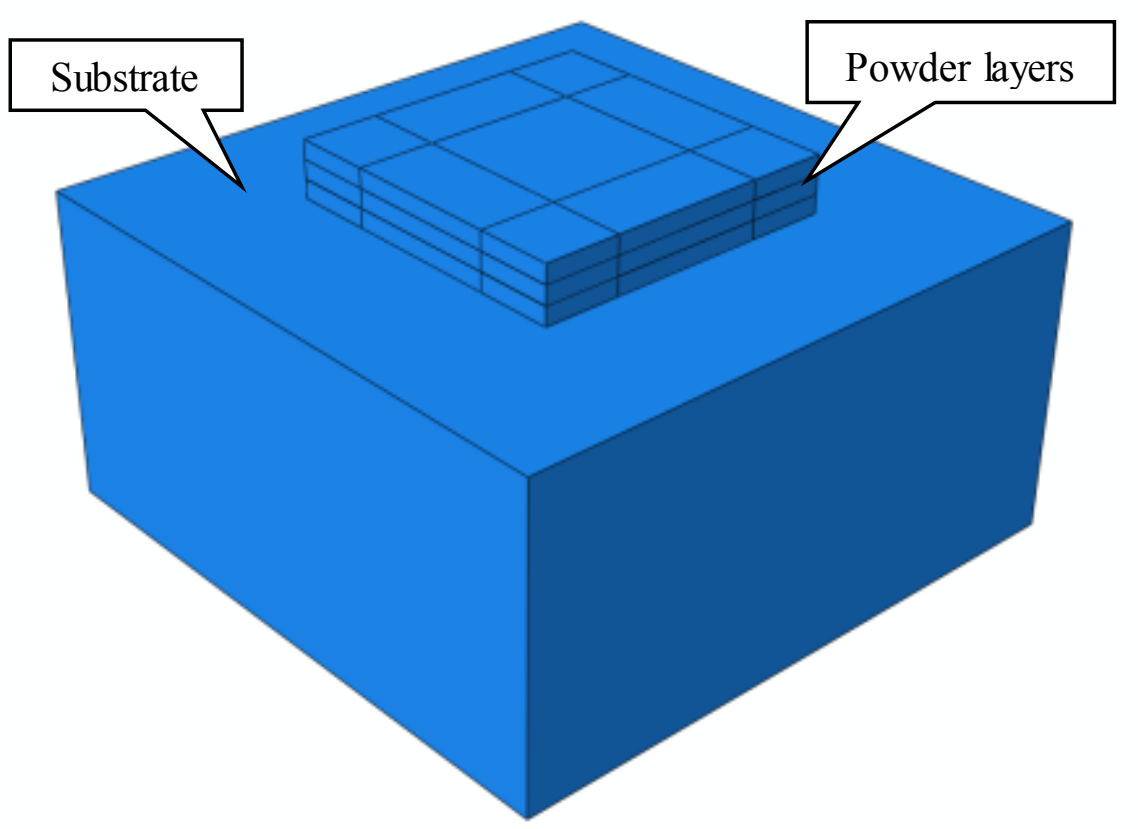

Figure 19. Assembly Overview 


\subsubsection{MATERIAL PROPERTIES}

The materials for both the $\mathrm{W}-\mathrm{Ni}-\mathrm{Fe}$ and $316 \mathrm{~L}$ stainless steel simulations are presented in this section. W-Ni-Fe was used a way to compare the simulation results to that of actual experimental results. Additionally, 316L SS was used since it is one of the most common materials used in SLS. As stated earlier, the material properties will vary with temperature and the properties of the powder are going to be different upon melting and reaching a "consolidated" phase.

The materials were defined using a field variable to distinguish within Abaqus the properties of the powdered state and the consolidated state. This was implemented by firth establishing an initial condition that all nodes were to use field variable "1.0". The initial condition is defined with the "Predefined Field" section of the input file using the syntax shown in Figure 20 below.

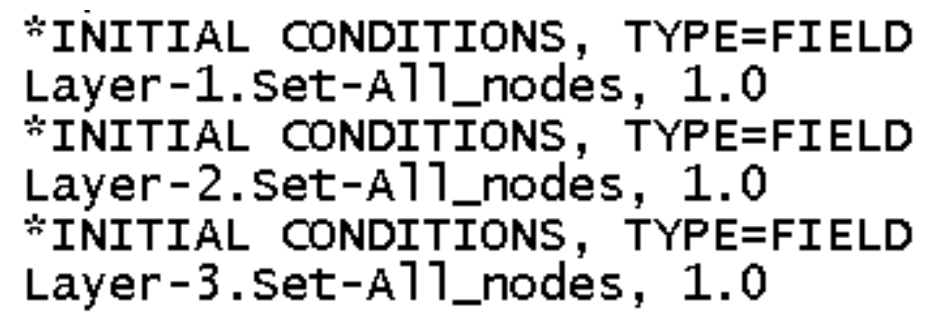

Figure 20. Implementation of defining initial Field Variable

Upon completion of the loading on the first layer of powder, the field variable for the first layer was then changed to " 2.0 " (Figure 21). This process was repeated for each layer of powder. Changing the field variable after each individual pass of the layer increased the computational time significantly, and thus it was decided that the field variable would be changed only at the end of each layer. One important note about using the "*FIELD" option is that a node set as opposed to an element set must be selected. 


\section{"FIELD, Variable=1 \\ Layer-1.SET-A11_NODES, 2.0}

Figure 21. Implementation of changing field variable during simulation

The substrate material used for all simulations was bulk stainless steel. The material properties used for this part are listed below in Table 8 (Hodge, Ferencz, and Solberg, 2014). The density of the powder for each material was calculated using equation [5] with an assumed porosity of 0.518 .

Table 8. Properties of Stainless Steel Substrate

\begin{tabular}{|c|c||c|c||c|}
\hline $\begin{array}{c}\text { Temperature, } \\
{[\mathbf{K}]}\end{array}$ & $\begin{array}{c}\text { Conductivity, } \\
{\left[\mathbf{W} / \mathbf{m}^{*} \mathbf{K}\right]}\end{array}$ & $\begin{array}{c}\text { Temperature, } \\
{[\mathbf{K}]}\end{array}$ & $\begin{array}{c}\text { Specific } \\
\text { Heat, }[\mathbf{k g} / \mathbf{K}]\end{array}$ & $\begin{array}{c}\text { Density, } \\
{\left[\mathbf{k g} / \mathbf{m}^{\wedge} \text { 3] }\right.}\end{array}$ \\
\hline \hline 273 & 12.76 & 273 & 440 & 8000 \\
\hline 432 & 14.94 & 432 & 510 & \\
\hline 590 & 17.18 & 590 & 545 \\
\hline 749 & 19.3 & 749 & 560 \\
\hline 907 & 21.48 & 907 & 585 \\
\hline 1066 & 23.66 & 1066 & 620 \\
\hline 1224 & 25.84 & 1224 & 650 \\
\hline 1383 & 28.02 & 1383 & 680 \\
\hline 1541 & 30.2 & 1541 & 713 \\
\hline 1700 & 32.38 & 1650 & 734 \\
\hline
\end{tabular}


The bulk material properties used for W-Ni-Fe were obtained from Zhang et al. (2010) and the powder properties were adapted using Equation [9] and [10] from Dai and Shaw (2004).

$$
k_{r}=4 F \sigma T^{3} x_{r}
$$

Where:

- $k_{r}$ - Thermal conductivity due to radiation among particles

- $F-$ View factor

- $\sigma$-Stefan-Boltzmann constant

- $T$ - Temperature of powder particles

- $x_{r}$ - Average diameter of powder particles

$$
\frac{k}{k_{f}}=(1-\sqrt{1-\phi})\left(1+\frac{\phi k_{r}}{k_{f}}\right)+\sqrt{1-\phi}\left(\frac{2}{1-\frac{k_{f}}{k_{s}}}\left(\frac{1}{1-\frac{k_{f}}{k_{s}}} \ln \left(\frac{k_{s}}{k_{f}}\right)-1\right)+\frac{k_{r}}{k_{f}}\right)
$$

Where:

- $k$ - Thermal conductivity of powder

- $k_{f}$ - Thermal conductivity of surrounding fluid (air)

- $k_{s}$ - Thermal conductivity of the solid

- $\phi$-Fractional Porosity

The parameters used to calculate the thermal conductivity due to radiation among particles is shown in Table 9. The view factor in equation [9] was taken to be approximately 1/3 (Dai and Shaw, 2004). The calculation of the conductivity of the powder at temperatures of 200 and $2000 \mathrm{~K}$ is shown in Table 10. The fluid conductivities, $\mathrm{K}_{\mathrm{f}}$, were taken from Incropera and Dewitt (2002). The density is shown in Table 11 and was taken from Lassner and Schubert (2012). A summary of the conductivity properties used during the simulations is shown in Table 12. The 
conductivity of the powder was only calculated at a few temperatures in order to reduce computational time. Upon reaching a temperature of $3500 \mathrm{~K}$ it is assumed that the properties of the powder will be approximately equal to that of the consolidated bulk material. Fu and Guo (2014) and Gusarov et al. (2009) also implemented the powder conductivity in a similar manner. The specific heat properties are displayed in Table 13 below. A scaling factor of " 0.518 " was used to scale the specific heat of the consolidated state to the powder state.

Table 9. Parameters used for calculation of the thermal conductivity due to radiation

\begin{tabular}{|c|c|}
\hline \multicolumn{2}{|c|}{ Parameters for calculation of $\mathbf{k}_{\mathbf{r}}$} \\
\hline $\begin{array}{c}\text { Stephan-Boltzman } \\
\text { Constant, } \sigma\left[\mathrm{kg} / \mathrm{s}^{3} \mathrm{~K}^{4}\right]\end{array}$ & $5.67 \mathrm{E}-08$ \\
\hline $\begin{array}{c}\text { Average Particle } \\
\text { Diameter, } \mathrm{Xr}[\mu \mathrm{m}]\end{array}$ & 100 \\
\hline View Factor, $\mathrm{F}$ & $1 / 3$ \\
\hline
\end{tabular}

Table 10. Calculation of powder conductivity

\begin{tabular}{|c|c|c|c|c|}
\hline $\begin{array}{c}\text { Temperature } \\
{[\mathbf{K}]}\end{array}$ & $\begin{array}{c}\mathbf{k}_{\mathbf{s}} \\
{\left[\mathbf{W} / \mathbf{m}^{*} \mathbf{K}\right]}\end{array}$ & $\begin{array}{c}\mathbf{k}_{\mathbf{r}} \\
{\left[\mathbf{W} / \mathbf{m}^{*} \mathbf{K}\right]}\end{array}$ & $\begin{array}{c}\mathbf{k}_{\mathbf{f}} \\
{\left[\mathbf{W} / \mathbf{m}^{*} \mathbf{K}\right]}\end{array}$ & $\begin{array}{c}\mathbf{k}_{\text {powder }} \\
{\left[\mathbf{W} / \mathbf{m}^{*} \mathbf{K}\right]}\end{array}$ \\
\hline 200 & 141.9 & $6.05 \mathrm{E}-05$ & 0.01809 & 0.206 \\
\hline 2000 & 103 & $6.05 \mathrm{E}-02$ & 0.137 & 1.066 \\
\hline
\end{tabular}

Table 11 . Density of W-Ni-Fe

\begin{tabular}{|c|c|c|}
\hline $\begin{array}{c}\text { Density, } \\
{\left[\mathrm{kg} / \mathbf{m}^{\wedge} 3\right]}\end{array}$ & $\begin{array}{c}\text { Field } \\
\text { Variable }\end{array}$ & Description \\
\hline \multicolumn{3}{|c|}{ Porosity $=\mathbf{0 . 5 1 8}$} \\
\hline 8435 & 1 & Powder \\
\hline 17500 & 2 & Consolidated \\
\hline
\end{tabular}


Table 12. Thermal conductivity values used in $\mathrm{W}-\mathrm{Ni}-\mathrm{Fe}$ simulations

\begin{tabular}{|c|c|c|c|}
\hline $\begin{array}{c}\text { Temperature, } \\
{[\mathrm{K}]}\end{array}$ & $\begin{array}{c}\text { Conductivity, } \\
{\left[\mathbf{W} / \mathbf{m}^{*} \mathbf{K}\right]}\end{array}$ & $\begin{array}{c}\text { Field } \\
\text { Variable }\end{array}$ & Description \\
\hline 200 & 0.206 & 1 & \multirow{3}{*}{ Powder } \\
\hline 2000 & 1.066 & 1 & \\
\hline 3500 & 83.0 & 1 & \\
\hline 200 & 141.9 & 2 & \multirow{6}{*}{ Consolidated } \\
\hline 600 & 112.2 & 2 & \\
\hline 800 & 110.0 & 2 & \\
\hline 1000 & 103.0 & 2 & \\
\hline 2000 & 95.0 & 2 & \\
\hline 3500 & 83.0 & 2 & \\
\hline
\end{tabular}

Table 13. Specific heat values used in W-Ni-Fe simulations

\begin{tabular}{|c|c|c|c|}
\hline $\begin{array}{c}\text { Temperature, } \\
{[\mathrm{K}]}\end{array}$ & $\begin{array}{c}\text { Specific } \\
\text { Heat, } \\
{[\mathrm{J}-/ \mathrm{kg}-\mathrm{K}]}\end{array}$ & $\begin{array}{c}\text { Field } \\
\text { Variable }\end{array}$ & Description \\
\hline \multicolumn{4}{|c|}{ Scalar Multiple $=.518$} \\
\hline 200 & 71 & 1 & \multirow{6}{*}{ Powder } \\
\hline 600 & 75 & 1 & \\
\hline 800 & 77 & 1 & \\
\hline 1,000 & 79 & 1 & \\
\hline 2,000 & 95 & 1 & \\
\hline 3,500 & 152 & 1 & \\
\hline 200 & 137 & 2 & \multirow{6}{*}{ Consolidated } \\
\hline 600 & 144 & 2 & \\
\hline 800 & 148 & 2 & \\
\hline 1,000 & 152 & 2 & \\
\hline 2,000 & 184 & 2 & \\
\hline 3,500 & 294 & 2 & \\
\hline
\end{tabular}


The properties used for 316L SS were obtained from Hodge, Ferencz, and Solberg (2014) and are summarized in Table 14 through Table 16 below. The properties of the powder were determined by using a scalar multiple of the consolidated properties. Hodge, Ferencz, and Solberg (2014) used an extensive list for the conductivity properties of the powder with respect to temperature. The list was shorten in this simulation in order to save computational time. Upon the transition from the powder to liquid state the material properties of the bulk materials are used (Hussein et al., 2009).

Table 14. Temperature Dependent Conductivity for 316L Stainless Steel

\begin{tabular}{|c|c|c|c|}
\hline $\begin{array}{c}\text { Temperature, } \\
{[\mathbf{K}]}\end{array}$ & $\begin{array}{c}\text { Conductivity, } \\
{\left[\mathbf{W} / \mathbf{m}^{*} \mathbf{K}\right]}\end{array}$ & $\begin{array}{c}\text { Field } \\
\text { Variable }\end{array}$ & Phase \\
\hline \multicolumn{3}{|c|}{ Scalar Multiple $=. \mathbf{0 1}$} \\
\hline 273 & 0.1276 & 1 & \multirow{2}{*}{ Powder } \\
\hline 1541 & 0.3020 & 1 & \\
\hline 1700 & 32.38 & 1 & \\
\hline 273 & 12.76 & 2 & \multirow{1}{*}{ Consolidated } \\
\hline 432 & 14.94 & 2 & \\
\hline 590 & 17.18 & 2 & \\
\hline 749 & 19.30 & 2 & \\
\hline 907 & 21.48 & 2 & \\
\hline 1066 & 23.66 & 2 & \\
\hline 1224 & 25.84 & 2 & \\
\hline 1383 & 28.02 & 2 & \\
\hline 1541 & 30.20 & 2 & \\
\hline 1700 & 32.38 & 2 & \\
\hline
\end{tabular}


Table 15. Temperature Dependent Specific Heat for 316L Stainless Steel

\begin{tabular}{|c|c|c|c|}
\hline $\begin{array}{c}\text { Temperature, } \\
{[\mathrm{K}]}\end{array}$ & $\begin{array}{c}\text { Specific Heat, } \\
{[\mathrm{J} / \mathrm{kg}-\mathrm{K}]}\end{array}$ & $\begin{array}{c}\text { Field } \\
\text { Variable }\end{array}$ & Phase \\
\hline \multicolumn{4}{|c|}{ Scalar Multiple $=.5$} \\
\hline 273 & 220 & 1 & \multirow{11}{*}{ Powder } \\
\hline 432 & 255 & 1 & \\
\hline 590 & 272.5 & 1 & \\
\hline 749 & 280 & 1 & \\
\hline 907 & 292.5 & 1 & \\
\hline 1066 & 310 & 1 & \\
\hline 1224 & 325 & 1 & \\
\hline 1383 & 340 & 1 & \\
\hline 1541 & 356.5 & 1 & \\
\hline 1650 & 367 & 1 & \\
\hline 1700 & 372 & 1 & \\
\hline 273 & 440 & 2 & \multirow{13}{*}{ Consolidated } \\
\hline 432 & 510 & 2 & \\
\hline 590 & 545 & 2 & \\
\hline 749 & 560 & 2 & \\
\hline 907 & 585 & 2 & \\
\hline 1066 & 620 & 2 & \\
\hline 1224 & 650 & 2 & \\
\hline 1383 & 680 & 2 & \\
\hline 1541 & 713 & 2 & \\
\hline 1650 & 734 & 2 & \\
\hline 1660 & 6190 & 2 & \\
\hline 1690 & 6190 & 2 & \\
\hline 1700 & 744 & 2 & \\
\hline
\end{tabular}


Table 16. Additional Material Properties for 316L Stainless Steel

\begin{tabular}{|c|c|}
\hline \multicolumn{2}{|c|}{$\begin{array}{l}\text { Mechanical and Physical Properties of } \\
\text { 316L Stainless Steel }\end{array}$} \\
\hline Density (bulk) $\left[\mathrm{kg} / \mathrm{m}^{\wedge} 3\right]$ & 8000 \\
\hline Porosity & 0.518 \\
\hline Density (Powder) $\left[\mathrm{kg} / \mathrm{m}^{\wedge} 3\right]$ & 3856 \\
\hline Solidus Temperature $[\mathrm{K}]$ & 1650 \\
\hline Liquidus Temperature $[\mathrm{K}]$ & 1675 \\
\hline Latent Heat $[\mathrm{kJ} / \mathrm{Kg}]$ & 280 \\
\hline
\end{tabular}

\subsubsection{LOADING CONDITIONS}

The governing heat transfer equation for this type of analysis can be taken from Bejan and Kraus (2003). This equation is for an isotropic material where the reference co-ordinate is the center of the beam (Roberts et al., 2009).

$$
\rho\left(\frac{\partial H}{\partial t}\right)=\nabla(k \nabla T)
$$

The boundary conditions used in this model were similar to those used in the Quasi-Static model. The conditions include predefined temperature fields and a surface film condition to account for convection. The predefined temperature field set all surfaces within the model to room temperature, $293 \mathrm{~K}$. This condition presets the powder bed to a uniform temperature distribution before any laser heating occurs as described by Hussien et al. (2013), where $\mathrm{T}_{0}$ corresponds to ambient room temperature.

$$
T(x, y, z, 0)=T_{0}(x, y, z)
$$


A surface film condition was applied to all exposed surfaces using a heat transfer coefficient of $10 \mathrm{~W} / \mathrm{m}^{\wedge} 2 * \mathrm{~K}$. This boundary condition can be explained by equation [13] where $\mathrm{h}$ is the heat transfer coefficient, $\mathrm{T}_{\mathrm{s}}$ represents the temperature of the powder bed, and Q is the volumetric heat generation (Hussien et al. 2013).

$$
-\left[\frac{\partial T}{\partial z}\right]_{z=0}=Q-h\left(T_{0}-T_{s}\right)
$$

Additionally, a tie constraint was used to fuse the mesh between the bottom of the powder layer and the top of the substrate since the meshes were dissimilar. A tie constraint was used between each layer of powder as well.

A Gaussian heat flux was applied through the use of the user subroutine DFLUX. Section 2.3 above outlined the general implementation steps and process used. This section will go into further detail of the underlying structure of the FORTRAN file and specific modifications to the input file.

The flux was modeled as a moving surface heat flux with the magnitude defined by the following equation (Fu and Guo, 2014):

$$
F L U X(1)=\frac{A P}{\pi r_{o}^{2}} e^{\left(-2 \frac{r^{2}}{r_{o}^{2}}\right)}
$$

An absorptivity values of 0.3 was used for $316 \mathrm{~L}$ SS simulations and 0.38 was used for the $\mathrm{W}-\mathrm{Ni}-\mathrm{Fe}$ simulations. The specific processing parameters such as the laser power and scanning speed are outlined in Table 18 as they were modified for various simulations. In order to model a moving heat flux the radial distance from the center of the laser, $r$, was adjusted relative to step time. The radial distance $r$ can be expressed as follows with respect to the coordinate system (Figure 22) used in the model: 


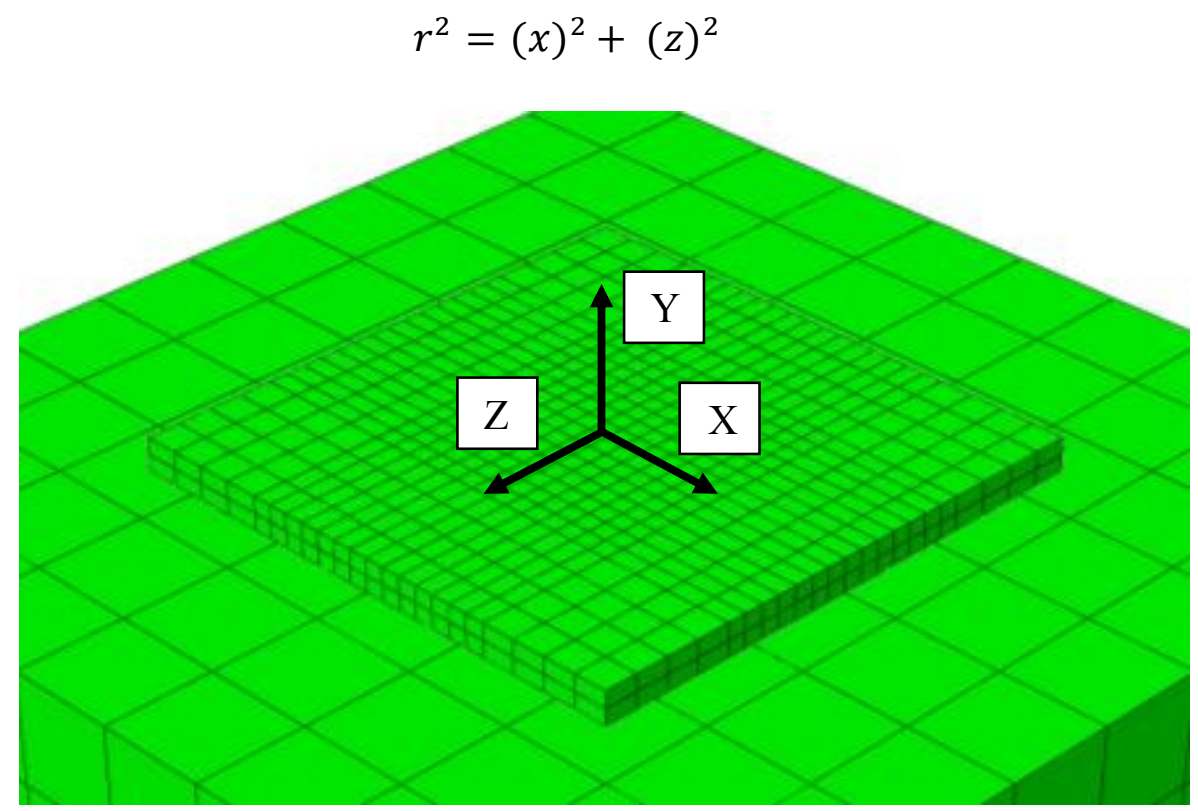

Figure 22. Coordinate System for model

Next, to adjust the value of the distance relative to the starting coordinates $\mathrm{x}_{0}$ and $\mathrm{z}_{0}$ the starting coordinates were subtracted from the current $\mathrm{x}$ and $\mathrm{z}$ coordinate within the model. Additionally, in order to incorporate a moving heat flux along the $\mathrm{x}$ direction, the product of the scanning speed, v, and the current time within the step, TIME(1), was subtracted from the $\mathrm{x}$ coordinate.

$$
r^{2}=\left(x-x_{o}-(v * \operatorname{time}(1))^{2}\right)+\left(z-z_{o}\right)^{2}
$$

Each pass of the layer was implemented within a different step, totaling 6 passes per layer of powder. For each pass of the laser, only the elements within the laser diameter were selected as the loading surface. A hatch spacing, the distance between each scan, of $0.35 \mu \mathrm{m}$ was used as it is exactly half of the laser diameter. Also, a snake pattern was used to progress the loading across the layer. After the $6^{\text {th }}$ pass of the laser, a 
"pause" step was implemented to replicate the cooling time the powder would experience while a new layer of powder was distributed across the build surface.

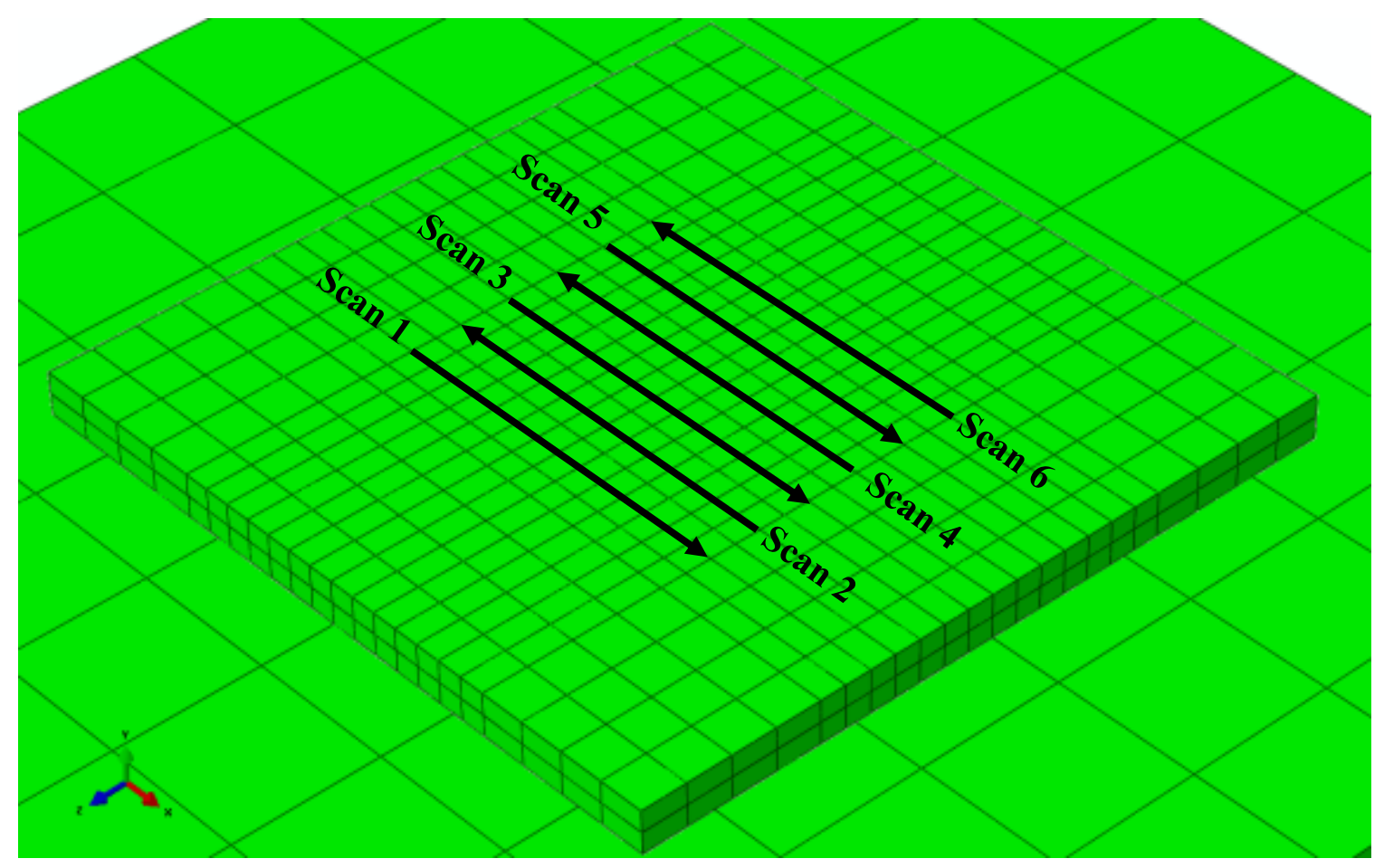

Figure 23. Scan description

The loading was applied in this manner to simplify the logic used within the FORTRAN file. Within the DFLUX file an if/else if statement was used to determine which step was currently being simulated by calling out the KSTEP variable. The scanning speed was then chosen to be negative or positive depending on the scanning direction. Additionally, the starting coordinates for each scan were selected based on which KSTEP the simulation was in. An example of the logic used in shown in Figure 24 below. 


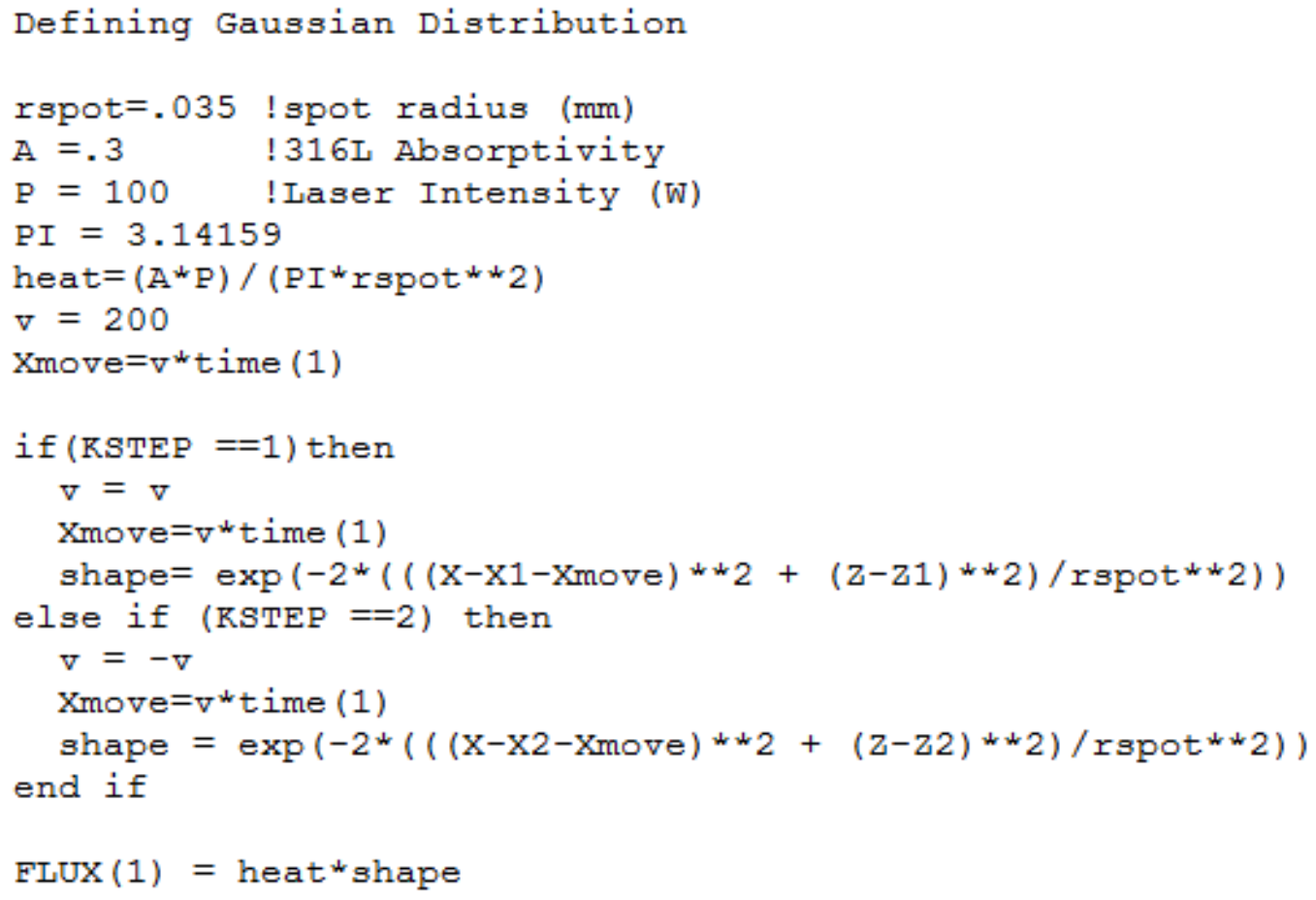

Figure 24. DFLUX Fortran coding to define flux

Figure 24 above only shows the if/else if logic for two scans. X1 and Z1

represent the starting coordinates for scan one. The $\mathrm{X}$ and $\mathrm{Z}$ variables are callouts to the coordinates within the model, COORDS(1) and COORDS(3). For the full model, the starting coordinates and "shape" parameters were defined for each scan.

As stated earlier, only the elements within the laser diameter were selected as the loading surface. The corresponding length of the loading surface resulted in four rows of elements which was based on the seed size of the mesh (Figure 25). The details of the mesh development will be discussed in further detail in Section 2.4.4. The flux type used to define the DFLUX load is S1NU, which corresponds to an element based surface heat flux. The top surface, surface 1 , of the elements was selected. Additionally, the OP= NEW parameter was used on all successive loads to remove the previous DFLUX loads. 

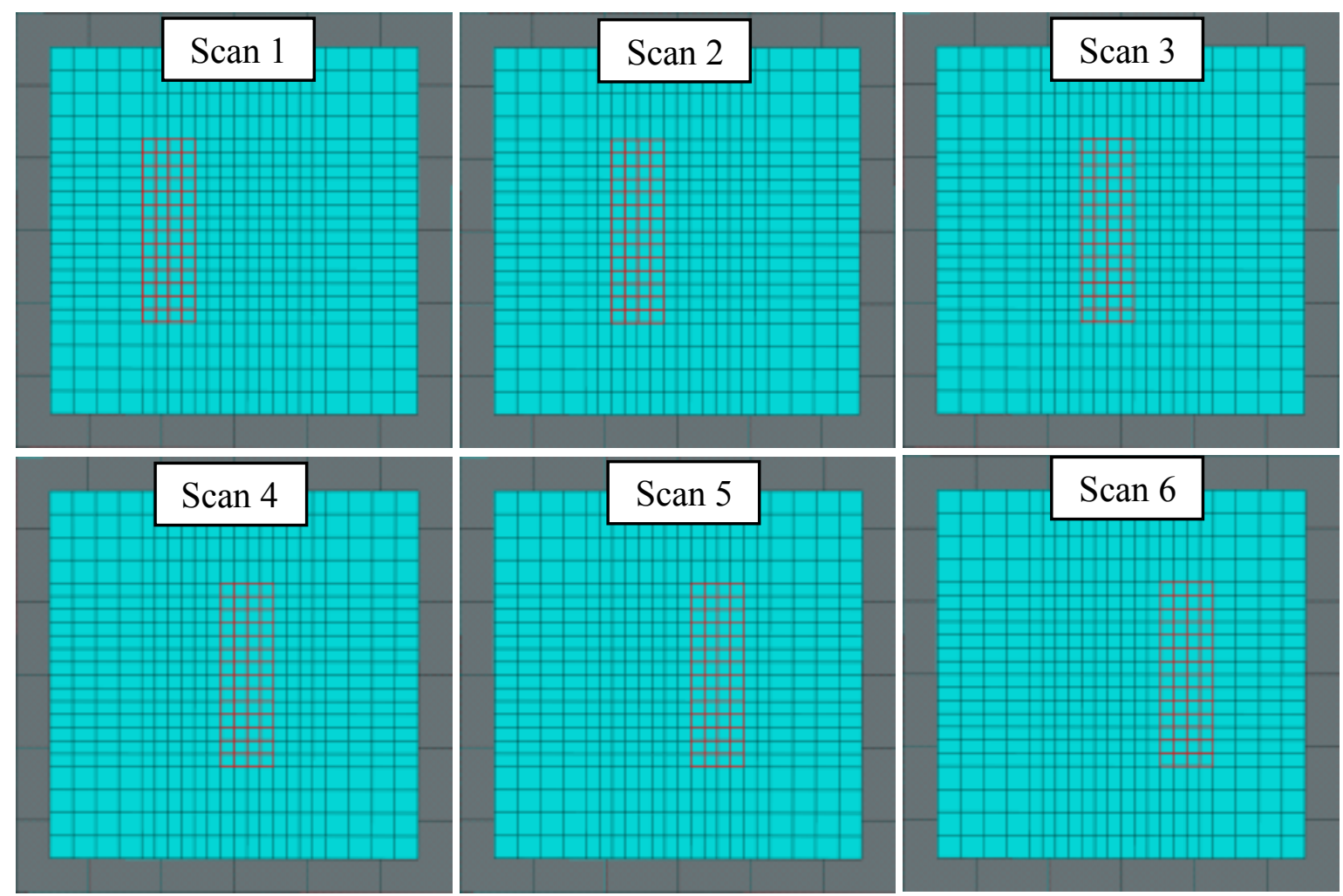

Figure 25. Selected loading surfaces for each scan 
Another important modeling consideration was the length of the step time. The step time was determined based on length of the powder being scanned $(0.25 \mathrm{~mm})$ and the scanning speed which was varied. As a result, whenever the scanning speed was changed within the DFLUX code, the step time had to be adjusted within the input file. The actual step time what determined by dividing the scan length by the scanning speed. However, the pause steps at the end of each layer remained at 5 seconds for each simulation as this is a common amount of time for an SLS machine to recoat the powder bed.

Lastly, the modeling of the layer build up process was implemented through element addition and removal. This was accomplished by initially beginning with a full three layer model assembly. Then, in the first step all of the elements in the second and third layers were removed. In the first scan of the second layer, the elements of the second layer were reactivated and likewise for the third layer. Figure 26 and 27 show the command lines used to remove and reactivate an element set. Table 17 summarizes the logistics of the sequence of commands used throughout the simulation.

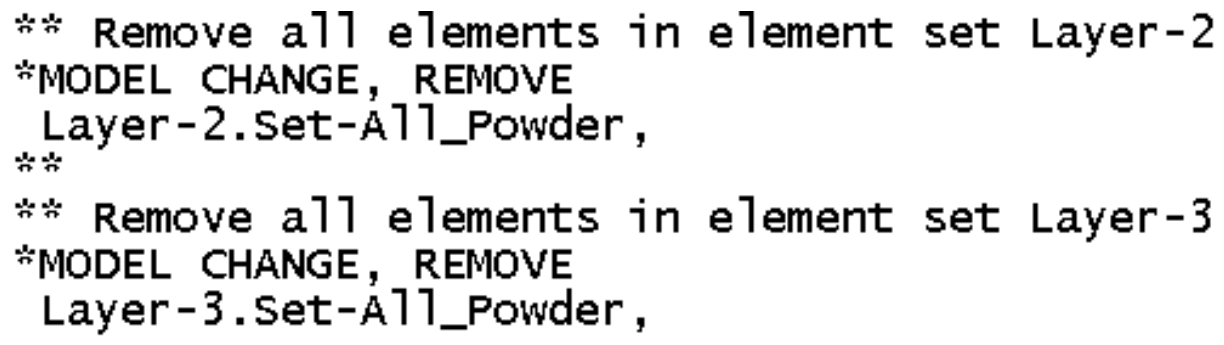

Figure 26. Implementation of element removal 


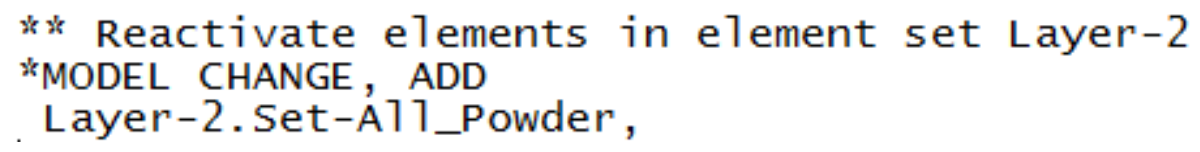

Figure 27. Implementation of element addition

Table 17. Summary of important input file modifications

\begin{tabular}{|c|c|c|}
\hline Step & Description & Command \\
\hline Initial Conditions & Predefined Fields & Set material field variable to "1.0" \\
\hline Step 1 & 1st step of layer 1 & Removal all elements in layers 2 and 3 \\
\hline Step 7 & Pause step after layer 1 & Set layer 1 material field variable to "2.0" \\
\hline Step 8 & 1st step of layer 2 & Reactivate elements in of layer 2 \\
\hline Step 14 & Pause step after layer 2 & Set layer 2 material field variable to "2.0" \\
\hline Step 15 & 1st step of layer 3 & Reactivate elements in of layer 3 \\
\hline
\end{tabular}

\subsubsection{MeSH DEVELOPMENT}

The mesh used for the final model was built upon the mesh used in the QausiStatic model however changes were made to account for difference in geometry and loading between models. The inner $.25 \times .25 \mathrm{~mm}$ section of the part was meshed using a finer element seed size of $0.0175 \mathrm{~mm}$ in the $\mathrm{X}$ and $\mathrm{Y}$ direction, which is equivalent to $1 / 4$ of the beam diameter $(0.07 \mathrm{~mm})$. This is finer than the $0.0222 \mathrm{~mm}$ seed size used in the Qausi-Static model for a few reasons. First, in order to make the laser flux loading surface more accurate, the element size needed to be a multiple of the overall beam diameter. Also this method of sizing the seed size is a common approach used in previous studies. Roberts et al. (2009) used a seed size equal to one-fourth of the laser diameter and Jiang et al. (2002) used a seed size equal to one-sixth of the laser diameter. 
A coarser seed size of $0.035 \mathrm{~mm}$ ( $\mathrm{X}$ and $\mathrm{Z}$ direction) was used on the part of the powder layer that was not under any direct loading. A coarser mesh was used to save computational time as this section of the powder layer was not of interest. As a result of the way the part was partitioned and meshed, some sections of the outer portion of the layer have a mixed meshed. A seed size of $0.15 \mathrm{~mm}$ was used in the $\mathrm{Y}$ direction for the entire layer as this is equal to exactly one half of the layer thickness $(.03 \mathrm{~mm}$ ) (Figure 28).

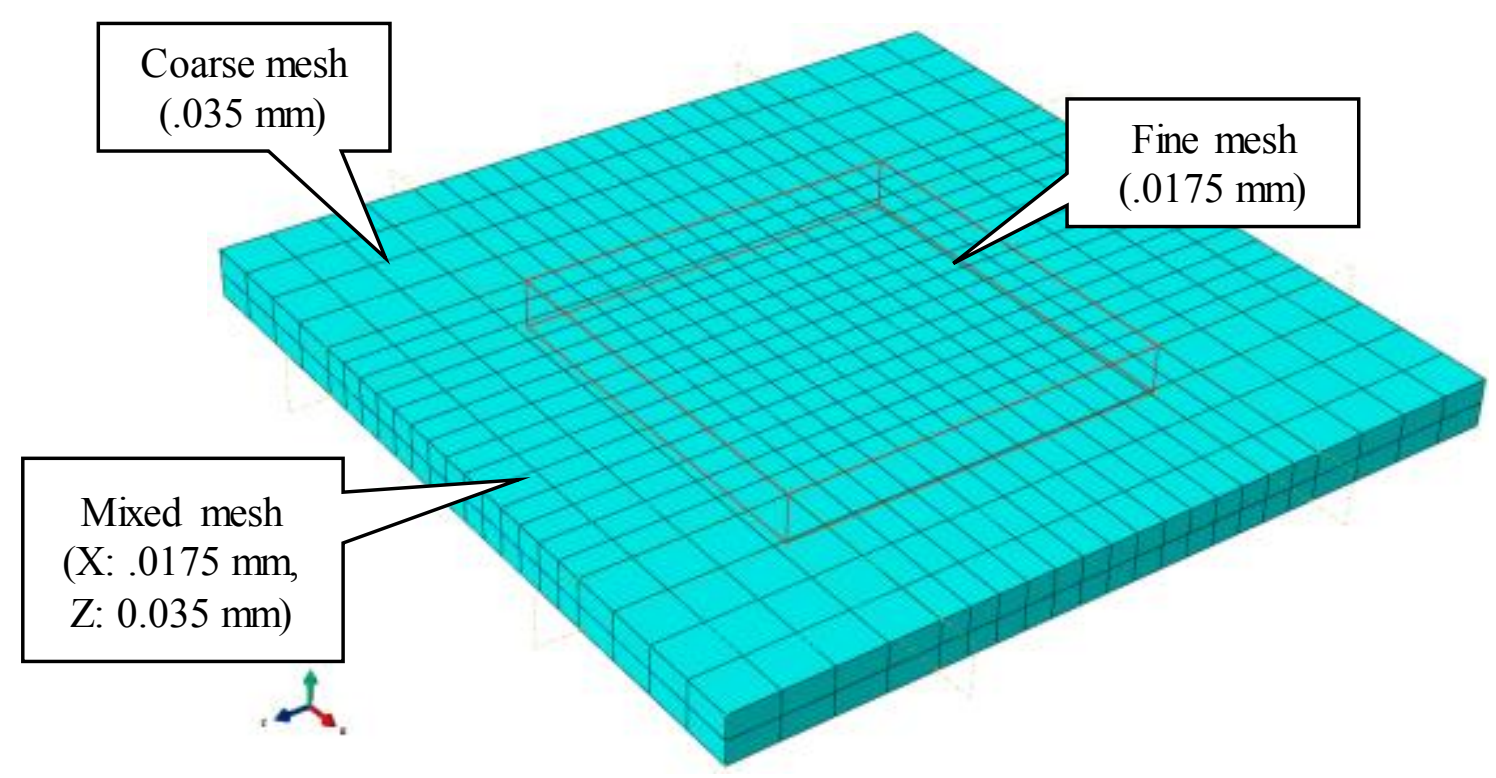

Figure 28. Part Layer Mesh

The powder layer was meshed using a quadratic hexahedral, DC3D20: A 20node linear heat transfer brick, as the element type. This element type resulted in the most accurate results in the quasi-static model and is common in similar heat conduction problems. The substrate was modeled as a linear hexahedral element with a seed size of 1.0E-4 m. A coarser mesh was used for the substrate to save computational time since the temperature distribution in this part was not of interest in this project. The total 
number of elements and degrees of freedom in the model are 3404 and 17769 , respectively. The elements were of high quality, meeting the Abaqus criteria for both aspect ratio and skew angle.

\subsubsection{JOB ANALYSIS}

The issues encountered during the analysis include the time increments for transient steps and properly defining the initial conditions. The time increment issue was solved by decreasing the initial and minimum increment size. Also, initially the model was unable to reach equilibrium because a surface film condition was not defined. Once this interaction was implemented, the model was able to be solved.

The following two warnings were displayed during the job simulation:

1. For *tie pair, adjusted nodes with very small adjustments were not printed

2. HEAT FLUX equilibrium accepted using the alternate tolerance.

After researching into the issues, I believe "warning 1" is stating that not all nodes were able to be tied between the two surfaces for the tie constraint. "Warning 2 " is stating that a wider tolerance that was specified in the transient steps options was used in attempt to reach equilibrium. I do not believe these warnings to have an effect on the results. Thus no changes were done to the model to alleviate these warnings. 


\subsubsection{HISTORY OUTPUT}

The ultimate purpose of this simulation was to obtain the time history of the temperature distribution. To obtain the element temperature, 28 elements were selected per layer and the temperature was recorded. Figure 29 shows the element numbers of the selected elements for each layer.

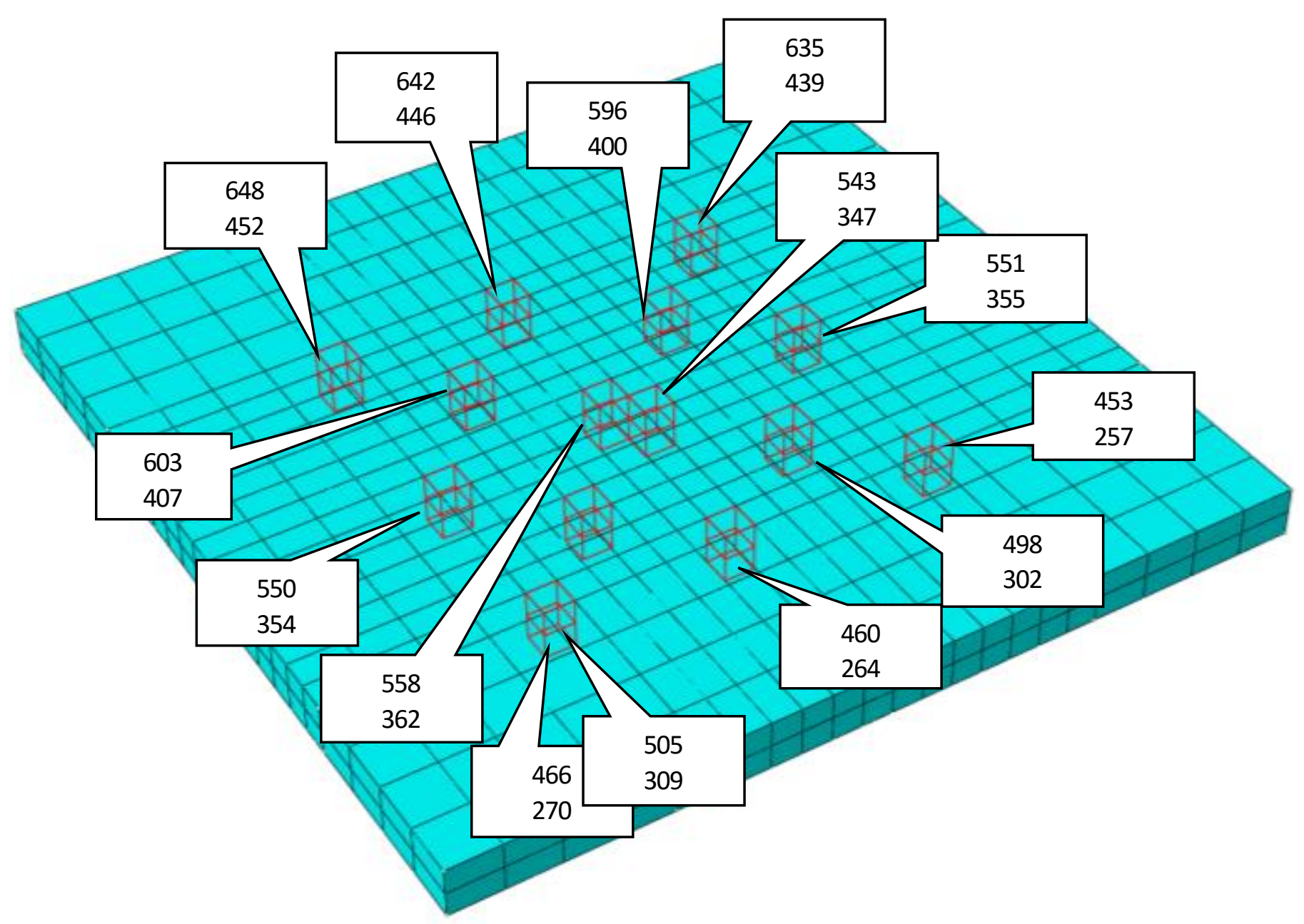

Figure 29. Element Numbers for History Output 
By default, Abaqus reports the temperature at the integration points for each element selected. The 20 node heat transfer brick used in the model has 27 integration points. The numbering scheme of the nodes for a 20 -node brick element and integration points for a hexahedral element are shown in Figure 30 below.
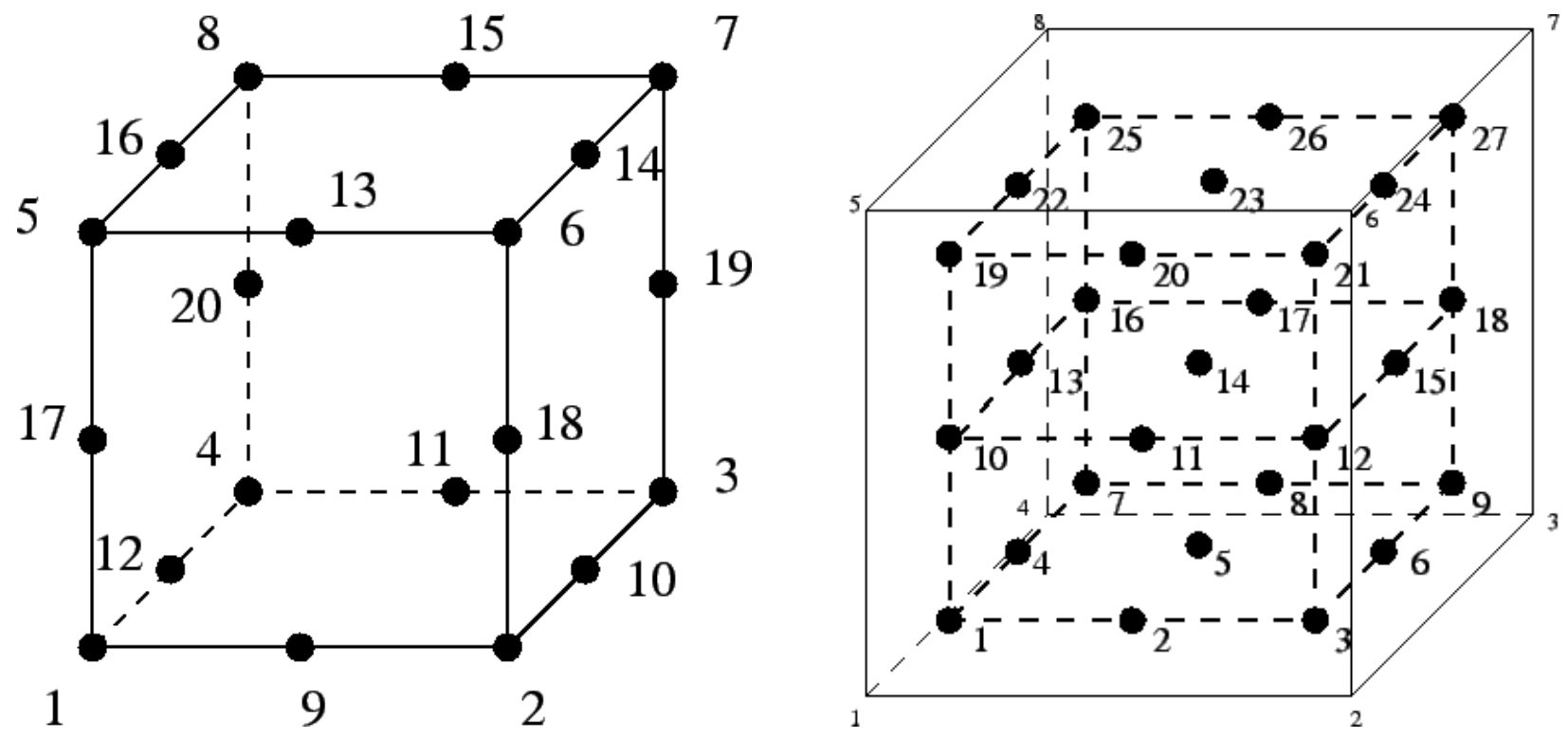

Figure 30. Nodes and Integration Points for a 20-Node Heat Transfer Brick (Dhondt 2014)

The temperature at the various integration points varied within the element. It was decided that the centroidal integration point (point 14) would be used to estimate the temperature of the element. 


\section{RESULTS AND DISCUSSION}

This section will introduce the different simulations and processing parameters used. Additionally, the MATLAB script used to filter and analyze the results from the Abaqus simulations is described. Finally, the results from experimental study and the results from the simulation model will be presented.

\subsection{DESIGN OF EXPERIMENT}

The experiment was designed such that the processing parameters matched those used in the study performed by Wang et al. (2016). Initially, a series of simulations were conducted using W-Ni-Fe and were compared to the experimental results. Next, an additional case study was performed using $316 \mathrm{~L} \mathrm{SS}$ as the material. The simulation experiments and process parameters are shown in Table 18 below.

Table 18. Design of Experiment for Simulations

\begin{tabular}{|c|c|c|c|c|c|c|}
\hline \multicolumn{7}{|c|}{ Design of Experiment } \\
\hline Simulation & Material & Absorptivity & $\begin{array}{c}\text { Laser } \\
\text { Power, P } \\
{[\mathbf{W}]}\end{array}$ & $\begin{array}{c}\text { Scanning } \\
\text { Speed, v } \\
{[\mathbf{m m} / \mathbf{s}]}\end{array}$ & Step Time & P/v ratio \\
\hline 1 & W-Ni-Fe & 0.38 & 230 & 300 & $8.33 \mathrm{E}-04$ & 0.77 \\
\hline 2 & W-Ni-Fe & 0.38 & 150 & 196 & $1.28 \mathrm{E}-03$ & 0.77 \\
\hline 3 & W-Ni-Fe & 0.38 & 230 & 635 & $3.94 \mathrm{E}-04$ & 0.36 \\
\hline 4 & W-Ni-Fe & 0.38 & 310 & 300 & $8.33 \mathrm{E}-04$ & 1.03 \\
\hline 5 & W-Ni-Fe & 0.38 & 393 & 300 & $8.33 \mathrm{E}-04$ & 1.31 \\
\hline 6 & W-Ni-Fe & 0.38 & 393 & 470 & $5.32 \mathrm{E}-04$ & 0.84 \\
\hline 7 & $316 \mathrm{~L}$ SS & 0.30 & 230 & 300 & $8.33 \mathrm{E}-04$ & 0.77 \\
\hline 8 & $316 \mathrm{~L}$ SS & 0.30 & 230 & 635 & $3.94 \mathrm{E}-04$ & 0.36 \\
\hline 9 & $316 \mathrm{~L}$ SS & 0.30 & 310 & 300 & $8.33 \mathrm{E}-04$ & 1.03 \\
\hline 10 & $316 \mathrm{~L}$ SS & 0.30 & 393 & 300 & $8.33 \mathrm{E}-04$ & 1.31 \\
\hline 11 & $316 \mathrm{~L}$ SS & 0.30 & 393 & 470 & $5.32 \mathrm{E}-04$ & 0.84 \\
\hline
\end{tabular}


Simulations $1,3,4,5$, and 6 were conducted according the same processing parameters used in the Wang et al. (2016) study. Simulation 2 was used as a way to validate the simulation results. It has the same $\mathrm{P} / \mathrm{v}$ ratio of simulation 1 and in theory should have matching results. The simulations were then all replicated with $316 \mathrm{~L} \mathrm{SS}$ as the material. For all simulations, the temperature at each time increments was recorded all 28 elements of each layer. The data was obtained by reporting the XY data within Abaqus.

\subsection{DATA ANALYSIS}

A MATLAB script was used to filter the raw data and calculate the total time above the melting temperature for each element. The script started by looking at the first temperate data point and continues until finding the first time increment above the melting temperature of $1738 \mathrm{~K}$ for $\mathrm{W}-\mathrm{Ni}-\mathrm{Fe}$ (Liu and German, 2001). A melting temperature of $1670 \mathrm{~K}$ was used for $316 \mathrm{~L}$ stainless steel. The script will then continue until the temperature is below the melting temperature and then record the time above the melting temperature. In this manner, the script is able to record each cycle the element experiences above the melting temperature. The total time for each element is then summed and sorted into an order that follows the path of the laser. The script used to filter the data can be found in Appendix C. To help visualize the data analysis, Figure 31 below shows how an element may fluctuate above and below the melting temperature during a single pass of the laser for a 316L SS stimulation. Additionally, the element temperature may go above the melting temperature during the scan of a subsequent layer. 


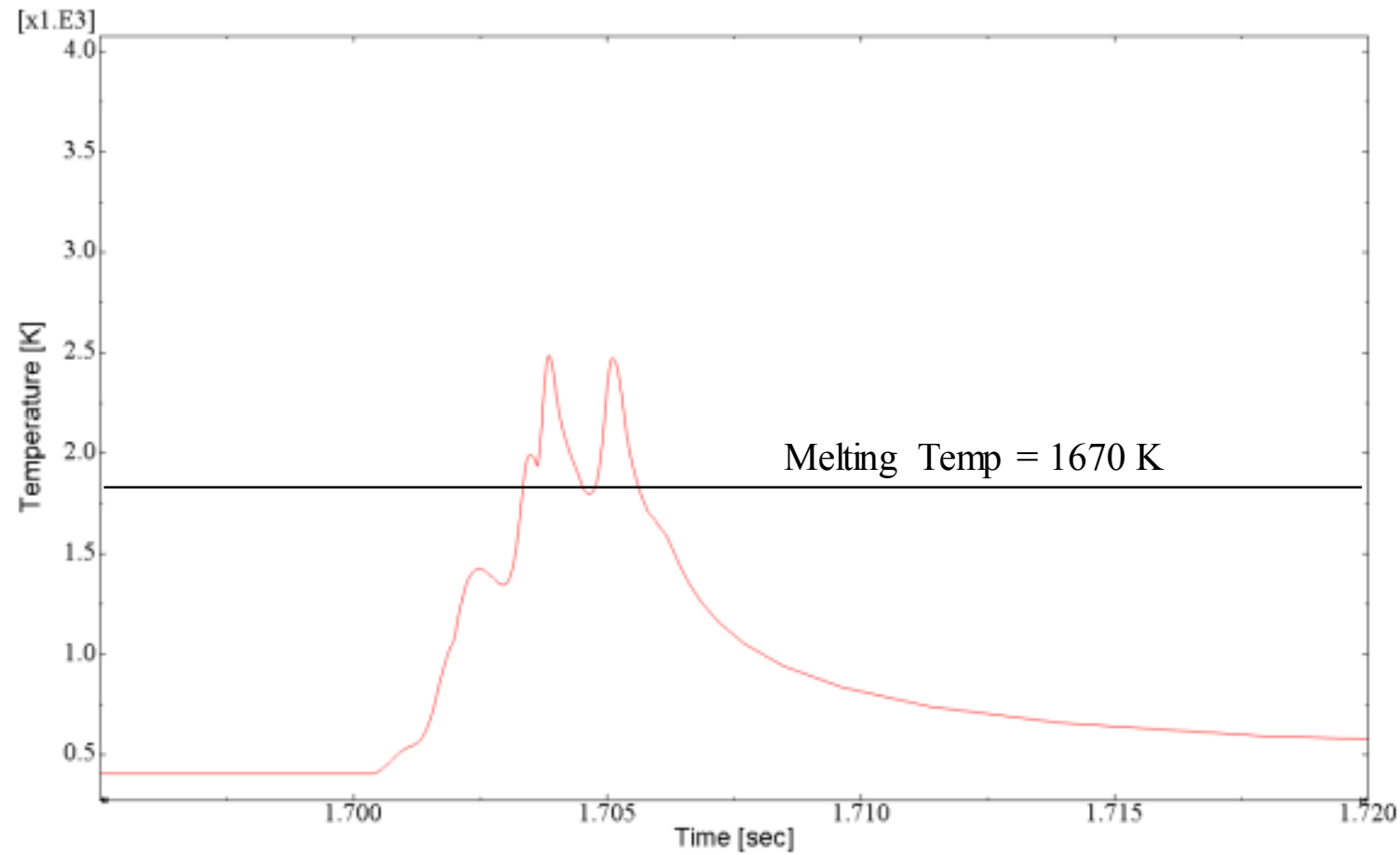

Figure 31. Example temperature output for an element 


\subsection{EXPERIMENTAL RESULTS}

The results from Wang et al. (2016) experiment were used as a way to compare with the simulation results. One issue that occurred when trying to calculate relative density of the simulation results is that some material properties, $\alpha$ (surface tension) and $\eta_{0}$ (viscosity) of equation [7], are not well published. Thus a modified approached was used to compare these experimental results to the simulation results.

Using the assumption from Wang et al. (2016) that:

$$
t=k \frac{P}{v}
$$

Equation [7] can now be represented as:

$$
\theta=\theta_{0} \exp \left(-\frac{9 \alpha k}{4 \eta_{0} r_{0}} \frac{P}{v}\right)
$$

Then dividing both sides by initial porosity, $\theta_{0}$ :

$$
\frac{\theta}{\theta_{0}}=\exp \left(-\frac{9 \alpha k}{4 \eta_{0} r_{0}} \frac{P}{v}\right)
$$

And taking the natural log of both sides:

$$
\ln \left(\frac{\theta}{\theta_{0}}\right)=-\left(\frac{9 \alpha k}{4 \eta_{0} r_{0}}\right) \frac{P}{v}
$$

Assuming that the following can be represented as a constant and is independent of material or processing parameters:

$$
C=\frac{9 \alpha k}{4 \eta_{0} r_{0}}
$$

Substituting equation [21] into [20], the following relationship can be obtained:

$$
\ln \left(\frac{\theta}{\theta_{0}}\right)=-C \frac{P}{v}
$$


Equation [22] proposes that there is a relationship between the $\mathrm{P} / \mathrm{v}$ ratio and the resulting porosity. The experimental results are shown in Table 19 and are plotted in Figure 32 below. 
Table 19. Experimental results from Wang et al. (2016)

\begin{tabular}{|c|c|c|c|c|c|c|c|}
\hline $\begin{array}{c}\text { Power } \\
\mathbf{P}(\mathbf{W})\end{array}$ & $\begin{array}{c}\text { Scanning } \\
\text { speed } \\
\mathbf{( m m} / \mathbf{s})\end{array}$ & TW & $\begin{array}{c}\text { Double } \\
\text { hit }\end{array}$ & $\begin{array}{c}\text { Relative } \\
\text { density }\end{array}$ & P/V & Porosity & $\begin{array}{c}\text { Ln } \\
\text { porosity }\end{array}$ \\
\hline 230 & 635 & 0.15 & $\mathrm{n}$ & 0.811 & 0.3622 & 0.189 & -1.0082 \\
\hline 230 & 635 & 0.125 & $\mathrm{n}$ & 0.777 & 0.3622 & 0.223 & -0.8428 \\
\hline 230 & 635 & 0.1 & $\mathrm{n}$ & 0.816 & 0.3622 & 0.184 & -1.035 \\
\hline 230 & 635 & 0.15 & $\mathrm{y}$ & 0.794 & 0.3622 & 0.206 & -0.9221 \\
\hline 230 & 300 & 0.15 & $\mathrm{n}$ & 0.867 & 0.76667 & 0.133 & -1.3596 \\
\hline 230 & 300 & 0.125 & $\mathrm{n}$ & 0.864 & 0.76667 & 0.136 & -1.3373 \\
\hline 230 & 300 & 0.1 & $\mathrm{n}$ & 0.825 & 0.76667 & 0.175 & -1.0852 \\
\hline 230 & 300 & 0.15 & $\mathrm{y}$ & 0.821 & 0.76667 & 0.179 & -1.0626 \\
\hline 393 & 470 & 0.15 & $\mathrm{n}$ & 0.838 & 0.83617 & 0.162 & -1.1624 \\
\hline 393 & 470 & 0.125 & $\mathrm{n}$ & 0.849 & 0.83617 & 0.151 & -1.2327 \\
\hline 393 & 470 & 0.1 & $\mathrm{n}$ & 0.821 & 0.83617 & 0.179 & -1.0626 \\
\hline 393 & 470 & 0.15 & $\mathrm{y}$ & 0.84 & 0.83617 & 0.16 & -1.1748 \\
\hline 310 & 300 & 0.15 & $\mathrm{n}$ & 0.84 & 1.03333 & 0.16 & -1.1748 \\
\hline 310 & 300 & 0.125 & $\mathrm{n}$ & 0.861 & 1.03333 & 0.139 & -1.3155 \\
\hline 310 & 300 & 0.1 & $\mathrm{n}$ & 0.855 & 1.03333 & 0.145 & -1.2732 \\
\hline 310 & 300 & 0.15 & $\mathrm{y}$ & 0.847 & 1.03333 & 0.153 & -1.2195 \\
\hline 230 & 200 & 0.15 & $\mathrm{n}$ & 0.8647 & 1.15 & 0.1353 & -1.3425 \\
\hline 393 & 300 & 0.15 & $\mathrm{n}$ & 0.869 & 1.31 & 0.131 & -1.3748 \\
\hline 393 & 300 & 0.125 & $\mathrm{n}$ & 0.875 & 1.31 & 0.125 & -1.4217 \\
\hline 393 & 300 & 0.1 & $\mathrm{n}$ & 0.86 & 1.31 & 0.14 & -1.3083 \\
\hline 393 & 300 & 0.15 & $\mathrm{y}$ & 0.865 & 1.31 & 0.135 & -1.3447 \\
\hline 230 & 150 & 0.15 & $\mathrm{y}$ & 0.875 & 1.53333 & 0.125 & -1.4217 \\
\hline 310 & 200 & 0.15 & $\mathrm{n}$ & 0.874 & 1.55 & 0.126 & -1.4137 \\
\hline 393 & 200 & 0.15 & $\mathrm{n}$ & 0.891 & 1.965 & 0.109 & -1.5586 \\
\hline 310 & 150 & 0.15 & $\mathrm{y}$ & 0.881 & 2.06667 & 0.119 & -1.4709 \\
\hline 230 & 100 & 0.15 & $\mathrm{n}$ & 0.8722 & 2.3 & 0.1278 & -1.3995 \\
\hline 393 & 150 & 0.15 & $\mathrm{y}$ & 0.906 & 2.62 & 0.094 & -1.7067 \\
\hline 310 & 100 & 0.15 & $\mathrm{n}$ & 0.911 & 3.1 & 0.089 & -1.7613 \\
\hline 393 & 100 & 0.15 & $\mathrm{n}$ & 0.926 & 3.93 & 0.074 & -1.9459 \\
\hline 230 & 50 & 0.15 & $\mathrm{n}$ & 0.911 & 4.6 & 0.089 & -1.7613 \\
\hline 310 & 50 & 0.15 & $\mathrm{n}$ & 0.947 & 6.2 & 0.053 & -2.2797 \\
\hline
\end{tabular}




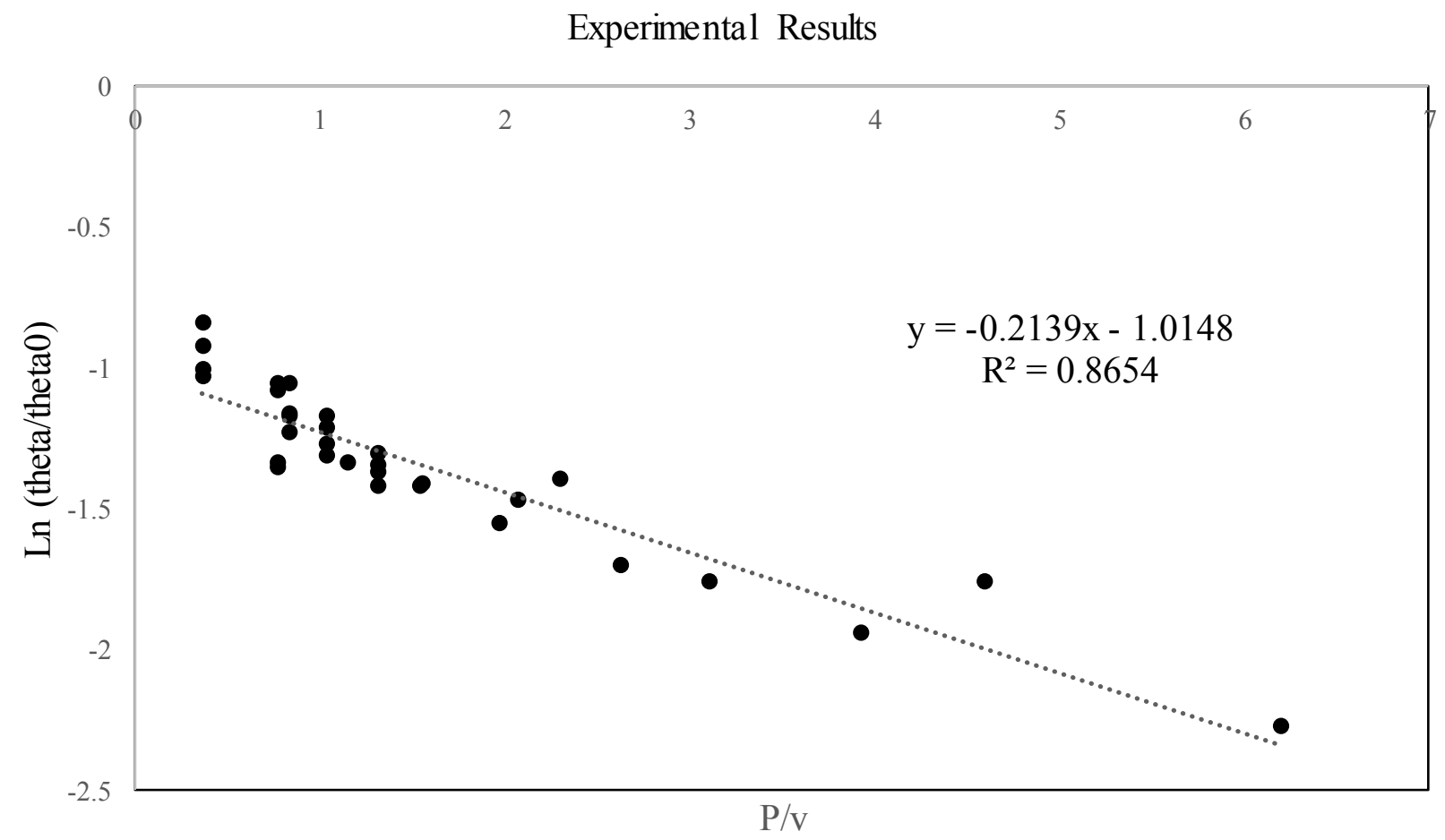

Figure 32. Experimental results from Wang et al. (2016) 


\subsection{W-Ni-FESIMULATION RESULTS}

This section will display and highlight the results from the experiments described in Table 18. The results from the simulation are plotted in a slightly different manner than the experimental results in order to prove the relationship between the total time above the melting temperature to the $\mathrm{P} / \mathrm{v}$ ratio. A linear relationship between these values of equation [17] would show that the FEA model matches the experimental model.

\subsubsection{Model VALIDATION}

First, a comparison between simulation 1 and simulation 2 is shown to validate that the model produces similar results when the same $\mathrm{P} / \mathrm{v}$ ratio is used for the processing parameters (Figures 33-35).

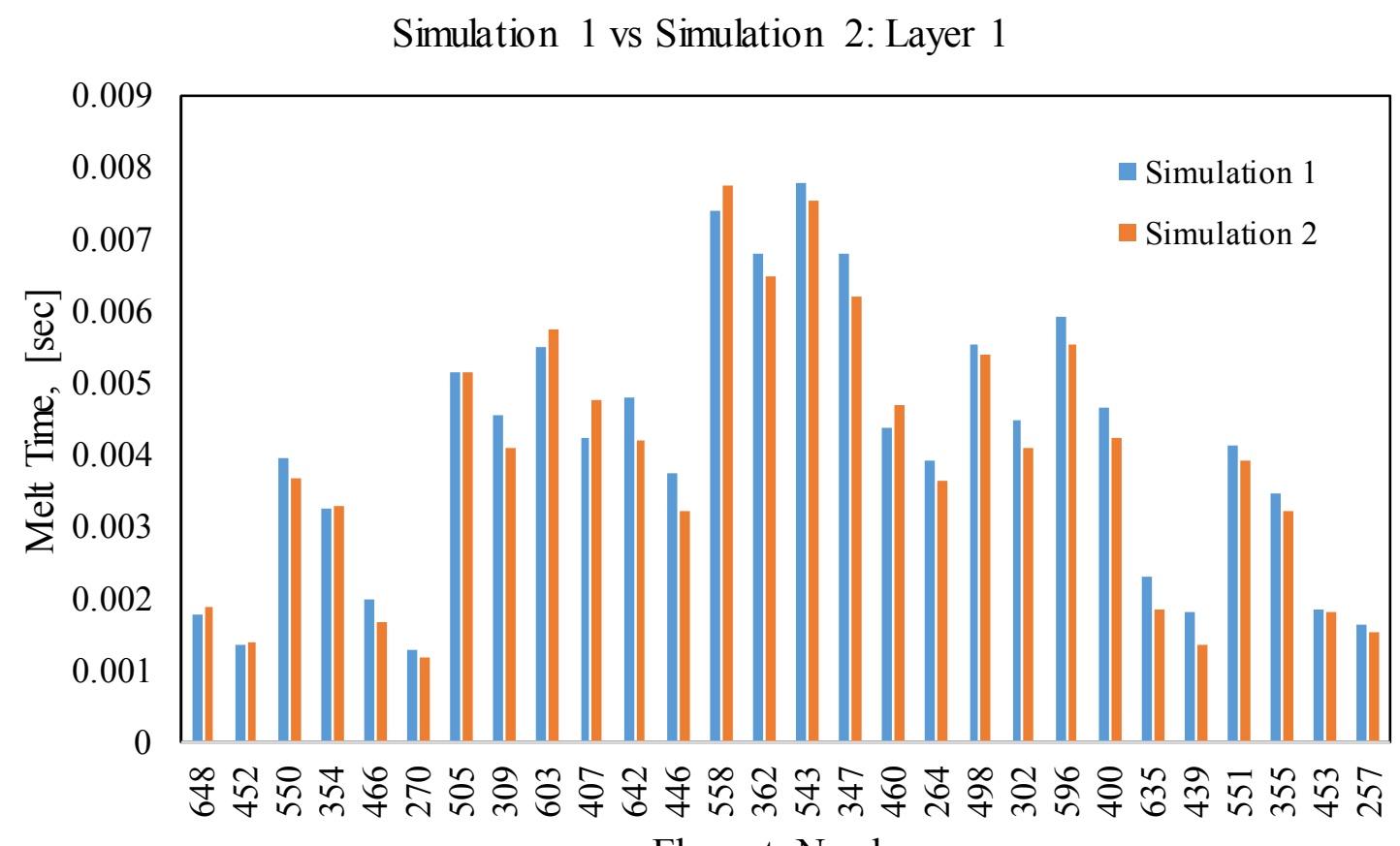

Element Number

Figure 33. Layer 1 melt time for simulation 1 vs. simulation 2 comparison 
Simulation 1 vs Simulation 2: Layer 2

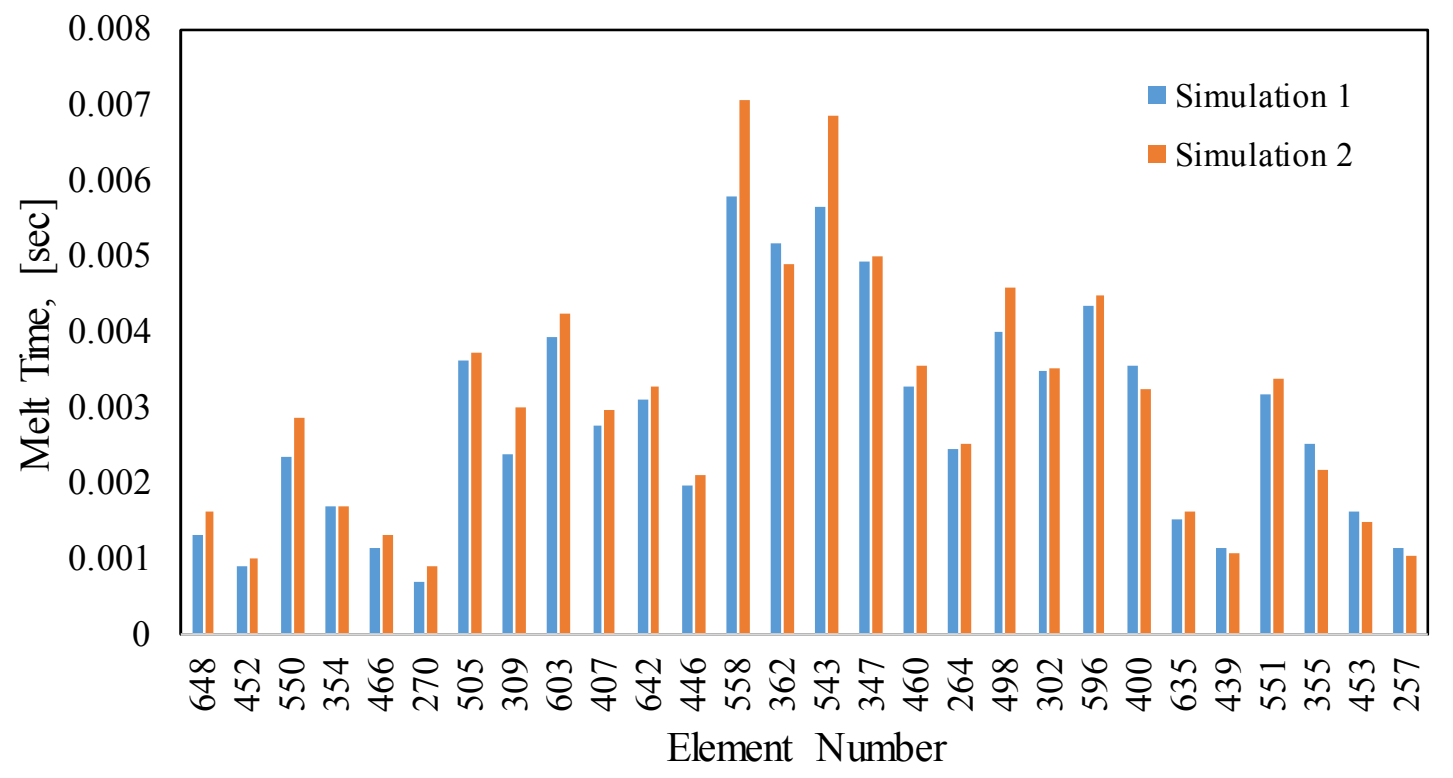

Figure 34. Layer 2 melt time for simulation 1 vs. simulation 2 comparison

Simulation 1 vs Simulation 2: Layer 3

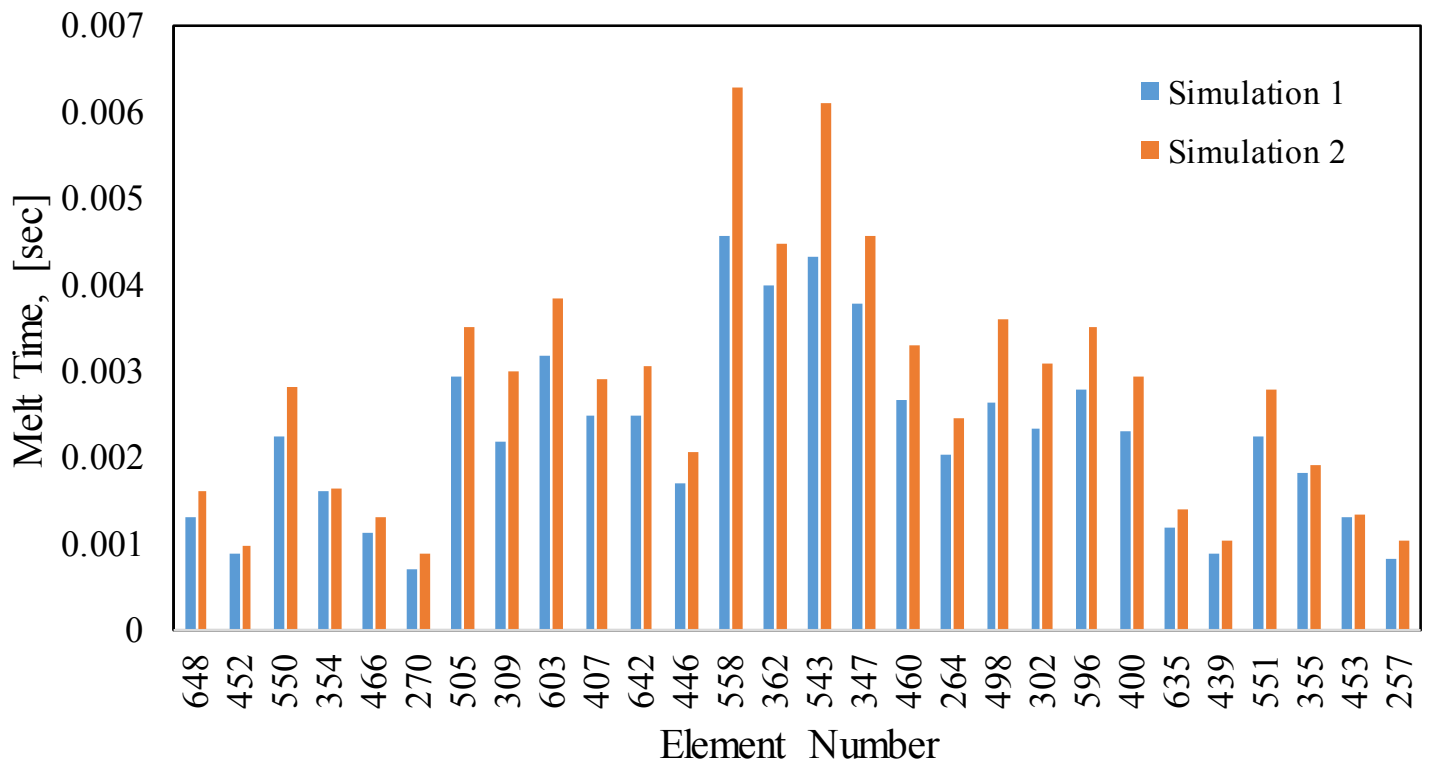

Figure 35. Layer 3 melt time for simulation 1 vs. simulation 2 comparison 
There are a couple of key observations to make about this comparison. The most notable discrepancy between simulation 1 and simulation 2 occurring during in the third layer. Layer 1 was near identical in melt time and layer 2 also showed strong agreement between simulations. Additionally, elements 558 and 543 resulted in the largest difference between simulations in each layer.

To begin, these results are for the full three layer simulation. Thus, layer 1 experiences three scans of the laser whereas layer 3 was only exposed to a single scan. This highlights the significance of multilayer analysis and the reheating that occurs during subsequent scans. It also suggests that the model is more accurate when layers are exposed to multiple passes of the layer as opposed to just a single scan.

Next, elements 558 and 543 resulted in the largest difference during the second and third layers. These elements are both located in the center and on top of the powder layer. It makes since that these element's time history results in the longest time above the melting temperature since their location allows them to experience more time in contact with the laser due to the hatch spacing.

Overall, the results of this comparison show that the $\mathrm{P} / \mathrm{v}$ ratio is a strong contributing factor in the resulting time history of the temperature distribution. Even though layer 3 showed some discrepancy as a couple elements, the overall magnitude of difference was quite small. The results follow a similar pattern with accuracy between experiments increasing with multiple scans. Table 20 below summarizes the results for each layer after experiencing a single pass of the laser. 
Table 20. Summary of results for comparison between Experiment 1 and Experiment 2

\begin{tabular}{|c|c|c|}
\hline Layer & $\begin{array}{c}\text { Average } \\
\text { Difference [sec] }\end{array}$ & $\begin{array}{c}\text { Average } \\
\text { Percent } \\
\text { Difference }\end{array}$ \\
\hline 1 & 0.00029 & $8 \%$ \\
\hline 2 & 0.00029 & $11 \%$ \\
\hline 3 & 0.00053 & $22 \%$ \\
\hline
\end{tabular}




\subsubsection{LINEAR REGRESSION RESULTS}

Next, the results at various locations throughout the powder layer will be shown. The element number corresponds to the labels shown in Figure 36. Each layer will have its own individual instance of that element. Thus, the results are plotted for each instance of that element ( 1 in each layer). Only a few of the critical locations will be presented in this section. The results for all elements of the history output can be found in Appendix A.

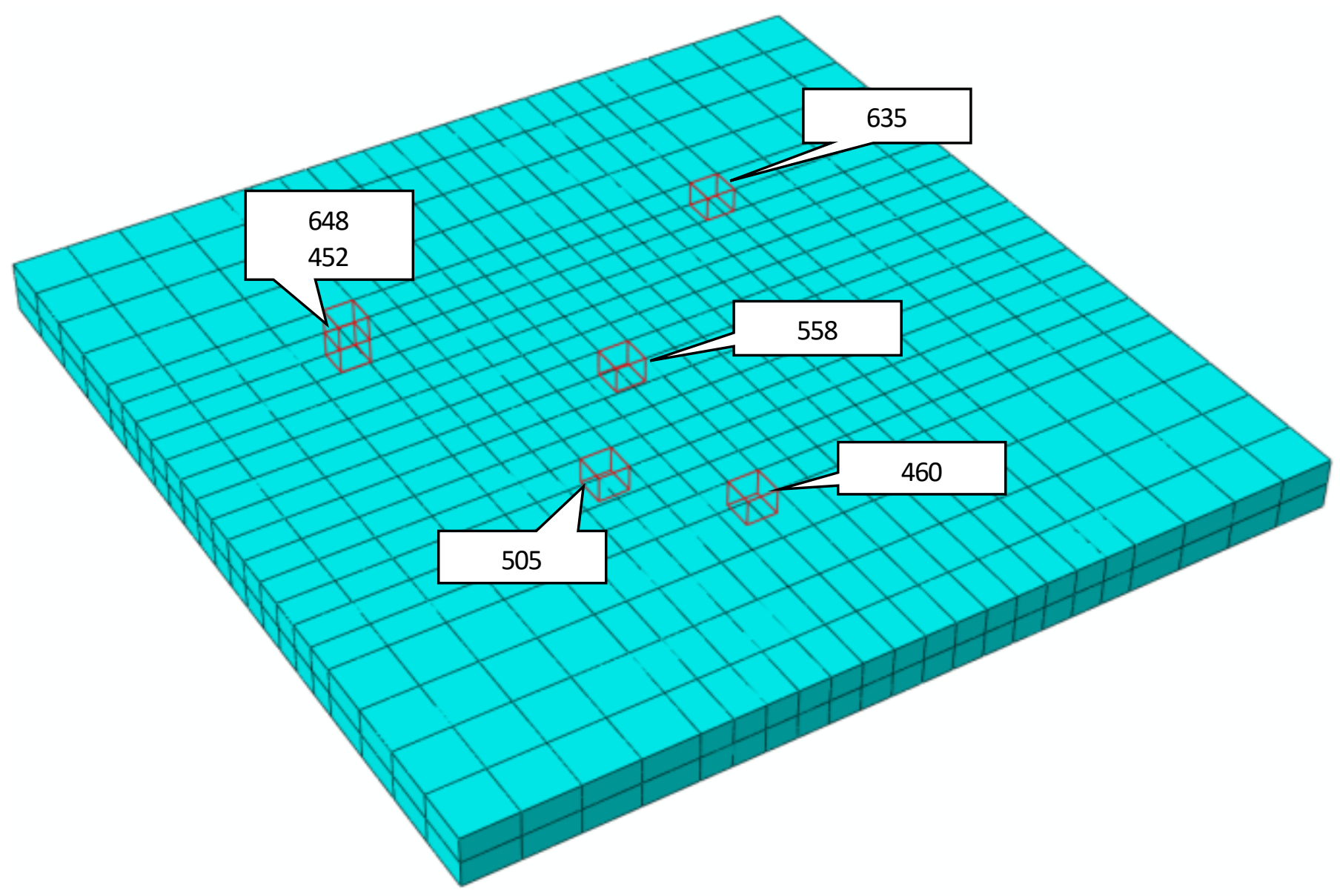

Figure 36. Elements numbers for elements shown in W-Ni-Fe results 


\section{Element 648}

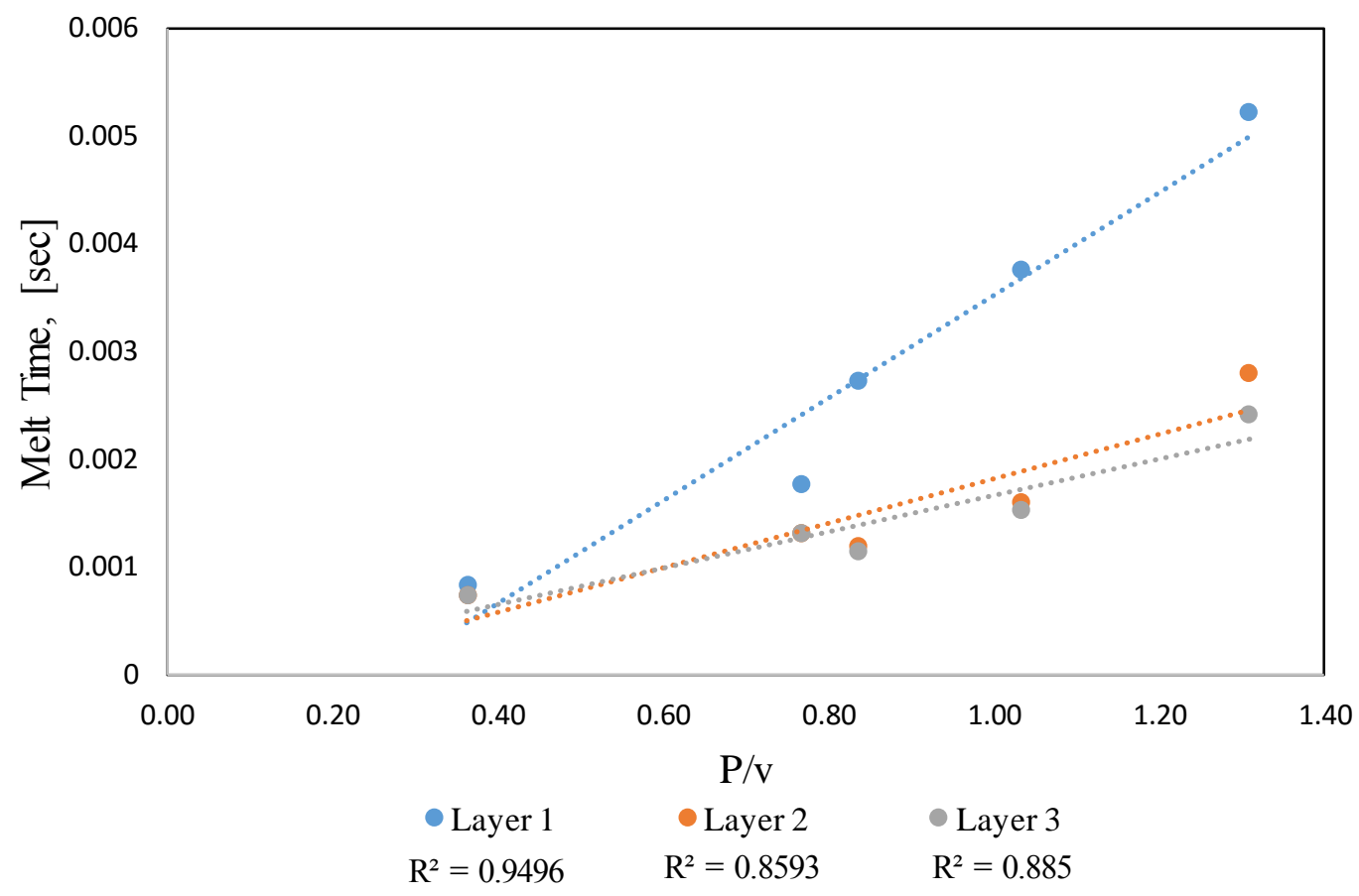

Figure 37. W-Ni-Fe - Total melt time vs P/v for Element 648

Element 452

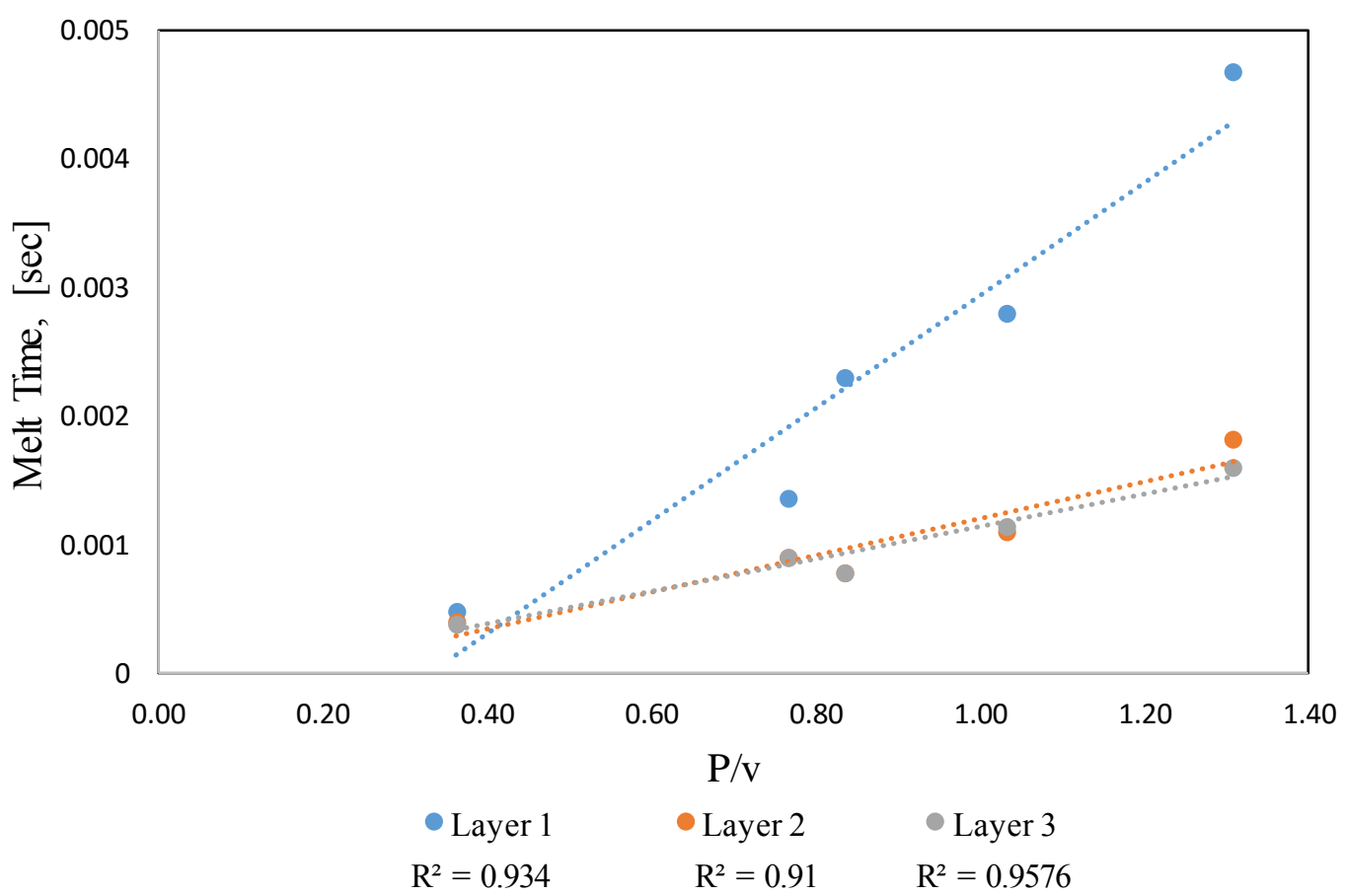

Figure 38. W-Ni-Fe - Total melt time vs P/v for Element 452 
Element 505

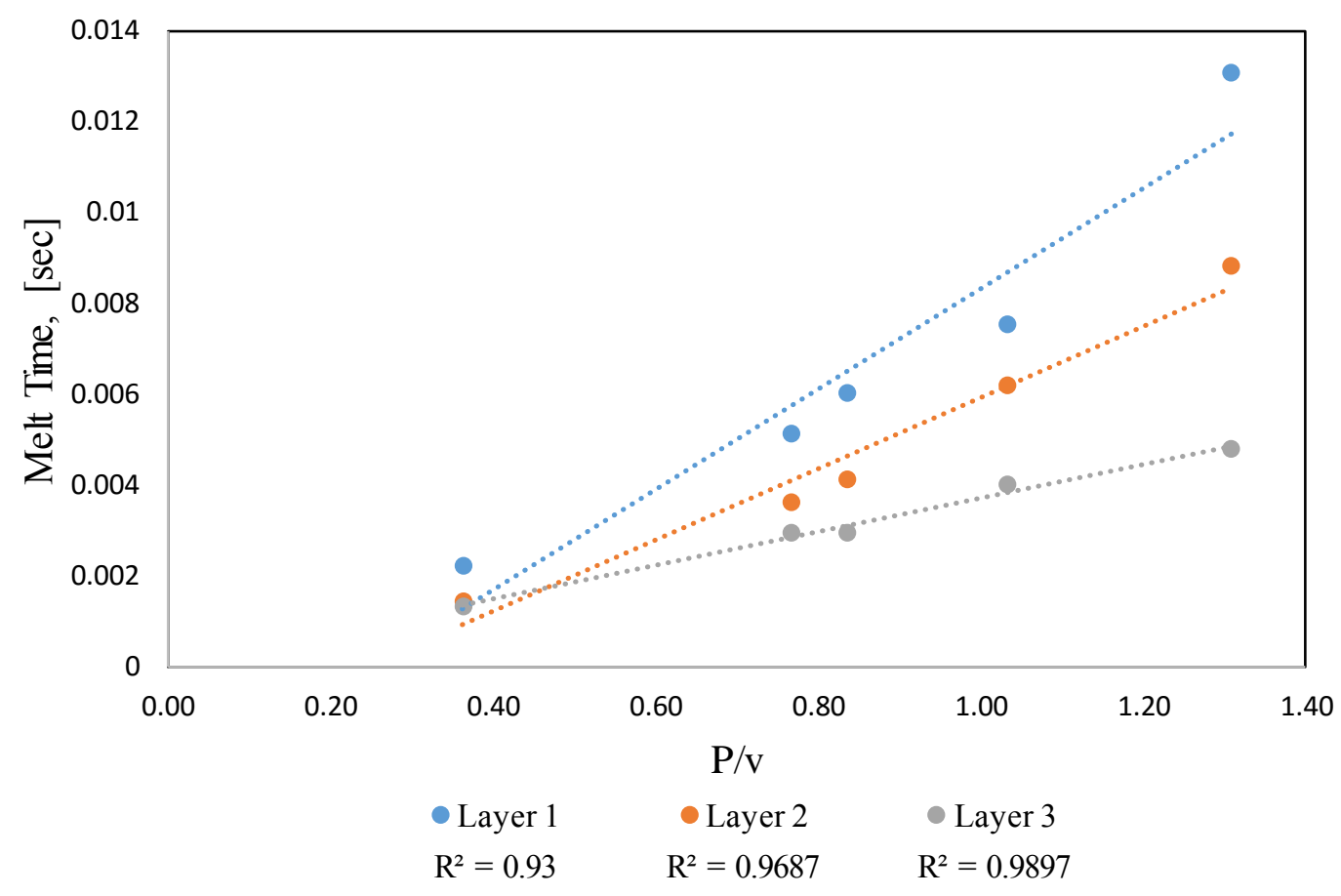

Figure 39. W-Ni-Fe - Total melt time vs $\mathrm{P} / \mathrm{v}$ for Element 505

Element 558

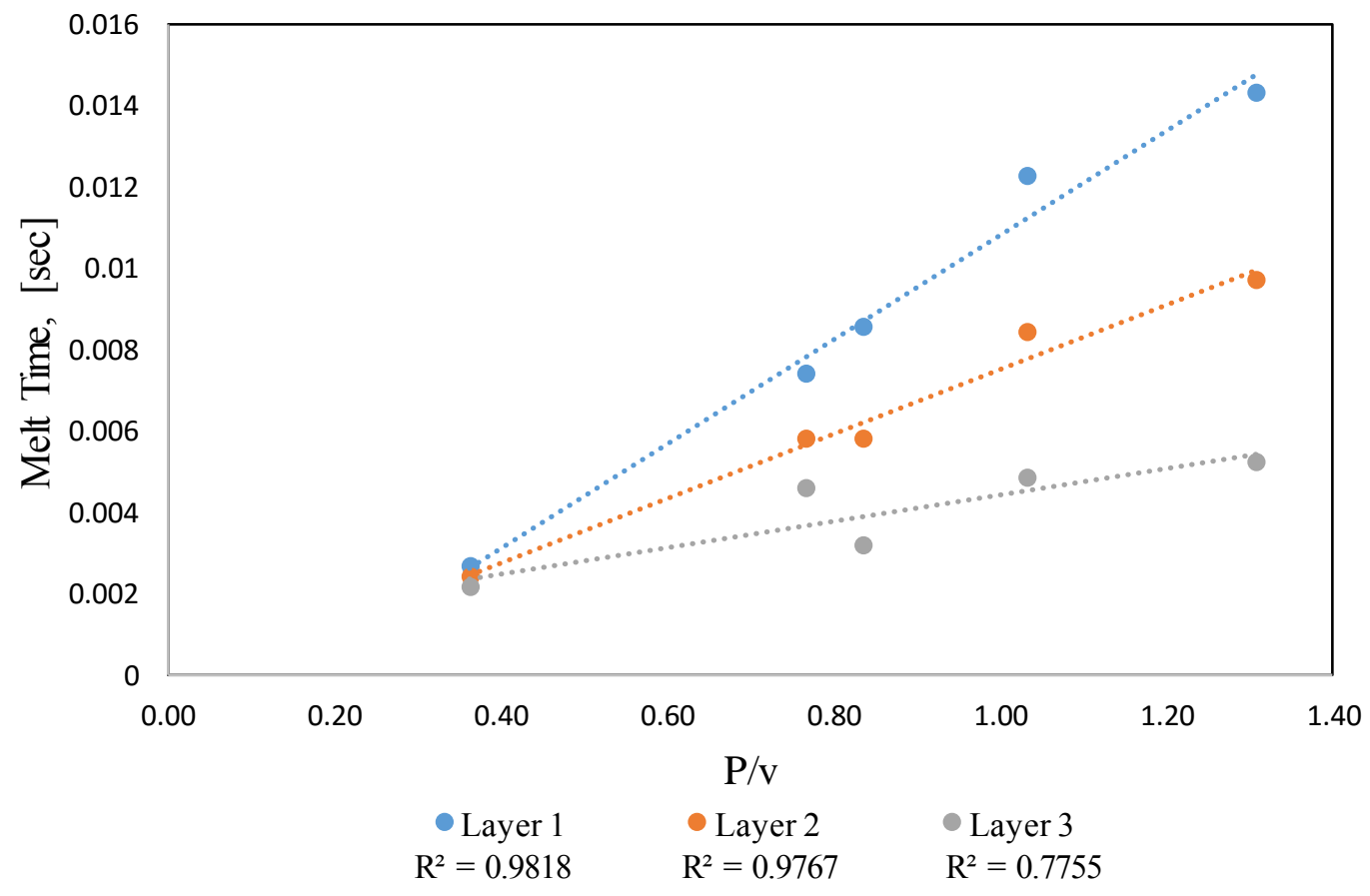

Figure 40. W-Ni-Fe - Total melt time vs $\mathrm{P} / \mathrm{v}$ for Element 558 
Element 460

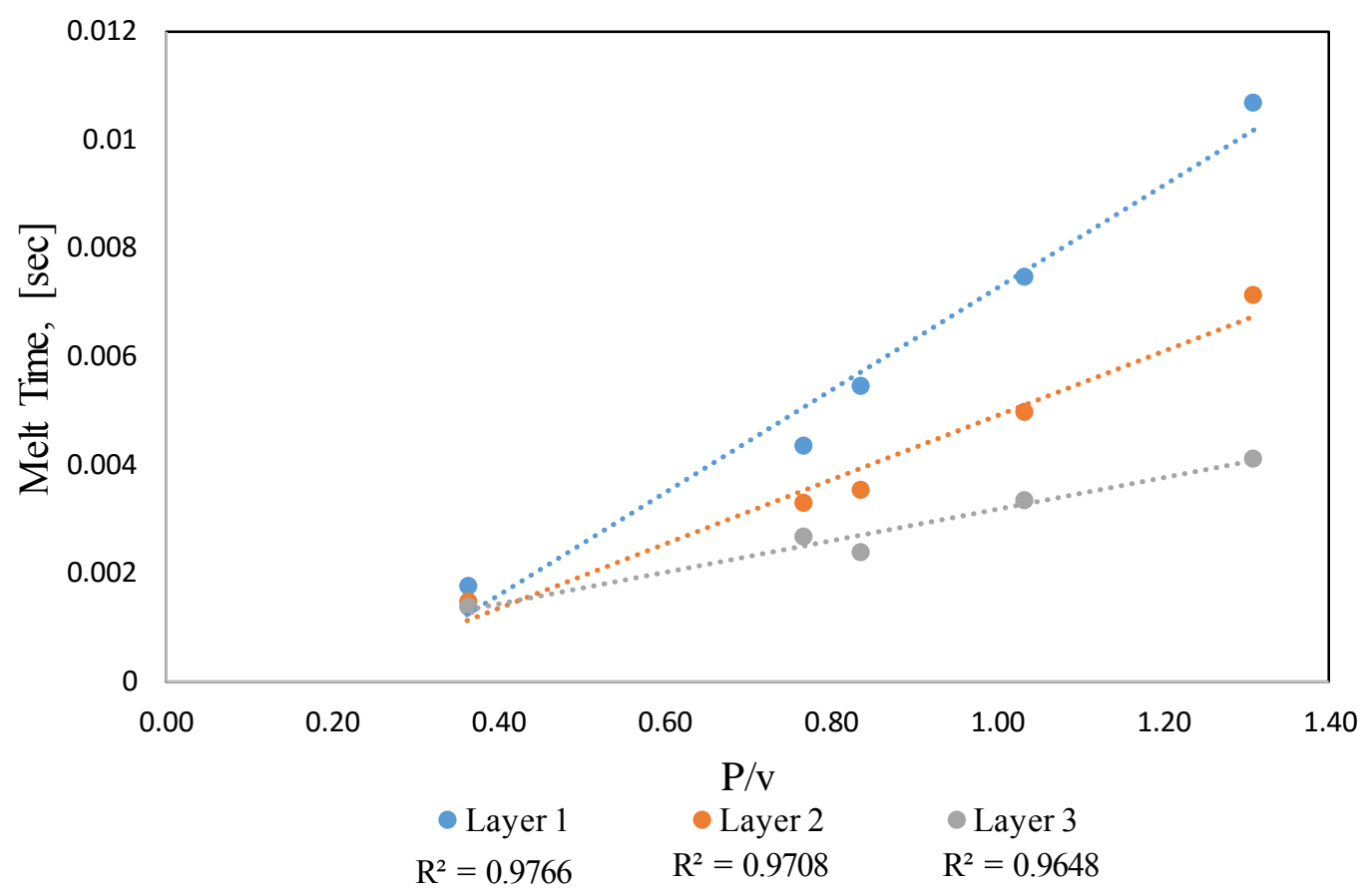

Figure 41 . W-Ni-Fe - Total melt time vs $\mathrm{P} / \mathrm{v}$ for Element 460

Element 635

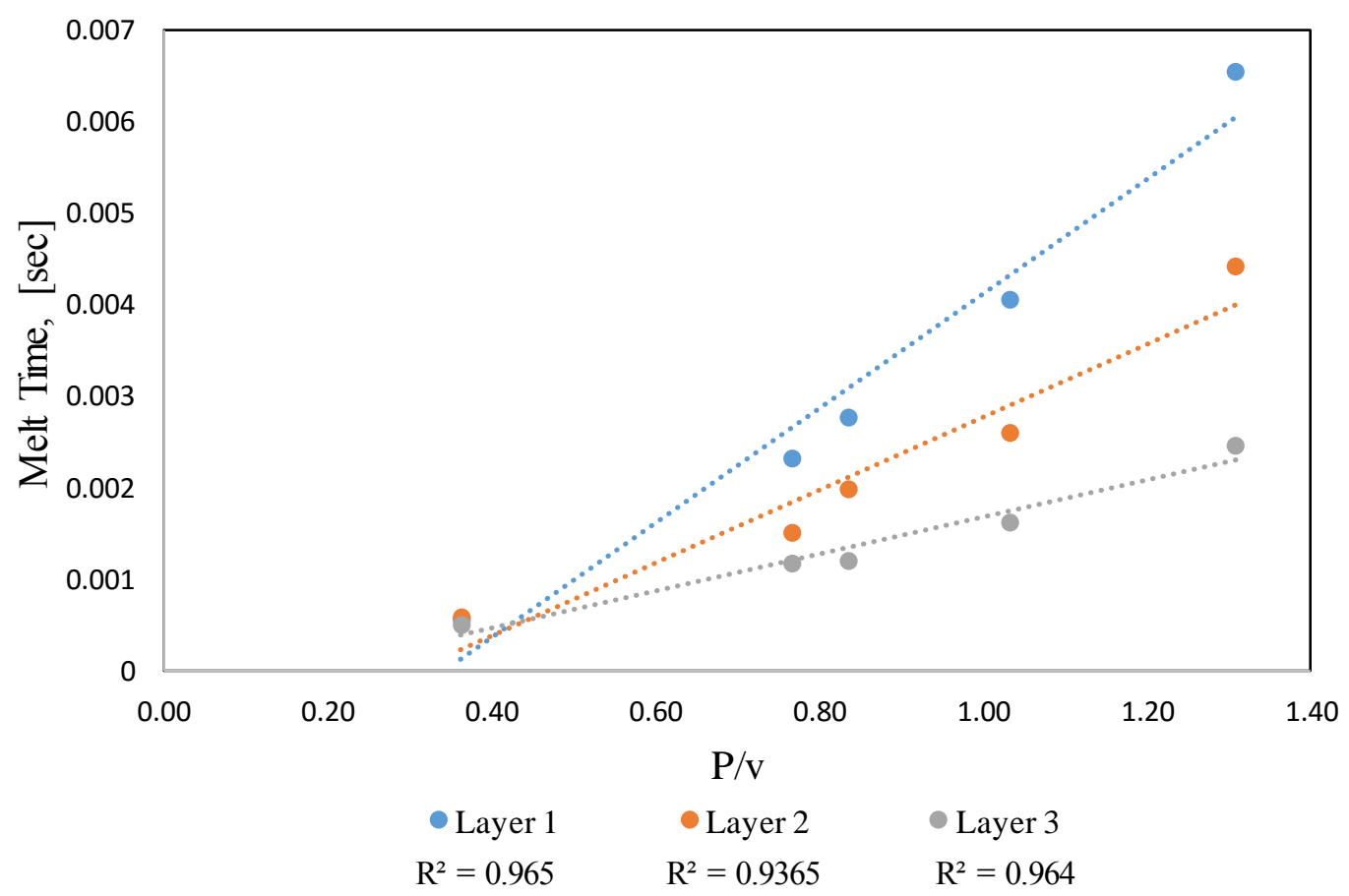

Figure 42. W-Ni-Fe - Total melt time vs $\mathrm{P} / \mathrm{v}$ for Element 635 
Table 21. W-Ni-Fe - $\mathrm{R}^{2}$ Value for all elements in history output

\begin{tabular}{|c|c|c|c|}
\hline \multicolumn{4}{|c|}{$\mathbf{R}^{2}$ Value for Melt Time vs P/v } \\
\hline Element & Layer 1 & Layer 2 & Layer 3 \\
\hline $\mathbf{6 4 8}$ & 0.950 & 0.859 & 0.885 \\
\hline $\mathbf{4 5 2}$ & 0.934 & 0.910 & 0.958 \\
\hline $\mathbf{5 5 0}$ & 0.931 & 0.904 & 0.964 \\
\hline $\mathbf{3 5 4}$ & 0.944 & 0.877 & 0.943 \\
\hline $\mathbf{4 6 6}$ & 0.964 & 0.953 & 0.995 \\
\hline $\mathbf{2 7 0}$ & 0.943 & 0.870 & 0.945 \\
\hline $\mathbf{5 0 5}$ & 0.930 & 0.969 & 0.990 \\
\hline $\mathbf{3 0 9}$ & 0.903 & 0.915 & 0.969 \\
\hline $\mathbf{6 0 3}$ & 0.956 & 0.953 & 0.965 \\
\hline $\mathbf{4 0 7}$ & 0.927 & 0.935 & 0.946 \\
\hline $\mathbf{6 4 2}$ & 0.978 & 0.977 & 0.990 \\
\hline $\mathbf{4 4 6}$ & 0.961 & 0.925 & 0.962 \\
\hline $\mathbf{5 5 8}$ & 0.982 & 0.977 & 0.776 \\
\hline $\mathbf{3 6 2}$ & 0.977 & 0.986 & 0.864 \\
\hline $\mathbf{5 4 3}$ & 0.986 & 0.979 & 0.820 \\
\hline $\mathbf{3 4 7}$ & 0.989 & 0.986 & 0.861 \\
\hline $\mathbf{4 6 0}$ & 0.977 & 0.971 & 0.965 \\
\hline $\mathbf{2 6 4}$ & 0.969 & 0.959 & 0.981 \\
\hline $\mathbf{4 9 8}$ & 0.989 & 0.977 & 0.923 \\
\hline $\mathbf{3 0 2}$ & 0.984 & 0.994 & 0.961 \\
\hline $\mathbf{5 9 6}$ & 0.986 & 0.987 & 0.953 \\
\hline $\mathbf{4 0 0}$ & 0.981 & 0.996 & 0.977 \\
\hline $\mathbf{6 3 5}$ & 0.965 & 0.937 & 0.964 \\
\hline $\mathbf{4 3 9}$ & 0.950 & 0.907 & 0.928 \\
\hline $\mathbf{5 5 1}$ & 0.993 & 0.987 & 0.920 \\
\hline $\mathbf{3 5 5}$ & 0.981 & 0.993 & 0.973 \\
\hline $\mathbf{4 5 3}$ & 0.962 & 0.974 & 0.961 \\
\hline $\mathbf{2 5 7}$ & 0.940 & 0.947 & 0.952 \\
\hline \hline Average & 0.962 & 0.950 & 0.939 \\
\hline & & & \\
\hline
\end{tabular}




\subsubsection{DISCUSSION}

The importance of the melt time of the powder can best be explained through the microstructure changes throughout the SLS process (Figure 43). Initially, the solid grains of the powder are loosely packed allowing for several pores to be present within the powder bed. As heating occurs and the solid grains melt, they being to rearrange. Upon reaching a liquid phase, the transport rates improve leading to "pore annihilation." As a result, there is microstructure coarsening and subsequent densification (German et al., 2009). Thus the longer the powder is above the melting temperature, the most time for the microstructure to remove pores and densify.

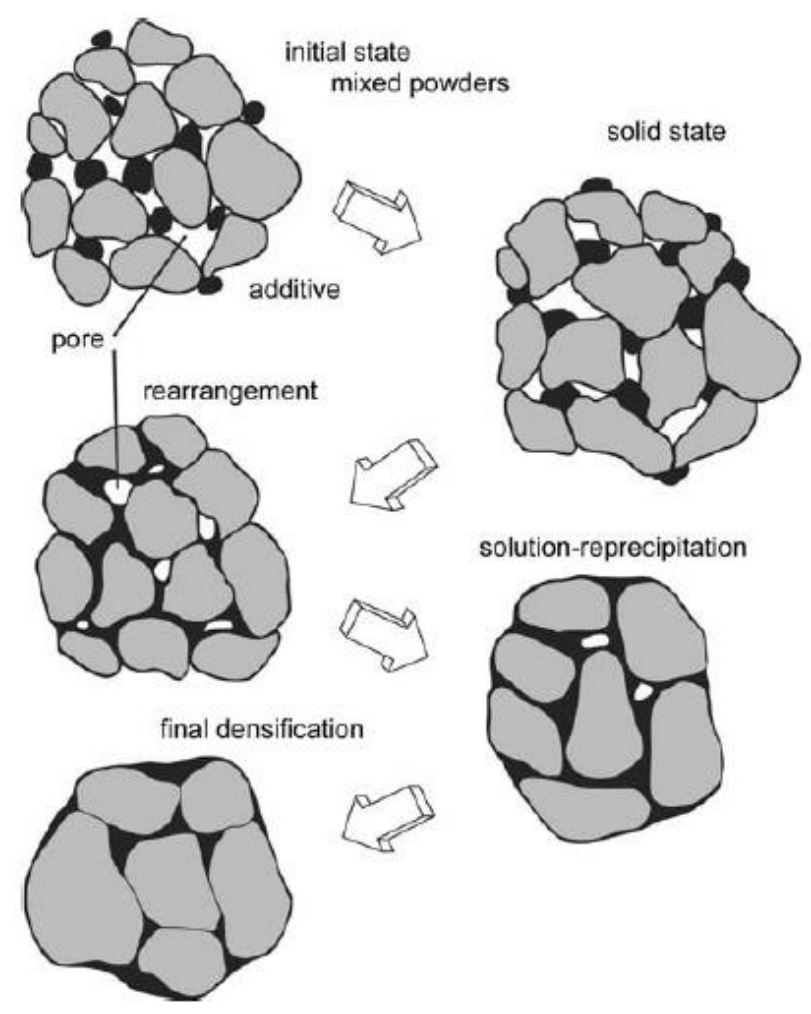

Figure 43. Microstructure evolution during SLS (German et al., 2009) 
The results showed that a linear relationship exists between the time above the melting temperature and the $\mathrm{P} / \mathrm{v}$ ratio. The lowest $\mathrm{R}^{2}$ value was 0.776 and occurred in the third layer of element 558. The highest $\mathrm{R}^{2}$ value was 0.996 and occurred in the second layer of element 400 . This section will highlight some of the trends that occurred with respect to location, layer, and other aspects within the model.

The powder layer was meshed such that the layer consisted of two elements in the Y direction. For most pairs of elements, the top element resulted in a slightly higher $\mathrm{R}^{2}$ value than the element beneath it. This results makes sense because the heat flux was applied as a surface based heat flux to the top element. As a result, the top element was in direct contact with the heat flux from the laser. In general, the pairs of elements in the Y direction resulted in the same melt time pattern with the top element experiencing slightly longer time above the melting temperature. Since both the top and bottom halves of the powder layer followed a similar melt history, a majority of elements presented in this section correspond to top half of the powder layer.

Next, the element's location within the model was an indicator of how linear the relationship would be. In general, interior elements resulted in higher $\mathrm{R}^{2}$ values and elements located on the corners resulted in lower $\mathrm{R}^{2}$ values. Figure 37 and 38 correspond to the element representing the starting point for the laser scans (a corner element). Although the left (starting) side of the model showed a strong linear relationship, the $\mathrm{R}^{2}$ values were slightly lower than the rest of the model. This could be due to the abrupt loading of the heat flux while all surrounding surfaces are at room temperature. The first scan of the model experiences the highest temperature gradient and so it reasonable that the most variance would be seen in this location. 
In contrast, interior elements showed the strongest linear relationship. Figures 39 and 40 both correspond to interior elements with Figures 39 representing the center the powder layer. These elements were more likely to be exposed to multiple scans during a single layer due to the trace width overlap during the scanning process. The stronger linear relationship seen in these areas could be due to the more thorough heating and longer exposure to the laser beam. However, the third layer in this section resulted in the lowest $\mathrm{R}^{2}$ values which could help explain the discrepancy between simulation 1 and simulation 2 shown in Figure 35.

One anomaly that occurred in a few elements throughout the powder layer was a decrease in melt time with an increase in the $\mathrm{P} / \mathrm{v}$ ratio. This discrepancy can be seen most clearly in Figures 39 for layers 2 and 3. The decrease in melt time only occurred between the $\mathrm{P} / \mathrm{v}$ ratios of 0.77 (simulation 1) and 0.84 (simulation 6). One explanation for this result is that the $\mathrm{P} / \mathrm{v}$ ratios were similar enough that there was not a big enough difference to cause a significant change in the melting time. This observation is most prevalent is layer 3 and also occurs a few times in layer 2. This results hints that since layer 1 is exposed to multiple layers of heating, the additional scans are able to adjust any error or variability from just a single scan. Additionally, the linear relationship will become stronger once the powder layers are exposed to multiple scans.

Next, the rightmost elements resulted in a slightly stronger linear relationship between melt time and the $\mathrm{P} / \mathrm{v}$ ratio. This result suggests that the model improves in accuracy towards the end of the simulation. Scan 1 occurs at different surrounding boundary temperatures than that of subsequent scans throughout the layer. As the laser progresses across the powder layer, the surrounding elements increase in temperature 
which in turn results in a stronger linear relationship. This observation can be seen by comparing Figure 37 (starting element) and Figure 42 (ending element). The $\mathrm{R}^{2}$ is higher in the last ending element than the symmetrical left side. This observation can also be made for the interior elements. Thus, it can be concluded that the initial scan results in lower $\mathrm{R}^{2}$ values due to the lower temperature of surrounding elements.

Overall, the finite element model showed a linear relationship between the melting time and $\mathrm{P} / \mathrm{v}$ ratio, ultimately suggesting that the assumption of equation [17] is valid. Although several observations were made suggesting possible weak areas within the model, a majority of elements still had an $\mathrm{R}^{2}$ value above 0.80 in these areas. In summary, the most substantial observation was that the interior elements and the rightmost side of the powder layer resulted in higher $\mathrm{R}^{2}$ values due to the surrounding boundaries temperatures. 


\subsection{L SS SIMULATION RESULTS}

An additional study was conducted using $316 \mathrm{~L}$ stainless steel as the material powder. This is one of the most common materials used in SLS and there are several models and simulation studies performed on this material. The purpose of this study is to show that the relationship between the $\mathrm{P} / \mathrm{v}$ ratio to melt time is also evident in other materials.

\subsubsection{LINEAR REGRESSION RESULTS}

Only a few of the critical locations will be presented in this section. In order to provide a wide variety of locations as well as a good comparison, some of the locations will be similar to those selected in the previous sections and some will highlight different areas. The full results for all elements of the history output can be found in Appendix B.

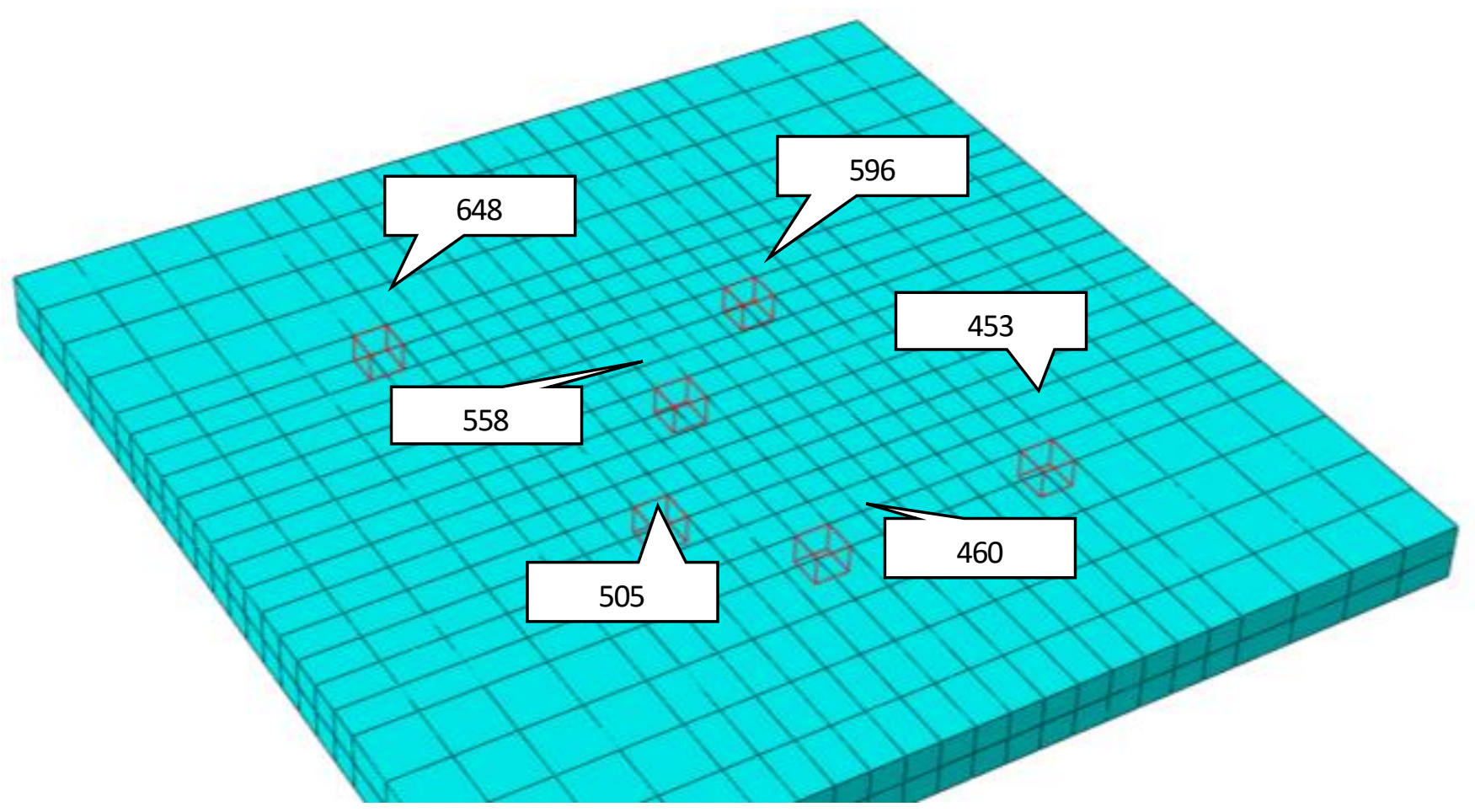

Figure 44. Elements numbers for elements shown in 316L SS results 


\section{Element 648}

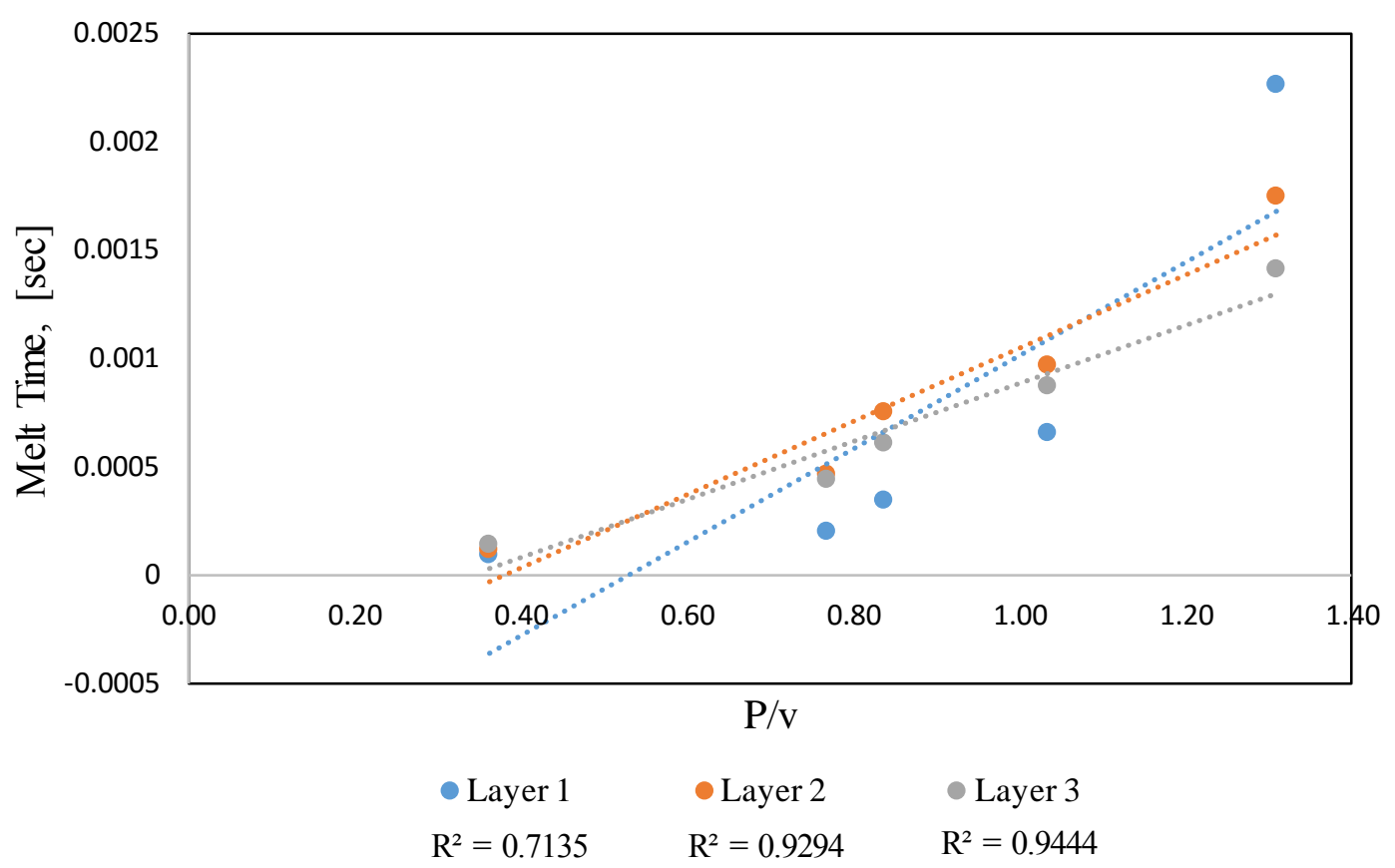

Figure 45. 316L SS - Total melt time vs P/v for Element 648

Element 505

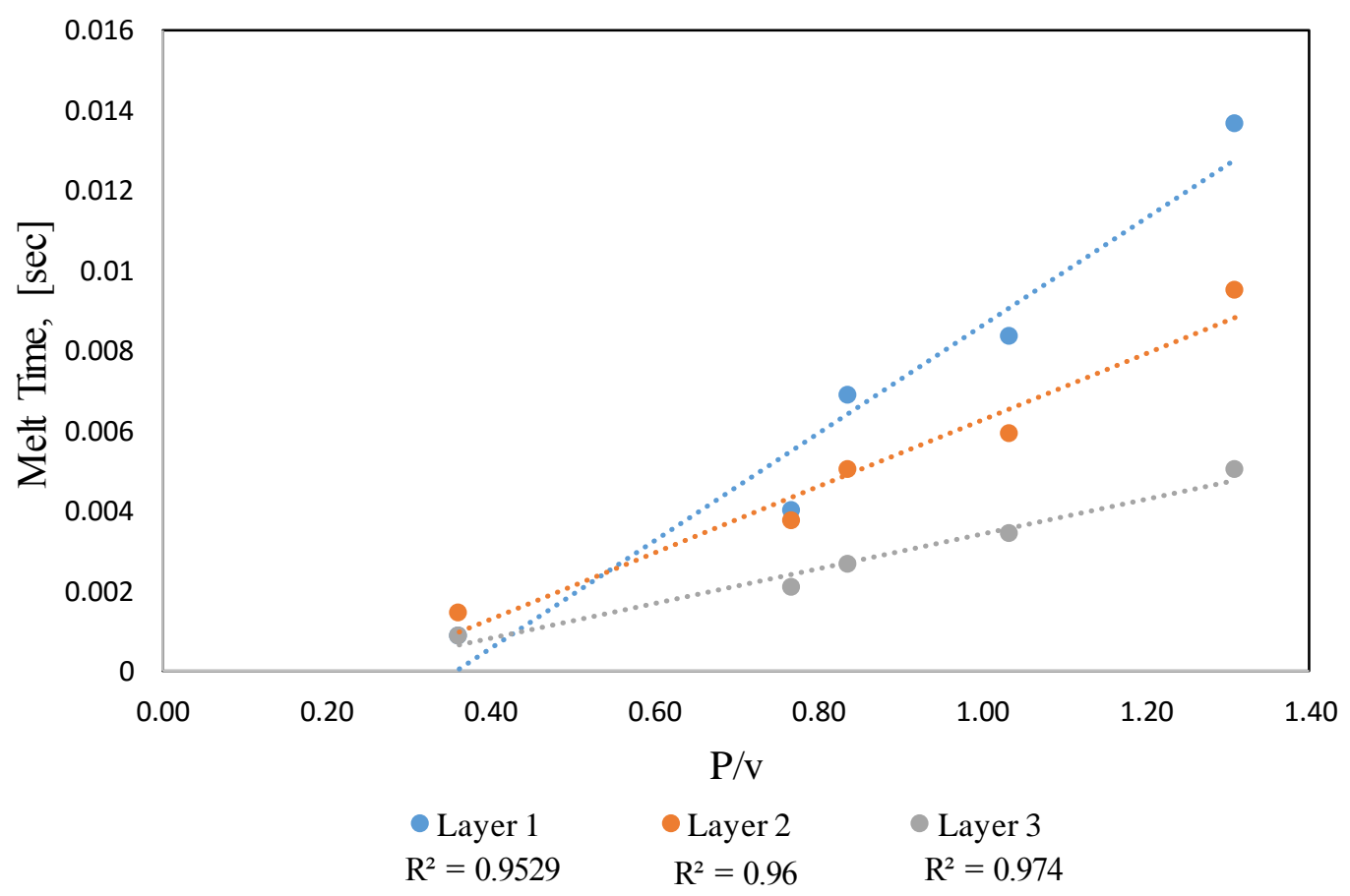

Figure 46. 316L SS - Total melt time vs $\mathrm{P} / \mathrm{v}$ for Element 505 
Element 558

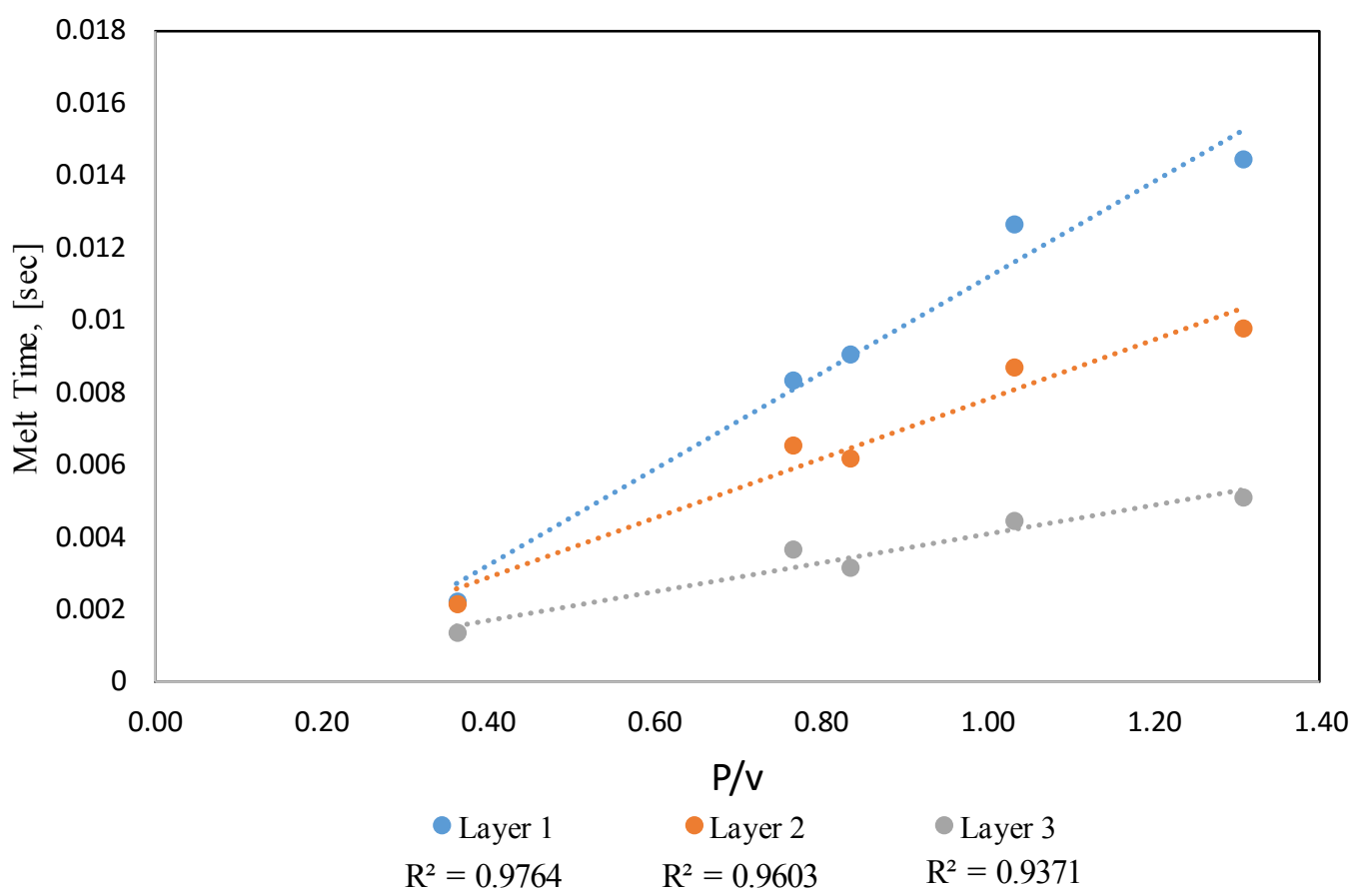

Figure 47. 316L SS - Total melt time vs $\mathrm{P} / \mathrm{v}$ for Element 558

Element 460

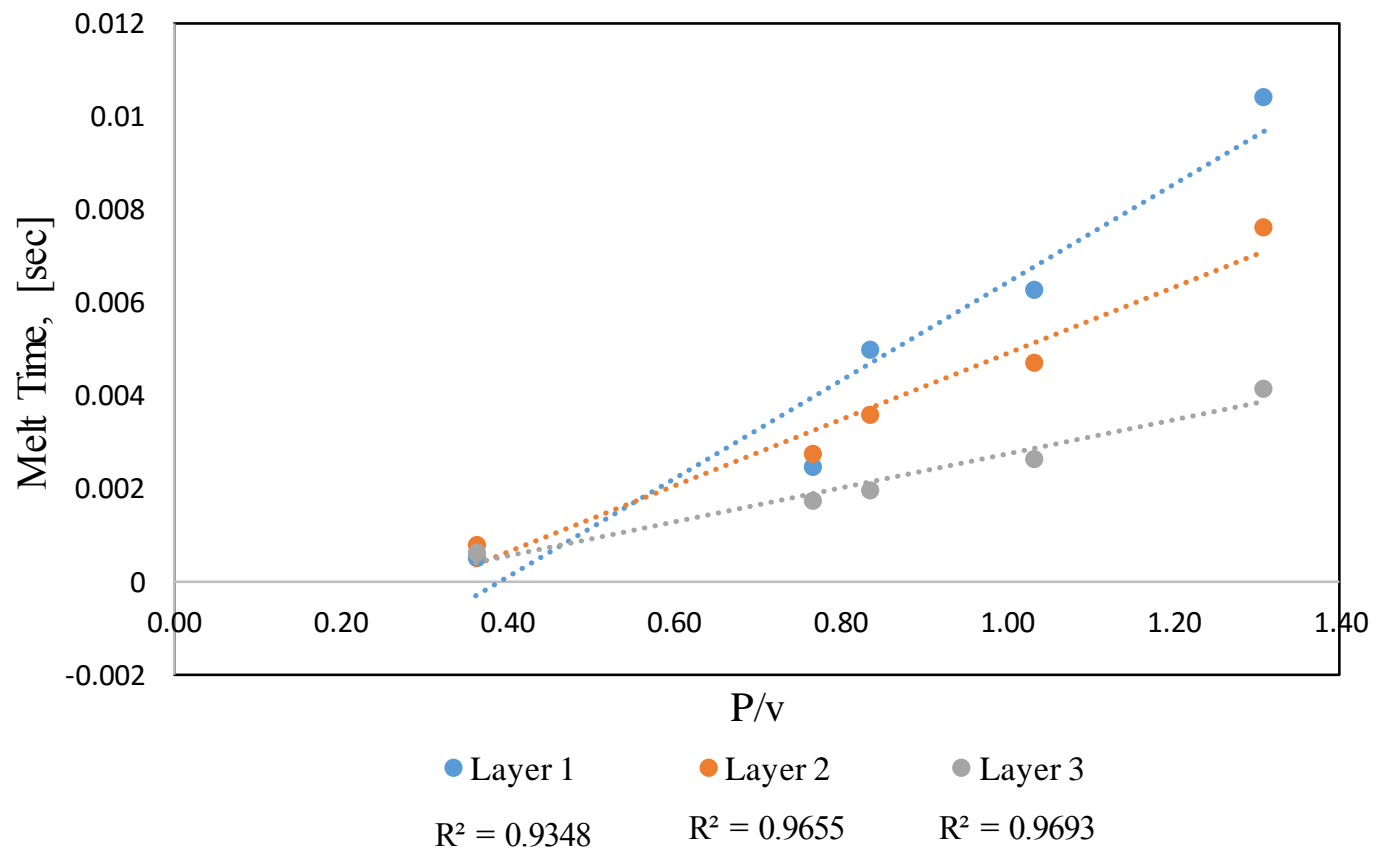

Figure 48. 316L SS - Total melt time vs $\mathrm{P} / \mathrm{v}$ for Element 460 
Element 596

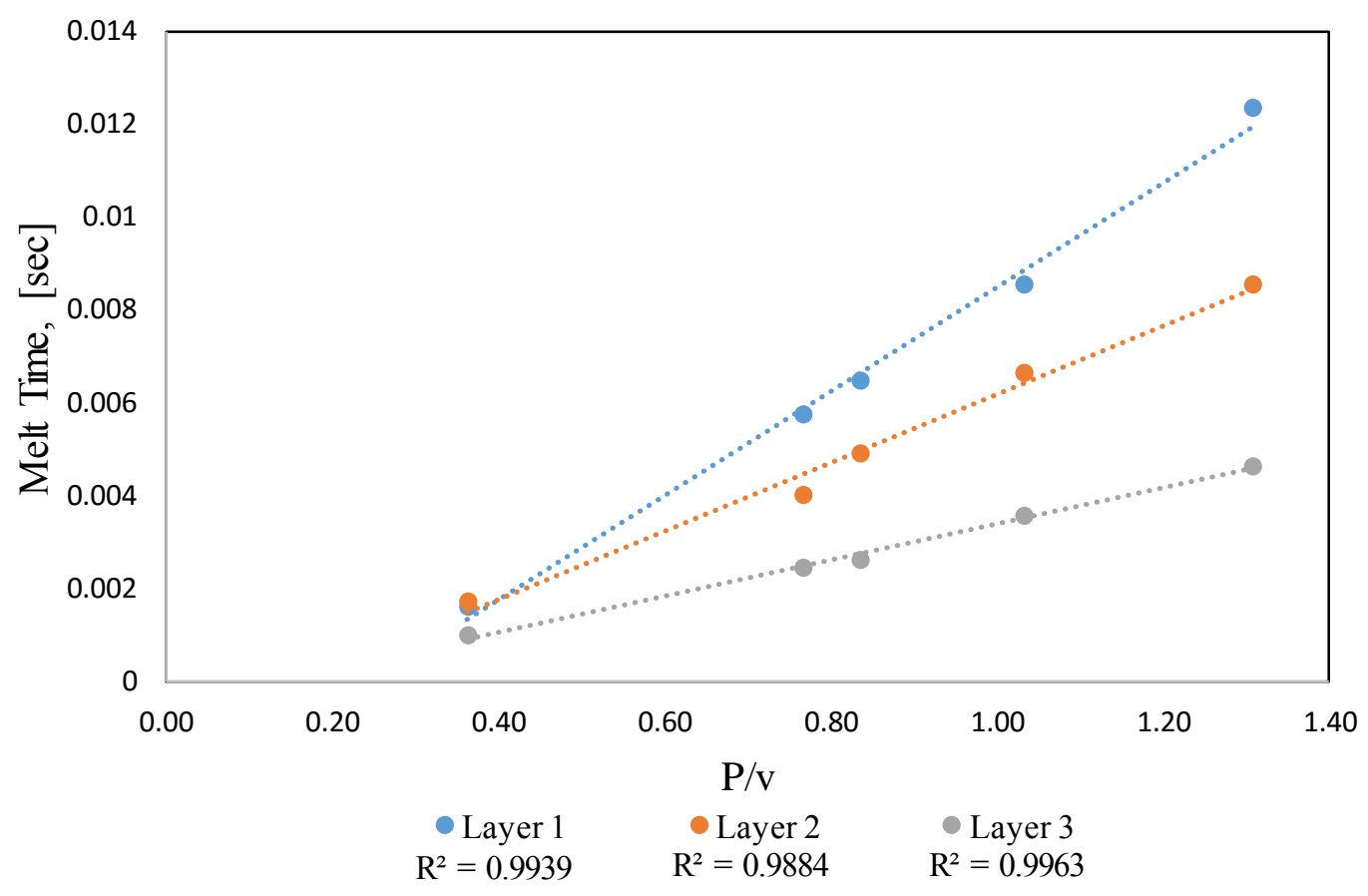

Figure 49. 316L SS - Total melt time vs P/v for Element 596

Element 453

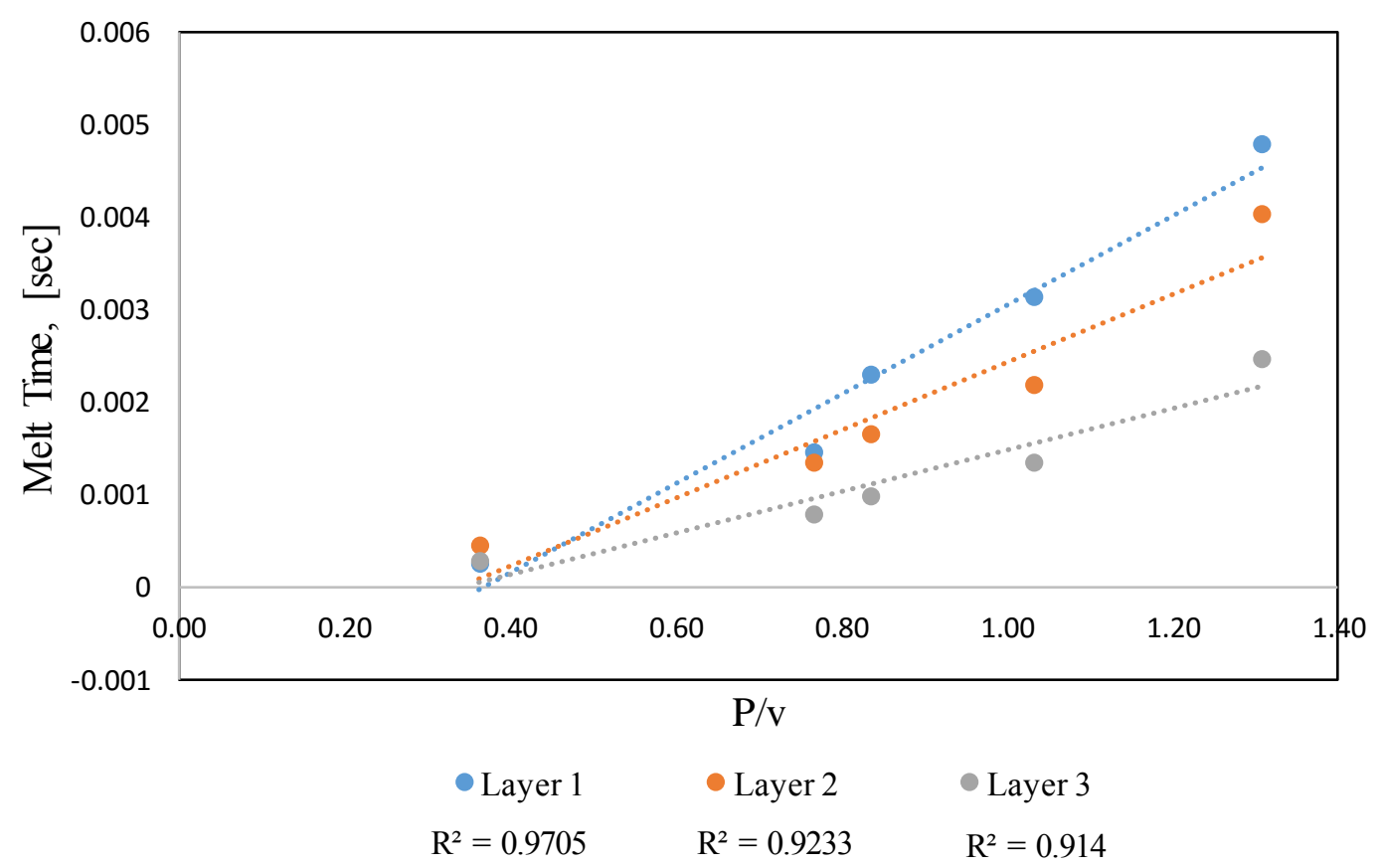

Figure 50. 316L SS - Total melt time vs $\mathrm{P} / \mathrm{v}$ for Element 453 
Table 22. 316L SS - $\mathrm{R}^{2}$ Value for all elements in history output

\begin{tabular}{|c|c|c|c|}
\hline \multicolumn{4}{|c|}{$\mathbf{R}^{2}$ Value for Melt Time vs P/v } \\
\hline Element & Layer 1 & Layer 2 & Layer 3 \\
\hline $\mathbf{6 4 8}$ & 0.714 & 0.929 & 0.944 \\
\hline $\mathbf{4 5 2}$ & 0.703 & 0.803 & 0.930 \\
\hline $\mathbf{5 5 0}$ & 0.868 & 0.883 & 0.922 \\
\hline $\mathbf{3 5 4}$ & 0.842 & 0.844 & 0.867 \\
\hline $\mathbf{4 6 6}$ & 0.820 & 0.910 & 0.907 \\
\hline $\mathbf{2 7 0}$ & 0.791 & 0.882 & 0.897 \\
\hline $\mathbf{5 0 5}$ & 0.953 & 0.960 & 0.974 \\
\hline $\mathbf{3 0 9}$ & 0.886 & 0.958 & 0.969 \\
\hline $\mathbf{6 0 3}$ & 0.936 & 0.945 & 0.960 \\
\hline $\mathbf{4 0 7}$ & 0.884 & 0.941 & 0.956 \\
\hline $\mathbf{6 4 2}$ & 0.930 & 0.948 & 0.975 \\
\hline $\mathbf{4 4 6}$ & 0.878 & 0.944 & 0.960 \\
\hline $\mathbf{5 5 8}$ & 0.976 & 0.960 & 0.937 \\
\hline $\mathbf{3 6 2}$ & 0.957 & 0.971 & 0.943 \\
\hline $\mathbf{5 4 3}$ & 0.989 & 0.960 & 0.945 \\
\hline $\mathbf{3 4 7}$ & 0.988 & 0.978 & 0.954 \\
\hline $\mathbf{4 6 0}$ & 0.935 & 0.966 & 0.969 \\
\hline $\mathbf{2 6 4}$ & 0.887 & 0.946 & 0.967 \\
\hline $\mathbf{4 9 8}$ & 0.993 & 0.994 & 0.996 \\
\hline $\mathbf{3 0 2}$ & 0.977 & 0.987 & 0.997 \\
\hline $\mathbf{5 9 6}$ & 0.994 & 0.988 & 0.996 \\
\hline $\mathbf{4 0 0}$ & 0.971 & 0.989 & 0.997 \\
\hline $\mathbf{6 3 5}$ & 0.883 & 0.936 & 0.955 \\
\hline $\mathbf{4 3 9}$ & 0.805 & 0.904 & 0.961 \\
\hline $\mathbf{5 5 1}$ & 0.995 & 0.990 & 0.988 \\
\hline $\mathbf{3 5 5}$ & 0.979 & 0.992 & 0.987 \\
\hline $\mathbf{4 5 3}$ & 0.971 & 0.923 & 0.914 \\
\hline $\mathbf{2 5 7}$ & 0.927 & 0.971 & 0.890 \\
\hline \hline Average & 0.908 & 0.943 & 0.952 \\
\hline & & & \\
\hline
\end{tabular}




\subsubsection{DISCUSSION}

The results for the 316L SS stimulations also showed a linear relationship between the melting temperature and $\mathrm{P} / \mathrm{v}$ ratio. The lowest $\mathrm{R}^{2}$ value was 0.703 and occurred in the first layer of element 452 . The highest $\mathrm{R}^{2}$ value was 0.997 and occurred in the third layer of element 302. This section will highlight some trends that occurred during these simulations and any differences with the W-Ni-Fe simulations.

First, the simulation results between both materials showed a lot of similarities. The element's location within the model was an indicator of the strength of the linear relationship. Interior elements resulted in higher $\mathrm{R}^{2}$ values and elements located on the corners resulted in lower $\mathrm{R}^{2}$ values. Additionally, the left (starting) side of the model resulted in slightly lower $\mathrm{R}^{2}$ values.

Also, these simulations showed the same discrepancy in which some elements had a decrease in melt time with an increase in the $\mathrm{P} / \mathrm{v}$ ratio. Similarly as before, the decrease in melt time only occurred between the $\mathrm{P} / \mathrm{v}$ ratios of 0.77 and 0.84 . However, for this simulation this observation only occurred in the very center of the powder layer. This discrepancy can be seen in Figure 47 for layer 2 and layer 3. This result confirms the theory that the small change in $\mathrm{P} / \mathrm{v}$ ratio may not have a strong enough influence to make a significant change in melt time.

The biggest difference between the simulations was the relative strength of the linear relationship with respect to the layer. In the $\mathrm{W}-\mathrm{Ni}-\mathrm{Fe}$, the first layer showed the strongest relationship and decreased slightly in subsequent layers (Table 21). In comparison, the $316 \mathrm{~L} \mathrm{SS} \mathrm{simulations} \mathrm{shows} \mathrm{the} \mathrm{weakest} \mathrm{relationship} \mathrm{in} \mathrm{layer} 1$ and increases slightly to layer 3 (Table 22). This observation suggests that even though a 
linear relationship between the $\mathrm{P} / \mathrm{v}$ ratio and melt time is present, there is a level of uncertainly and error occurring. Considering that SLS is a very complicated process, it is reasonable to assume that there are several other factors attributing to the overall melt time.

Overall, the results for the 316L SS simulations show a strong linear relationship. Additionally, there was several similarities between both series of simulations showing that the finite element model is capable of incorporating various materials. The differences between the series of simulations shows that there may be some slight differences in trends but the overall relationship is strongly linear. 


\section{CONCLUSIONS AND RECOMMENDATIONS}

\subsection{CONCLUSION}

The goal of this thesis was to develop a reliable simulation in order to better understand the effect of processing parameters on selective laser sintering. A three layer simulation was developed within Abaqus and the laser heat flux was modeled using a Gaussian distribution. Other important modeling considerations include incorporation of temperature dependent material properties and layer addition capabilities. Ultimately, the simulation results were compared to the experimental results of the Wang et al. (2016) study to show that a linear relationship exists between the time above the melting temperature and the corresponding $\mathrm{P} / \mathrm{v}$ ratio used in the process.

The experimental and simulation results both revealed that a linear relationship exists between the $\mathrm{P} / \mathrm{v}$ processing parameters used and the resulting properties of the SLS part. The experimental results revealed that the final porosity is directly related to the $\mathrm{P} / \mathrm{v}$ ratio. The simulation results revealed that the total time above the melting temperature is directly related to the $\mathrm{P} / \mathrm{v}$ ratio. Thus, there is a correlation in that the greater the $\mathrm{P} / \mathrm{v}$ ratio, the longer the powder will be above the melting temperature, and as a result, the SLS part will have a higher relative density.

An experiment was performed to validate the model by running two different simulations at the same $\mathrm{P} / \mathrm{v}$ ratio. Layer 1 (Figure 33) resulted in near identical results with only an average of $8 \%$ difference in melt time. Layer 3 (Figure 35) resulted in the largest discrepancy between simulations occurring mainly in the center elements of the powder layer. Since this location experiences the most exposure to the laser due to the 
overlap of the hatch spacing, it makes since that the largest difference between simulation 1 and 2 would occur in this area.

Additionally, within the FEA model there were a few important observations made about the results with respect to location. The model was least linear at the starting elements and increased in linearity as the laser progressed across the powder layer. The discrepancy with respect to location is believed to be caused by the temperature of surrounding elements. Also, interior elements showed a stronger linear relationship due to the exposure to multiple scans due to the repeated heated from the overlap of the hatch spacing. The average $\mathrm{R}^{2}$ values for the $\mathrm{W}-\mathrm{Ni}-\mathrm{Fe}$ simulations for layer $1,2,3$ were 0.962 , 0.950 , and 0.939 , respectively. A second series of simulations were performed with $316 \mathrm{~L}$ SS for the material powder. The average $\mathrm{R}^{2}$ values for the $316 \mathrm{~L}$ SS simulations for layer $1,2,3$ were $0.908,0.943$, and 0.952 , respectively. This shows that a linear relationship is present and that the assumption of equation [17] is valid.

\subsection{RECOMMENDATIONS FOR FUTURE WORK}

This section will highlight some areas that should be considered for future work based off the results and findings presented in this thesis. The following recommendations should be considered for future work:

- One of the biggest gaps in accurately being able to predict results from SLS is having reliable material properties. The powder properties of $\mathrm{W}-\mathrm{Ni}-\mathrm{Fe}$ were derived from the bulk material properties. However, it is desirable to use a variety of materials in the model and any new mixture of metal powders in the future. It is recommended that the specific heat and conductivity be measured experimentally if a new or unknown powder material is used in FEA simulations. 
- Another modeling consideration is the use of a body heat flux instead of a surfaced based heat flux. A majority of studies and papers have used a surfaced based heat flux, however it would be interesting to compare simulation results between the two.

- The scan pattern appeared to have an influence on the results of the simulation. A study could be performed analyzing the effect of different scan patterns.

- One of the goals of this thesis was to develop a time efficient model. The simulations ran in this experiment could take up to 6 hours to complete and the layers modeled were only $0.25 \mathrm{~mm} \times 0.25$ in size. A way to analyze larger scale models or a methodology to reduce computational time should be considered in future work. 


\section{WORKS CITED}

Bejan, A., \& Kraus, A. D. Heat Transfer Handbook, 2003, p. 1480.

Blackman, G. (2008, June). Design freedom at last?. In electrooptics.com. Retrieved January 9, 2016.

Campbell, G. H., Foiles, S. M., Huang, H., Hughes, D. A., King, W. E., Lassila, D. H., ... \& Smyshlyaev, V. P. (1998). Multi-scale modeling of polycrystal plasticity: a workshop report. Materials Science and Engineering: A, 251(1), 1-22.

Contuzzi, N., Campanelli, S. L., \& Ludovico, A. D. (2011). 3 D FINITE ELEMENT ANALYSIS IN THE SELECTIVE LASER MELTING PROCESS.International Journal of Simulation Modelling, 10(3), 113-121.

Dai, K., \& Shaw, L. (2005). Finite element analysis of the effect of volume shrinkage during laser densification. Acta materialia, 53(18), 4743-4754.

Dai, K., \& Shaw, L. (2004). Thermal and mechanical finite element modeling of laser forming from metal and ceramic powders. Acta Materialia, 52(1), 69-80.

Dhondt, G. (2014, March 2). Twenty-node brick element (C3D20 and F3D20). In CalculiX. Retrieved March 5, 2016.

"Direct Metal Laser Sintering." DMLS with ProtoLabs.com.. N.p., 2016. Web. 12 Jan. 2016. <https://www.protolabs.com/3d-printing/direct-metal-laser-sintering/>.

The Editors of Encyclopædia Britannica, . (2012). 3D printing. In Encyclopedia Britannica Online. Retrieved January 9, 2016.

Fu, C. H., \& Guo, Y. B. (2014). 3-DIMENSIONAL FINITE ELEMENT MODELING OF SELECTIVE LASER MELTING TI-6AL-4V ALLOY. 25th Annual International Solid Freeform Fabrication Symposium

German, R. M., Suri, P., \& Park, S. J. (2009). Review: liquid phase sintering. Journal of Materials Science, 44(1), 1-39.

Guan, K., Wang, Z., Gao, M., Li, X., \& Zeng, X. (2013). Effects of processing parameters on tensile properties of selective laser melted 304 stainless steel. Materials \& Design, 50, 581-586.

Gusarov, A. V., Yadroitsev, I., Bertrand, P., \& Smurov, I. (2009). Model of radiation and heat transfer in laser-powder interaction zone at selective laser melting. Journal of heat transfer, 131(7), 072101. 
Hodge, N. E., Ferencz, R. M., \& Solberg, J. M. (2014). Implementation of a thermomechanical model for the simulation of selective laser melting. Computational Mechanics, 54(1), 33-51.

Hussein, A., Hao, L., Yan, C., \& Everson, R. (2013). Finite element simulation of the temperature and stress fields in single layers built without-support in selective laser melting. Materials \& Design, 52, 638-647.

Incropera, F. P., \& Dewitt, D. P. (2002). Introduction to Heat Transfer (4th ed., p. 831). New York: John Wiley \& Sons.

Jiang, W., Dalgarno, K. W., \& Childs, T. H. C. (2002). Finite Element Analysis of Residual Stresses and Deformations in Direct Metal SLS Process. InProc. of 13th Solid Freeform Fabrication Symposium(pp. 5-7).

Lassner, E., \& Schubert, W. D. (2012). Tungsten: properties, chemistry, technology of the element, alloys, and chemical compounds (p.270-274). Springer Science \& Business Media.

Li, R., Liu, J., Shi, Y., Wang, L., \& Jiang, W. (2012). Balling behavior of stainless steel and nickel powder during selective laser melting process. The International Journal of Advanced Manufacturing Technology, 59(9-12), 1025-1035.

Liu, J., \& German, R. M. (2001). Rearrangement densification in liquid-phase sintering. Metallurgical and Materials Transactions A, 32(12), 3125-3131.

Palermo, E. (2013, August 13). What is Selective Laser Sintering?. In LiveScience. Retrieved November 26, 2016. <http:/www.livescience.com/38862-selectivelaser-sintering.html $>$.

Papadakis, L., Loizou, A., Risse, J., Bremen, S., \& Schrage, J. (2014). A computational reduction model for appraising structural effects in selective laser melting manufacturing: a methodical model reduction proposed for time-efficient finite element analysis of larger components in Selective Laser Melting. Virtual and Physical Prototyping, 9(1), 17-25.

Roberts, I. A., Wang, C. J., Esterlein, R., Stanford, M., \& Mynors, D. J. (2009). A threedimensional finite element analysis of the temperature field during laser melting of metal powders in additive layer manufacturing. International Journal of Machine Tools and Manufacture, 49(12), 916-923.

Teng, C., Pal, D., Gong, H., \& Stucker, B. (2015). A Two Dimensional Analytical Evaluation of Thermal Fields during Metal Laser Sintering Processes. 
Wang, X., Wraith, M., Burke, S., Rathbun, H., \& DeVlugt, K. (2016). Densification of $\mathrm{W}-\mathrm{Ni}$-Fe powders using laser sintering. International Journal of Refractory Metals and Hard Materials.

Wong, K. V., \& Hernandez, A. (2012). A review of additive manufacturing. ISRN Mechanical Engineering, 2012.

Zhang, D. Q., Cai, Q. Z., Liu, J. H., Zhang, L., \& Li, R. D. (2010). Select laser melting of $\mathrm{W}-\mathrm{Ni}-\mathrm{Fe}$ powders: simulation and experimental study. The International Journal of Advanced Manufacturing Technology, 51(5), 649-658. 
Appendix A: W-Ni-Fe Full Simulation Results

\begin{tabular}{|c|c|c|c|c|c|c|c|c|c|c|c|c|c|c|c|c|c|c|}
\hline \multicolumn{19}{|c|}{ W-Ni-Fe - Element Temperature Time } \\
\hline Simulation & & 1 & & & 2 & & & 3 & & & 4 & & & 5 & & & 6 & \\
\hline Element & Layer 1 & Layer 2 & Layer 3 & Layer 1 & Layer 2 & Layer 3 & Layer 1 & Layer 2 & Layer 3 & Layer 1 & Layer 2 & Layer 3 & Layer 1 & Layer 2 & Layer 3 & Layer 1 & Layer 2 & Dayer \\
\hline 648 & 0.0018 & \begin{tabular}{|l|}
0.0013 \\
\end{tabular} & \begin{tabular}{|l|}
0.0013 \\
\end{tabular} & .0019 & 0.0016 & 0.0016 & \begin{tabular}{|l|}
0.0008 \\
\end{tabular} & & 0.0007 & 0.0038 & \begin{tabular}{|l|}
0.0016 \\
\end{tabular} & \begin{tabular}{|l|}
0.0015 \\
\end{tabular} & 0.0052 & \begin{tabular}{|l|}
0.0028 \\
\end{tabular} & \begin{tabular}{|l|}
0.0024 \\
\end{tabular} & .0027 & 0.0012 & 0.0011 \\
\hline 452 & 0.0014 & 0.0009 & 0.0009 & \begin{tabular}{|l|} 
\\
\end{tabular} & 0.0010 & 0.0010 & 0.0005 & .0004 & 0.0004 & 0.0028 & 0.0011 & \begin{tabular}{|l|} 
\\
\end{tabular} & 0.0047 & 0.0018 & 0.0016 & 0.0023 & 0.0008 & 0.0008 \\
\hline 550 & 0.0039 & \begin{tabular}{|l|}
0.0023 \\
\end{tabular} & \begin{tabular}{|l|}
0.0022 \\
\end{tabular} & \begin{tabular}{|l|}
0.0037 \\
\end{tabular} & 0.0029 & \begin{tabular}{|l|}
0.0028 \\
\end{tabular} & \begin{tabular}{|l|}
0.0015 \\
\end{tabular} & \begin{tabular}{|l|}
0.0011 \\
\end{tabular} & \begin{tabular}{|l|}
0.0011 \\
\end{tabular} & 0.0052 & \begin{tabular}{|l|}
0.0035 \\
\end{tabular} & \begin{tabular}{|l|}
0.0031 \\
\end{tabular} & .0085 & \begin{tabular}{|l|}
0.0062 \\
\end{tabular} & \begin{tabular}{|l|}
0.0042 \\
\end{tabular} & .0035 & 0027 & 0.0021 \\
\hline 354 & 0.0032 & 0.0017 & 0.0016 & \begin{tabular}{|l|} 
\\
\end{tabular} & 0017 & 0.0016 & 0.0012 & 0007 & 006 & 0.0045 & 0.0027 & 0.0021 & .0076 & 0.0055 & 0.0036 & .0033 & 0020 & 0.0017 \\
\hline 466 & 0.0020 & 0.0011 & \begin{tabular}{|l|}
0.0011 \\
\end{tabular} & 017 & 0013 & \begin{tabular}{|l|}
0.0013 \\
\end{tabular} & & & & 032 & 018 & 016 & 0051 & 029 & \begin{tabular}{|l|}
0.0022 \\
\end{tabular} & 028 & 014 & 0.0012 \\
\hline 270 & 0.0013 & 0.0007 & 0.0007 & 0.0012 & 0.0009 & 0.0009 & 0.0003 & 0.0003 & 0.0003 & 0.0027 & 0.0011 & 0.0010 & 0.0045 & 0.0021 & 0.0017 & 0.0021 & 0.0008 & 0.0008 \\
\hline 505 & 0.0051 & \begin{tabular}{|l|}
0.0036 \\
\end{tabular} & \begin{tabular}{|l|}
0.0029 \\
\end{tabular} & \begin{tabular}{|l|}
0.0052 \\
\end{tabular} & 0.0037 & \begin{tabular}{|l|}
0.0035 \\
\end{tabular} & \begin{tabular}{|l|}
0.0022 \\
\end{tabular} & \begin{tabular}{|l|}
0.0015 \\
\end{tabular} & \begin{tabular}{|l|}
0.0013 \\
\end{tabular} & 0.0075 & \begin{tabular}{|l|}
0.0062 \\
\end{tabular} & \begin{tabular}{|l|}
0.0040 \\
\end{tabular} & 0.0131 & \begin{tabular}{|l|}
0.0088 \\
\end{tabular} & \begin{tabular}{|l|}
0.0048 \\
\end{tabular} & \begin{tabular}{|l|}
0.0060 \\
\end{tabular} & 0.0041 & 0.0029 \\
\hline 309 & 0.0045 & 0.0024 & 0.0022 & 0.0041 & 0.0030 & 0.0030 & 0.0019 & 010 & 0.0010 & 0.0064 & 0.0050 & 0.0030 & 120 & 0.0086 & 0.0046 & 051 & 37 & 0.0024 \\
\hline 603 & 0.0055 & 0.0039 & 0.0032 & 0.0057 & 0.0043 & 0.0038 & 0.0023 & 0.0018 & 0.0016 & 0.0082 & 0.0054 & 0.0038 & 0.0128 & 0.0084 & 0.0050 & 0.0060 & 0.0041 & 0.0028 \\
\hline 407 & 0.0042 & 0.0028 & 0.0025 & \begin{tabular}{|l|}
0.0047 \\
\end{tabular} & 0.0030 & \begin{tabular}{|l|}
0.0029 \\
\end{tabular} & \begin{tabular}{|l|}
0.0019 \\
\end{tabular} & \begin{tabular}{|l|}
0.0011 \\
\end{tabular} & \begin{tabular}{|l|}
0.0010 \\
\end{tabular} & 0.0073 & \begin{tabular}{|l|}
0.0047 \\
\end{tabular} & \begin{tabular}{|l|}
0.0031 \\
\end{tabular} & 0.0124 & \begin{tabular}{|l|}
0.0081 \\
\end{tabular} & \begin{tabular}{|l|}
0.0047 \\
\end{tabular} & \begin{tabular}{|l|}
0.0054 \\
\end{tabular} & 0.0036 & 0.0022 \\
\hline 642 & 0.0048 & \begin{tabular}{|l|}
0.0031 \\
\end{tabular} & \begin{tabular}{|l|}
0.0025 \\
\end{tabular} & \begin{tabular}{|l|}
0.0042 \\
\end{tabular} & 0.0033 & \begin{tabular}{|l|}
0.0031 \\
\end{tabular} & \begin{tabular}{|l|}
0.0016 \\
\end{tabular} & 12 & \begin{tabular}{|l|}
0.0010 \\
\end{tabular} & 0.0073 & \begin{tabular}{|l|}
0.0049 \\
\end{tabular} & \begin{tabular}{|l|}
0.0032 \\
\end{tabular} & 110 & \begin{tabular}{|l|}
0.0074 \\
\end{tabular} & 0.0043 & .0053 & 037 & 0.0024 \\
\hline 446 & 0.0037 & \begin{tabular}{|l|}
0.0020 \\
\end{tabular} & \begin{tabular}{|l|}
0.0017 \\
\end{tabular} & \begin{tabular}{|l|}
0.0032 \\
\end{tabular} & 0.0021 & \begin{tabular}{|l|}
0.0021 \\
\end{tabular} & \begin{tabular}{|l|}
0.0012 \\
\end{tabular} & & & 964 & 0.0039 & 25 & 03 & 69 & 38 & 47 & 331 & 18 \\
\hline 558 & 0.0074 & \begin{tabular}{|l|}
0.0058 \\
\end{tabular} & \begin{tabular}{|l|}
0.0046 \\
\end{tabular} & \begin{tabular}{|l|}
0.0077 \\
\end{tabular} & 0.0071 & \begin{tabular}{|l|}
0.0063 \\
\end{tabular} & \begin{tabular}{|l|}
0.0027 \\
\end{tabular} & 0.0024 & \begin{tabular}{|l|}
0.0021 \\
\end{tabular} & 0.0123 & \begin{tabular}{|l|}
0.0084 \\
\end{tabular} & \begin{tabular}{|l|}
0.0048 \\
\end{tabular} & 0.0143 & \begin{tabular}{|l|}
0.0097 \\
\end{tabular} & \begin{tabular}{|l|}
0.0052 \\
\end{tabular} & \begin{tabular}{|l|}
0.0085 \\
\end{tabular} & 0.0058 & 0.0032 \\
\hline 362 & 0.0068 & \begin{tabular}{|l|}
0.0052 \\
\end{tabular} & \begin{tabular}{|l|}
0.0040 \\
\end{tabular} & \begin{tabular}{|l|}
0.0065 \\
\end{tabular} & 0.0049 & 0.0045 & \begin{tabular}{|l|}
0.0021 \\
\end{tabular} & 0.0018 & \begin{tabular}{|l|}
0.0016 \\
\end{tabular} & 0.0119 & \begin{tabular}{|l|}
0.0079 \\
\end{tabular} & \begin{tabular}{|l|}
0.0045 \\
\end{tabular} & 0.0138 & \begin{tabular}{|l|}
0.0093 \\
\end{tabular} & \begin{tabular}{|l|}
0.0050 \\
\end{tabular} & 082 & 054 & 0.0030 \\
\hline 543 & 0.0078 & \begin{tabular}{|l|}
0.0056 \\
\end{tabular} & \begin{tabular}{|l|}
0.0043 \\
\end{tabular} & \begin{tabular}{|l|}
0.0075 \\
\end{tabular} & 0.0069 & \begin{tabular}{|l|}
0.0061 \\
\end{tabular} & \begin{tabular}{|l|}
0.0026 \\
\end{tabular} & 0.0022 & \begin{tabular}{|l|}
0.0019 \\
\end{tabular} & 118 & \begin{tabular}{|l|}
0.0081 \\
\end{tabular} & \begin{tabular}{|l|}
0.0046 \\
\end{tabular} & 139 & \begin{tabular}{|l|}
0.0093 \\
\end{tabular} & \begin{tabular}{|l|}
0.0051 \\
\end{tabular} & .0083 & 0.0056 & 0.0031 \\
\hline 347 & 0.0068 & \begin{tabular}{|l|}
0.0049 \\
\end{tabular} & \begin{tabular}{|l|}
0.0038 \\
\end{tabular} & \begin{tabular}{|l|}
0.0062 \\
\end{tabular} & 0.0050 & 0.0046 & \begin{tabular}{|l|}
0.0022 \\
\end{tabular} & \begin{tabular}{|l|}
0.0018 \\
\end{tabular} & \begin{tabular}{|l|}
0.0017 \\
\end{tabular} & 0.0112 & \begin{tabular}{|l|}
0.0074 \\
\end{tabular} & \begin{tabular}{|l|}
0.0041 \\
\end{tabular} & 136 & \begin{tabular}{|l|}
0.0088 \\
\end{tabular} & \begin{tabular}{|l|}
0.0048 \\
\end{tabular} & 078 & 0.0051 & 0.0027 \\
\hline 460 & 0.0044 & 0.0033 & 0.0027 & \begin{tabular}{|l|}
0.0047 \\
\end{tabular} & 0.0036 & 0.0033 & 0.0018 & 0.0015 & \begin{tabular}{|l|} 
\\
\end{tabular} & 0.0075 & 0.0050 & 0.0033 & 0.0107 & \begin{tabular}{|l|} 
\\
\end{tabular} & \begin{tabular}{|l|} 
\\
\end{tabular} & \begin{tabular}{|l|} 
\\
\end{tabular} & 0.0035 & 0.0024 \\
\hline 264 & 0.0039 & \begin{tabular}{|l|}
0.0025 \\
\end{tabular} & \begin{tabular}{|l|}
0.0020 \\
\end{tabular} & \begin{tabular}{|l|}
0.0036 \\
\end{tabular} & 0.0025 & \begin{tabular}{|l|}
0.0025 \\
\end{tabular} & \begin{tabular}{|l|}
0.0014 \\
\end{tabular} & \begin{tabular}{|l|}
0.0009 \\
\end{tabular} & \begin{tabular}{|l|}
0.0008 \\
\end{tabular} & 0.0066 & \begin{tabular}{|l|}
0.0043 \\
\end{tabular} & \begin{tabular}{|l|}
0.0027 \\
\end{tabular} & 0.0102 & \begin{tabular}{|l|}
0.0067 \\
\end{tabular} & \begin{tabular}{|l|}
0.0037 \\
\end{tabular} & \begin{tabular}{|l|}
0.0048 \\
\end{tabular} & 0.0031 & 0.0019 \\
\hline 498 & 0.0055 & \begin{tabular}{|l|}
0.0040 \\
\end{tabular} & \begin{tabular}{|l|}
0.0026 \\
\end{tabular} & \begin{tabular}{|l|}
0.0054 \\
\end{tabular} & 0.0046 & \begin{tabular}{|l|}
0.0036 \\
\end{tabular} & \begin{tabular}{|l|}
0.0019 \\
\end{tabular} & 0.0016 & \begin{tabular}{|l|}
0.0013 \\
\end{tabular} & 0.0081 & \begin{tabular}{|l|}
0.0053 \\
\end{tabular} & \begin{tabular}{|l|}
0.0031 \\
\end{tabular} & 0.0116 & \begin{tabular}{|l|}
0.0072 \\
\end{tabular} & \begin{tabular}{|l|}
0.0039 \\
\end{tabular} & \begin{tabular}{|l|}
0.0059 \\
\end{tabular} & 0.0037 & 0.0021 \\
\hline 302 & 0.0045 & 0.0035 & \begin{tabular}{|l|}
0.0023 \\
\end{tabular} & \begin{tabular}{|l|}
0.0041 \\
\end{tabular} & 0.0035 & \begin{tabular}{|l|}
0.0031 \\
\end{tabular} & \begin{tabular}{|l|}
0.0015 \\
\end{tabular} & \begin{tabular}{|l|}
0.0012 \\
\end{tabular} & \begin{tabular}{|l|}
0.0010 \\
\end{tabular} & 0.0075 & \begin{tabular}{|l|}
0.0052 \\
\end{tabular} & \begin{tabular}{|l|}
0.0029 \\
\end{tabular} & 0.0108 & \begin{tabular}{|l|}
0.0068 \\
\end{tabular} & \begin{tabular}{|l|}
0.0035 \\
\end{tabular} & \begin{tabular}{|l|}
0.0055 \\
\end{tabular} & 0.0037 & 0.0020 \\
\hline 596 & 0.0059 & \begin{tabular}{|l|}
0.0043 \\
\end{tabular} & \begin{tabular}{|l|}
0.0028 \\
\end{tabular} & \begin{tabular}{|l|}
0.0055 \\
\end{tabular} & 0.0045 & 0.0035 & \begin{tabular}{|l|}
0.0019 \\
\end{tabular} & \begin{tabular}{|l|}
0.0017 \\
\end{tabular} & \begin{tabular}{|l|}
0.0014 \\
\end{tabular} & 0.0091 & \begin{tabular}{|l|}
0.0056 \\
\end{tabular} & \begin{tabular}{|l|}
0.0035 \\
\end{tabular} & 0.0108 & \begin{tabular}{|l|}
0.0075 \\
\end{tabular} & \begin{tabular}{|l|}
0.0042 \\
\end{tabular} & \begin{tabular}{|l|}
0.0062 \\
\end{tabular} & 0.0041 & 0.0024 \\
\hline 400 & 0.0047 & \begin{tabular}{|l|}
0.0036 \\
\end{tabular} & \begin{tabular}{|l|}
0.0023 \\
\end{tabular} & \begin{tabular}{|l|}
0.0042 \\
\end{tabular} & 0.0033 & \begin{tabular}{|l|}
0.0029 \\
\end{tabular} & \begin{tabular}{|l|}
0.0014 \\
\end{tabular} & & \begin{tabular}{|l|}
0.0010 \\
\end{tabular} & 0.0087 & \begin{tabular}{|l|}
0.0053 \\
\end{tabular} & \begin{tabular}{|l|}
0.0031 \\
\end{tabular} & 0.0105 & \begin{tabular}{|l|}
0.0072 \\
\end{tabular} & \begin{tabular}{|l|}
0.0039 \\
\end{tabular} & 0.0059 & 0.0038 & 0.0021 \\
\hline 635 & 0.0023 & \begin{tabular}{|l|}
0.0015 \\
\end{tabular} & \begin{tabular}{|l|}
0.0012 \\
\end{tabular} & \begin{tabular}{|l|}
0.0018 \\
\end{tabular} & 0.0016 & \begin{tabular}{|l|}
0.0014 \\
\end{tabular} & \begin{tabular}{|l|}
0.0006 \\
\end{tabular} & 0.0006 & \begin{tabular}{|l|}
0.0005 \\
\end{tabular} & 0.0041 & \begin{tabular}{|l|}
0.0026 \\
\end{tabular} & \begin{tabular}{|l|}
0.0016 \\
\end{tabular} & 0.0065 & \begin{tabular}{|l|}
0.0044 \\
\end{tabular} & \begin{tabular}{|l|}
0.0025 \\
\end{tabular} & \begin{tabular}{|l|}
0.0028 \\
\end{tabular} & 0.0020 & 0.0012 \\
\hline 439 & 0.0018 & \begin{tabular}{|l|}
0.0011 \\
\end{tabular} & \begin{tabular}{|l|}
0.0009 \\
\end{tabular} & \begin{tabular}{|l|}
0.0014 \\
\end{tabular} & 0.0011 & \begin{tabular}{|l|}
0.0010 \\
\end{tabular} & \begin{tabular}{|l|}
0.0003 \\
\end{tabular} & 0.0003 & \begin{tabular}{|l|}
0.0004 \\
\end{tabular} & 0.0038 & \begin{tabular}{|l|}
0.0023 \\
\end{tabular} & \begin{tabular}{|l|}
0.0014 \\
\end{tabular} & 0.0064 & \begin{tabular}{|l|}
0.0043 \\
\end{tabular} & \begin{tabular}{|l|}
0.0024 \\
\end{tabular} & \begin{tabular}{|l|}
0.0025 \\
\end{tabular} & 0.0016 & 0.0010 \\
\hline 551 & 0.0041 & \begin{tabular}{|l|}
0.0032 \\
\end{tabular} & \begin{tabular}{|l|}
0.0022 \\
\end{tabular} & \begin{tabular}{|l|}
0.0039 \\
\end{tabular} & 0.0034 & 0.0028 & \begin{tabular}{|l|}
0.0011 \\
\end{tabular} & \begin{tabular}{|l|}
0.0010 \\
\end{tabular} & \begin{tabular}{|l|}
0.0008 \\
\end{tabular} & 0.0071 & \begin{tabular}{|l|}
0.0044 \\
\end{tabular} & \begin{tabular}{|l|}
0.0025 \\
\end{tabular} & 0.0094 & \begin{tabular}{|l|}
0.0061 \\
\end{tabular} & \begin{tabular}{|l|}
0.0033 \\
\end{tabular} & \begin{tabular}{|l|}
0.0048 \\
\end{tabular} & 0.0031 & 0.0017 \\
\hline 355 & 0.0035 & \begin{tabular}{|l|}
0.0025 \\
\end{tabular} & \begin{tabular}{|l|}
0.0018 \\
\end{tabular} & \begin{tabular}{|l|}
0.0032 \\
\end{tabular} & 0.0022 & \begin{tabular}{|l|}
0.0019 \\
\end{tabular} & \begin{tabular}{|l|}
0.0009 \\
\end{tabular} & 0.0007 & \begin{tabular}{|l|}
0.0006 \\
\end{tabular} & 0.0068 & \begin{tabular}{|l|}
0.0043 \\
\end{tabular} & \begin{tabular}{|l|}
0.0024 \\
\end{tabular} & 0.0092 & \begin{tabular}{|l|}
0.0057 \\
\end{tabular} & \begin{tabular}{|l|}
0.0029 \\
\end{tabular} & \begin{tabular}{|l|}
0.0046 \\
\end{tabular} & 0.0030 & 0.0017 \\
\hline 453 & 0.0019 & \begin{tabular}{|l|}
0.0016 \\
\end{tabular} & \begin{tabular}{|l|}
0.0013 \\
\end{tabular} & \begin{tabular}{|l|}
0.0018 \\
\end{tabular} & 0.0015 & 0.0013 & \begin{tabular}{|l|}
0.0005 \\
\end{tabular} & 0.0005 & \begin{tabular}{|l|}
0.0005 \\
\end{tabular} & 0.0043 & \begin{tabular}{|l|}
0.0026 \\
\end{tabular} & \begin{tabular}{|l|}
0.0017 \\
\end{tabular} & 0.0061 & \begin{tabular}{|l|}
0.0040 \\
\end{tabular} & 0.0024 & 0.0031 & 0.0018 & 0.0011 \\
\hline 257 & 0.0016 & 0.0012 & 0.0008 & \begin{tabular}{|l|} 
\\
\end{tabular} & 0.0011 & \begin{tabular}{|l|}
0.0010 \\
\end{tabular} & 0.0004 & 0.0004 & \begin{tabular}{|l|}
0.0003 \\
\end{tabular} & 0.0036 & $0.0023 \mid$ & \begin{tabular}{|l|} 
\\
\end{tabular} & 0.0060 & \begin{tabular}{|l|}
0.0037 \\
\end{tabular} & 0.0022 & \begin{tabular}{|l|} 
\\
\end{tabular} & 0.0015 & 0.0009 \\
\hline
\end{tabular}


Appendix B: 316L SS Full Simulation Results

\begin{tabular}{|c|c|c|c|c|c|c|c|c|c|c|c|c|c|c|c|}
\hline \multicolumn{16}{|c|}{ 316L SS - Element Temperature Time } \\
\hline \multirow{2}{*}{$\begin{array}{c}\text { Simulation } \\
\text { Element } \\
\end{array}$} & \multicolumn{3}{|c|}{7} & \multicolumn{3}{|c|}{8} & \multicolumn{3}{|c|}{9} & \multicolumn{3}{|c|}{10} & \multicolumn{3}{|c|}{11} \\
\hline & Layer 1 & Layer 2 & Layer 3 & Layer 1 & Layer 2 & Layer 3 & Layer 1 & Layer 2 & Layer 3 & Layer 1 & Layer 2 & Layer 3 & Layer 1 & Layer 2 & Layer 3 \\
\hline 648 & 0.0002 & 0.0005 & 0.0004 & 0.0001 & 0.0001 & 0.0002 & 0.0007 & 0.0010 & 0.0009 & 0.0023 & 0.0017 & 0.0014 & 0.0004 & 0.0008 & 0.0006 \\
\hline 452 & 0.0000 & 0.0001 & 0.0002 & 0.0000 & 0.0000 & 0.0000 & 0.0004 & 0.0005 & 0.0007 & 0.0014 & 0.0015 & 0.0013 & 0.0001 & 0.0004 & 0.0005 \\
\hline 550 & 0.0013 & 0.0015 & 0.0011 & 0.0002 & 0.0003 & 0.0004 & 0.0038 & 0.0033 & 0.0022 & 0.0084 & 0.0070 & 0.0040 & 0.0032 & 0.0028 & 0.0020 \\
\hline 354 & 0.0010 & 0.0007 & 0.0009 & 0.0001 & 0.0002 & 0.0003 & 0.0025 & 0.0027 & 0.0019 & 0.0065 & 0.0060 & 0.0040 & 0.0022 & 0.0021 & 0.0019 \\
\hline 466 & 0.0003 & 0.0008 & 0.0005 & 0.0001 & 0.0002 & 0.0002 & 0.0012 & 0.0013 & 0.0009 & 0.0028 & 0.0025 & 0.0017 & 0.0007 & 0.0010 & 0.0007 \\
\hline 270 & 0.0001 & 0.0005 & 0.0005 & 0.0000 & 0.0001 & 0.0002 & 0.0008 & 0.0010 & 0.0008 & 0.0017 & 0.0021 & 0.0017 & 0.0003 & 0.0007 & 0.0006 \\
\hline 505 & 0.0040 & 0.0038 & 0.0021 & 0.0009 & 0.0014 & 0.0009 & 0.0083 & 0.0059 & 0.0034 & 0.0137 & 0.0095 & 0.0050 & 0.0069 & 0.0050 & 0.0027 \\
\hline 309 & 0.0022 & 0.0033 & 0.0020 & 0.0003 & 0.0008 & 0.0008 & 0.0060 & 0.0054 & 0.0032 & 0.0125 & 0.0093 & 0.0049 & 0.0054 & 0.0047 & 0.0026 \\
\hline 603 & 0.0033 & 0.0031 & 0.0019 & 0.0008 & 0.0011 & 0.0008 & 0.0077 & 0.0054 & 0.0031 & 0.0131 & 0.0091 & 0.0049 & 0.0061 & 0.0041 & 0.0025 \\
\hline 407 & 0.0019 & 0.0026 & 0.0018 & 0.0003 & 0.0008 & 0.0006 & 0.0057 & 0.0050 & 0.0029 & 0.0117 & 0.0086 & 0.0048 & 0.0046 & 0.0038 & 0.0023 \\
\hline 642 & 0.0027 & 0.0026 & 0.0016 & 0.0006 & 0.0010 & 0.0006 & 0.0062 & 0.0046 & 0.0026 & 0.0110 & 0.0076 & 0.0040 & 0.0051 & 0.0036 & 0.0020 \\
\hline 446 & 0.0016 & 0.0023 & 0.0014 & 0.0002 & 0.0006 & 0.0006 & 0.0046 & 0.0043 & 0.0025 & 0.0100 & 0.0074 & 0.0039 & 0.0039 & 0.0033 & 0.0019 \\
\hline 558 & 0.0083 & 0.0065 & 0.0037 & 0.0022 & 0.0022 & 0.0013 & 0.0126 & 0.0087 & 0.0045 & 0.0144 & 0.0098 & 0.0051 & 0.0091 & 0.0062 & 0.0031 \\
\hline 362 & 0.0061 & 0.0059 & 0.0036 & 0.0016 & 0.0017 & 0.0012 & 0.0117 & 0.0086 & 0.0044 & 0.0140 & 0.0097 & 0.0050 & 0.0084 & 0.0061 & 0.0031 \\
\hline 543 & 0.0087 & 0.0070 & 0.0037 & 0.0025 & 0.0024 & 0.0016 & 0.0123 & 0.0086 & 0.0045 & 0.0150 & 0.0101 & 0.0052 & 0.0089 & 0.0063 & 0.0032 \\
\hline 347 & 0.0070 & 0.0063 & 0.0036 & 0.0018 & 0.0018 & 0.0015 & 0.0117 & 0.0083 & 0.0044 & 0.0141 & 0.0100 & 0.0052 & 0.0085 & 0.0061 & 0.0032 \\
\hline 460 & 0.0025 & 0.0028 & 0.0018 & 0.0005 & 0.0008 & 0.0006 & 0.0063 & 0.0047 & 0.0026 & 0.0105 & 0.0076 & 0.0042 & 0.0050 & 0.0036 & 0.0020 \\
\hline 264 & 0.0014 & 0.0020 & 0.0017 & 0.0002 & 0.0006 & 0.0005 & 0.0047 & 0.0044 & 0.0025 & 0.0094 & 0.0072 & 0.0041 & 0.0038 & 0.0034 & 0.0019 \\
\hline 498 & 0.0054 & 0.0041 & 0.0024 & 0.0016 & 0.0015 & 0.0009 & 0.0091 & 0.0065 & 0.0034 & 0.0118 & 0.0081 & 0.0042 & 0.0069 & 0.0050 & 0.0025 \\
\hline 302 & 0.0038 & 0.0036 & 0.0023 & 0.0008 & 0.0013 & 0.0009 & 0.0076 & 0.0063 & 0.0033 & 0.0111 & 0.0080 & 0.0041 & 0.0059 & 0.0048 & 0.0025 \\
\hline 596 & 0.0057 & 0.0040 & 0.0025 & 0.0016 & 0.0017 & 0.0010 & 0.0085 & 0.0066 & 0.0036 & 0.0123 & 0.0085 & 0.0046 & 0.0065 & 0.0049 & 0.0026 \\
\hline 400 & 0.0036 & 0.0037 & 0.0024 & 0.0007 & 0.0015 & 0.0009 & 0.0079 & 0.0063 & 0.0035 & 0.0113 & 0.0083 & 0.0045 & 0.0061 & 0.0046 & 0.0026 \\
\hline 635 & 0.0010 & 0.0015 & 0.0010 & 0.0002 & 0.0004 & 0.0004 & 0.0032 & 0.0026 & 0.0017 & 0.0062 & 0.0047 & 0.0027 & 0.0022 & 0.0020 & 0.0013 \\
\hline 439 & 0.0005 & 0.0010 & 0.0009 & 0.0001 & 0.0003 & 0.0002 & 0.0021 & 0.0023 & 0.0016 & 0.0055 & 0.0045 & 0.0027 & 0.0014 & 0.0018 & 0.0012 \\
\hline 551 & 0.0040 & 0.0031 & 0.0018 & 0.0007 & 0.0010 & 0.0007 & 0.0066 & 0.0054 & 0.0030 & 0.0096 & 0.0069 & 0.0037 & 0.0050 & 0.0040 & 0.0022 \\
\hline 355 & 0.0029 & 0.0028 & 0.0017 & 0.0004 & 0.0007 & 0.0006 & 0.0060 & 0.0049 & 0.0029 & 0.0084 & 0.0067 & 0.0036 & 0.0045 & 0.0036 & 0.0021 \\
\hline 453 & 0.0015 & 0.0013 & 0.0008 & 0.0002 & 0.0004 & 0.0003 & 0.0031 & 0.0022 & 0.0013 & 0.0048 & 0.0040 & 0.0025 & 0.0023 & 0.0016 & 0.0010 \\
\hline 257 & 0.0008 & 0.0012 & 0.0008 & 0.0001 & 0.0003 & 0.0003 & 0.0026 & 0.0021 & 0.0012 & 0.0044 & 0.0034 & 0.0024 & 0.0017 & 0.0015 & 0.0009 \\
\hline
\end{tabular}




\section{Melt Loop Time Code}

\section{Table of Contents}

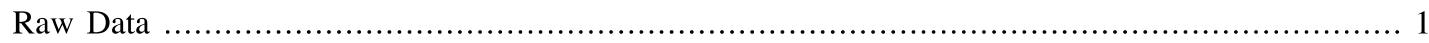

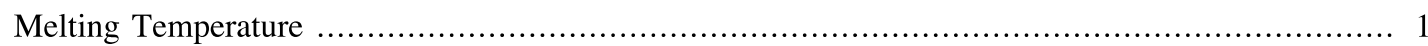

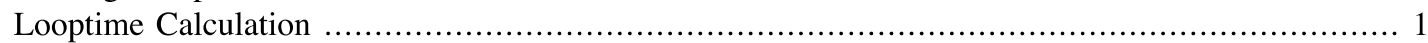

\section{Raw Data}

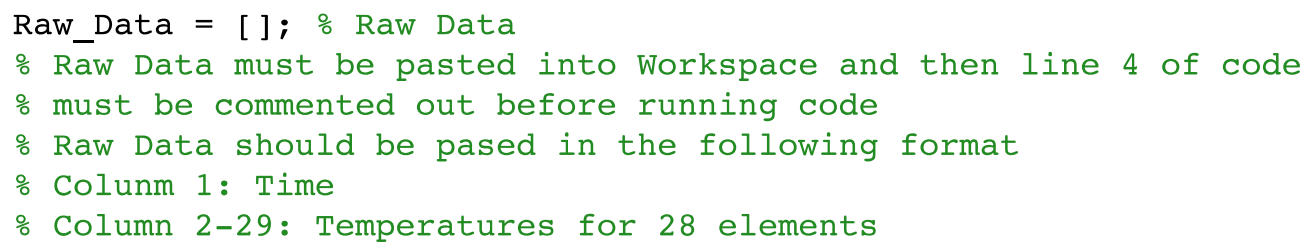

\section{Melting Temperature}

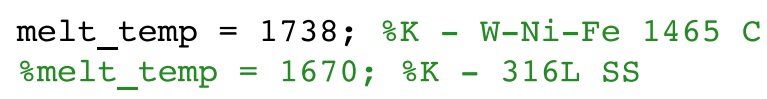

\section{Looptime Calculation}

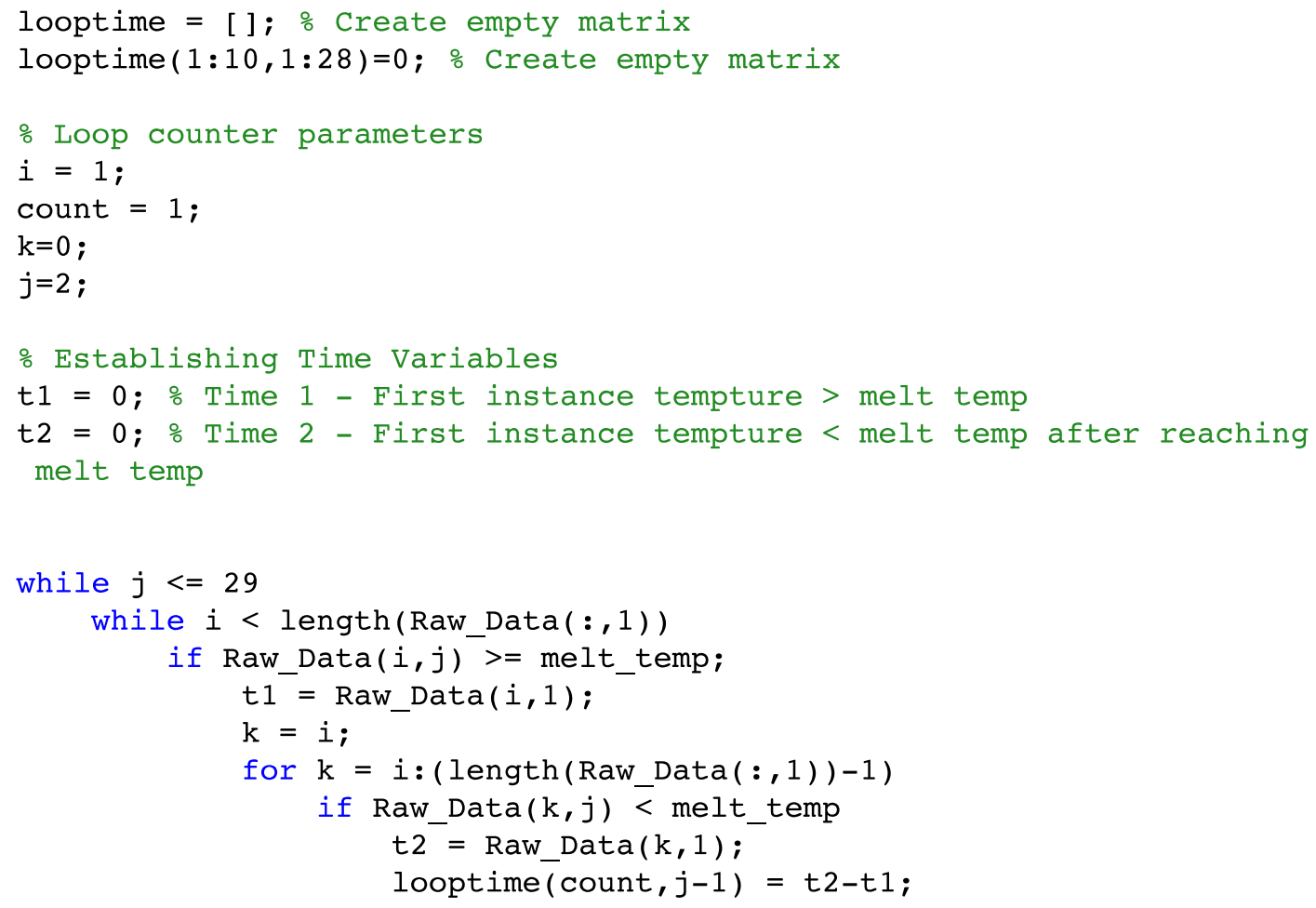




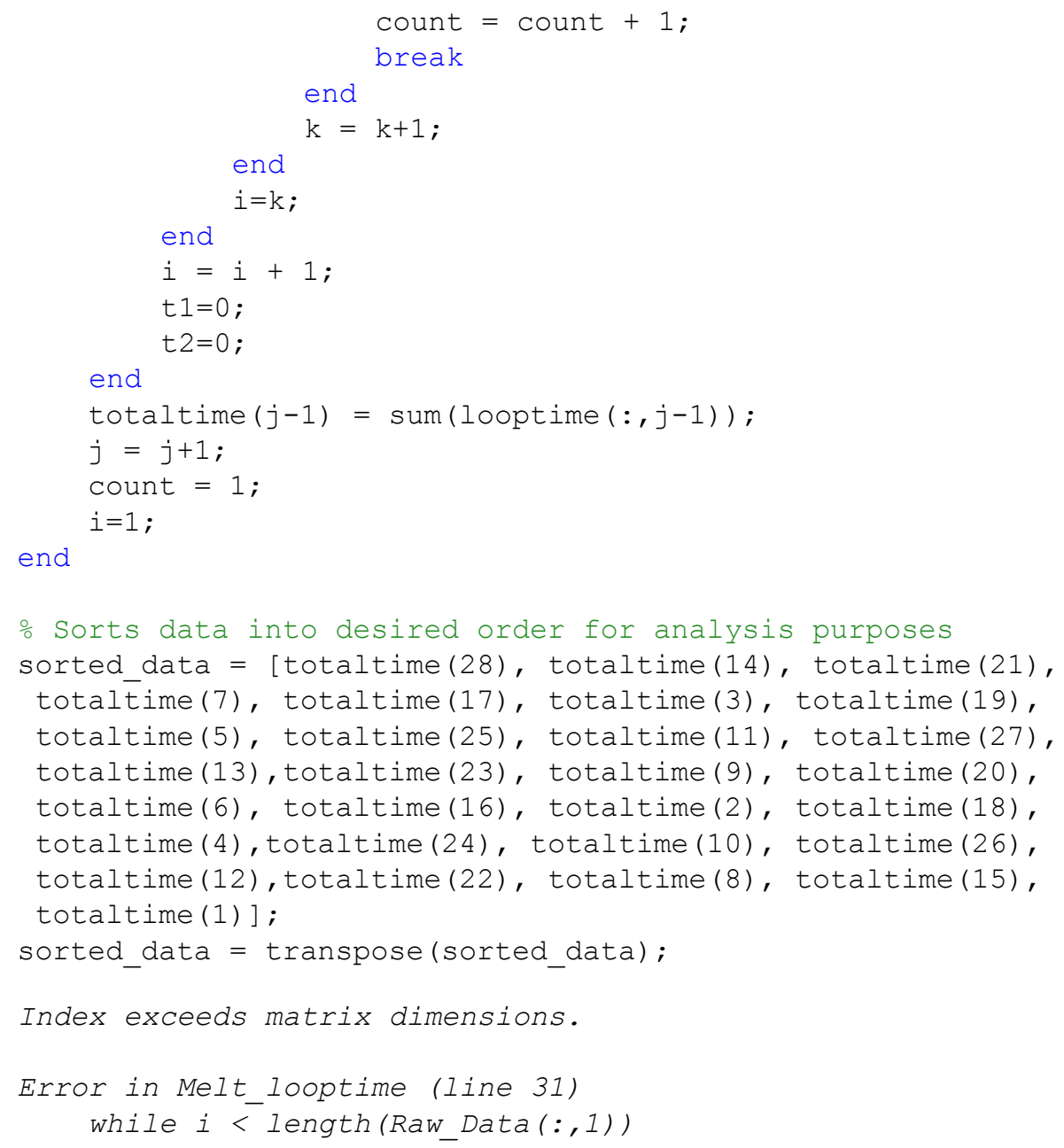

Published with MATLAB ${ }^{\circledR}$ R2015a 